NBER WORKING PAPER SERIES

\title{
GLOBAL PORTFOLIO REBALANCING AND EXCHANGE RATES
}

\author{
Nelson Camanho \\ Harald Hau \\ Hélène Rey \\ Working Paper 24320 \\ http://www.nber.org/papers/w24320
NATIONAL BUREAU OF ECONOMIC RESEARCH
1050 Massachusetts Avenue
Cambridge, MA 02138
February 2018, Revised December 2021

We are grateful to the editor and two anonymous referees for very helpful comments. We thank Maury Obstfeld, Katharina Bergeant, Daniele Bianchi, Karen Lewis as well as seminar participants at the the CEBRA-CEPR-Riksbank 2020 Conference, the WFA 2020 Meeting in San Francisco, the NBER Summer Institute in International Asset Pricing in 2019, the ASSA 2019 meetings in Atlanta, the 2018 EUROFIDAI Finance meetings in Paris, the 8th Workshop on Exchange Rates at Banque de France, the 2018 FMA Annual meetings in San Diego, Banco de Portugal, the 2018 Lubramacro-Portuguese-Brazilian Macroeconomics meetings in Aveiro, the 2018 European meetings of the the Econometric Society in Cologne, the 2018European Finance Association meetings in Warsaw, the 2018 Vienna Symposium on Foreign Exchange Markets, the 2018 Spanish Finance Forum in Santander, the 2018 Annual meetings of the Multinational Finance Society in Budapest and the 2018 Frontiers of Finance conference in Lancaster for comments. We are grateful to Paolo Surico for providing his software to calculate quantile range statistics. This research project benefited from a grant from the Swiss National Science Foundation (SNSF). Hélène Rey is grateful to the ERC for financial support (grant 695722). This research project benefited from the grants UID/GES/00407/2013 and PTDC/IIM-FIN/2977/2014 from the Portuguese Foundation for Science and Technology-FCT. The views expressed herein are those of the authors and do not necessarily reflect the views of the National Bureau of Economic Research.

NBER working papers are circulated for discussion and comment purposes. They have not been peer-reviewed or been subject to the review by the NBER Board of Directors that accompanies official NBER publications.

(C) 2018 by Nelson Camanho, Harald Hau, and Hélène Rey. All rights reserved. Short sections of text, not to exceed two paragraphs, may be quoted without explicit permission provided that full credit, including $\odot$ notice, is given to the source. 
Global Portfolio Rebalancing and Exchange Rates

Nelson Camanho, Harald Hau, and Hélène Rey

NBER Working Paper No. 24320

February 2018, Revised December 2021

JEL No. F3,F31,F32,F62,G15

\section{ABSTRACT}

We examine international equity allocations at the fund level and show how excess foreign returns influence portfolio rebalancing, capital flows and currencies. Our equilibrium model of incomplete FX risk trading where exchange rate risk partially segments international equity markets is consistent with the observed dynamics of equity returns, exchange rates, and fundlevel capital flows. We document that rebalancing is more intense under higher FX volatility and find heterogeneous rebalancing behavior across different fund characteristics. A granular instrumental variable (GIV) approach identifies a positive currency supply elasticity.

Nelson Camanho

School of Economics and Finance

Queen Mary University of London

Mile End Road

E1 4NS

London

United Kingdom

n.camanho@qmul.ac.uk

Harald Hau

University of Geneva, GFRI

\& Swiss Finance Institute

Bâtiment Pignon

40 Bd du Pont d'Arve

1211 Genèva 4

Switzerland

prof@haraldhau.com
Hélène Rey

London Business School

Regents Park

London NW1 4SA

United Kingdom

and CEPR

and also NBER

hrey@london.edu 


\section{Introduction}

Understanding the links between exchange rates and capital flows is a long standing issue in international economics. This issue is becoming more pressing as gross capital flows have dwarfed trade flows and gross stocks of cross-border assets and liabilities have increased dramatically from around $60 \%$ of world GDP in the mid-1990s to approximately $200 \%$ in 2015 (Lane and Milesi-Ferretti (2017)). ${ }^{1}$ Capital gains and losses on those assets have significant effects on the dynamics of countries' external asset positions. The macroeconomic literature finds that valuation effects induced by asset price changes have become quantitatively large relative to the traditional determinants of the current account. ${ }^{2}$ Valuation effects impact the portfolio allocation decisions of investors and may trigger capital flows. ${ }^{3}$ Most transactions on the foreign exchange market are due to asset trade rather than goods trade. Yet, there is surprisingly little systematic documentation about the interaction between exchange rates and trade in assets at the microeconomic level. How do international investors adjust their risk exposure in response to the fluctuations in realized returns they experience on their positions? Do they rebalance their portfolios toward their desired weights or do they increase their exposure to appreciating assets? What are the consequences of those portfolio decisions for capital flows and exchange rate dynamics?

This paper analyzes time series variation in international asset allocations of a large crosssection of institutional investors. A distinctive feature of our approach is its microeconomic

\footnotetext{
${ }^{1}$ They peaked at slightly more than $200 \%$ in 2007 , at the eve of the financial crisis. We use the Coordinated Portfolio Investment Survey (CPIS) dataset to estimate the portfolio component of the same statistics: it increased from $43 \%$ of world GDP in 2001 to more than $76 \%$ in 2015.

${ }^{2}$ For data on the increase of gross assets and liabilities and valuation effects see Lane and Milesi-Ferretti (2007), Tille (2008), Gourinchas and Rey (2007) and Fratzscher, Juvenal, and Sarno (2010). For a special focus on exchange rate valuations and currency composition of external assets see Lane and Shambaugh (2010), Della Corte, Sarno, and Sestieri (2012), Benetrix, Lane, and Shambaugh (2015), and Maggiori, Neiman, and Schreger (2020).

${ }^{3}$ Portes and Rey (2005) provide an early study of the geography of capital flows. ? highlights a strong correlation between portfolio flows and exchange rates for the financial crisis period. Stavrakeva and Tang (2019) show how flight to safety and dollar appreciation are intimately linked during the great recession period.
} 
focus: while international capital flows and returns are two key variables in international macroeconomics, a purely aggregate analysis is plagued by issues of endogeneity, heterogeneity and statistical power. For example, asset returns may be reasonably exogenous to the individual fund and its allocation decisions, but this is not true at the aggregate level, where capital flows are likely to influence asset and exchange rate returns. Fund heterogeneity can obscure the aggregate dynamics, but can also generate testable predictions on rebalancing behavior at the micro level. We exploit this heterogeneity by constructing a granular instrumental variable following Gabaix and Koijen (2020) and we use idiosyncratic large funds shocks to identify the elasticity of supply of foreign exchange, a key parameter in our model.

To better frame our analysis, we start with a two-country equilibrium model of optimal dynamic portfolio rebalancing and an endogenous exchange rate. There are very few microfounded macroeconomic models of exchange rate determination based on capital flows and imperfect financial integration. One prominent exception is Gabaix and Maggiori (2015) where exchange rate changes follow from financial flows induced by trade in segmented goods market and limits to intertemporal FX arbitrage. In their model, the exchange rate is determined by speculators who are the only agents who can hold both countries' debt. Our model builds on Hau and Rey (2006), does not model the goods market, but focuses instead on international trade in assets and its interactions with the foreign exchange market. ${ }^{4}$ In this respect, we follow the spirit of portfolio balance models in international finance pioneered by Kouri (1976), Kouri (1982) and Kouri et al. (1978) who model the joint behavior of asset prices (bonds and equity) and of the exchange rate. ${ }^{5}$ Our model allows for a joint deter-

\footnotetext{
${ }^{4}$ See Stavrakeva and Tang (2020) for a general equilibrium model taking into account the institutional details of the foreign exchange markets and allowing for deviations from rational expectations using survey data.

${ }^{5}$ See also Branson and Henderson (1985) and Blanchard, Giavazzi, and Sá (2005). These early portfolio balance models are rich in insights but they lack microfoundations. Empirical testing of the portfolio balance approach, relying on aggregate data,
} 
mination of optimal equity portfolios of domestic and foreign investors and of the exchange rate. This is a crucial difference with Gabaix and Maggiori (2015), where demand for foreign exchange is driven solely by goods trade as their model does not feature endogenous asset trade nor optimal portfolio choice. ${ }^{6}$

Our model has two representative investors (home and foreign) with two distinct stock markets and a local riskless bond in fully price-elastic supply. Differential returns and endogenous exchange rate risk across the two stock markets motivate the rebalancing behavior of the international investors in both countries and simultaneously drive the exchange rate and asset price dynamics in an incomplete market setting. Taking the short term rates as given, we solve jointly for equity prices and the exchange rate using optimal equity demands, two market clearing conditions for the equity markets and a market clearing condition for the exchange rate market where net currency demand meets the supply of risk averse foreign exchange arbitrageurs. Our approach is closely related to the recent paper of Koijen and Yogo (2020) who use optimal demand for countries' equity and bonds as well as market clearing equations for short term bonds, long term bonds and equities to determine asset prices and the exchange rate. They assume that the short term rate is pinned down by monetary policy. Like us they also assume that risky asset prices and exchange rates are jointly determined. Importantly, this allows for substitution effect across assets to affect the exchange rate. Building on Koijen and Yogo (2019), they estimate an entire demand system using cross-country aggregate holdings for 36 countries and decompose asset prices in three

proved difficult (see Frankel (1982a); Frankel (1982b); Rogoff (1984)). Driskill and McCafferty (1980), using a portfolio balance model with sticky prices, distinguish between the effects of real and monetary shocks on exchange rate volatility.

${ }^{6}$ For linearized microfounded dynamic stochastic general equilibrium models of the open economy with optimal portfolio choice see, for example, Coeurdacier (2009), Devereux and Sutherland (2010), Devereux and Sutherland (2011) and Tille and Van Wincoop (2010). This class of models focused on goods markets. It has had difficulty to match exchange rate dynamics. Bacchetta and Van Wincoop (2010) model agents who infrequently rebalance their portfolio in an overlapping generations (OLG) setting; Bacchetta et al. (2021) introduce quadratic costs to portfolio adjustments. Sandulescu, Trojani, and Vedolin (2021) link proxies of financial intermediaries' risk-bearing capacity to international SDFs. Some recent papers such as Dou and Verdelhan (2015) seek to model gross capital flows; Caballero and Simsek (2020) and Jeanne and Sandri (2020) rationalize comovements of aggregate gross inflows and outflows via models in which risk diversification, scarcity of domestic safe assets and the global financial cycle play important roles. 
sources of variation: policy variables, macroeconomic factors and latent demand. We focus instead on the interaction between equity portfolios and differential in equity returns at the fund level and use a granular instrumental variable approach to estimate the effect of equity flows on currencies.

A key prediction of our model is that excess returns on the foreign equity market portion of the investor portfolio should be partially repatriated to maintain an optimal trade-off between international asset diversification and exchange rate exposure. The model also predicts that this trade-off is influenced by the level of exchange rate volatility. ${ }^{7}$ From a macroeconomic point of view, our model generates home bias as an endogenous outcome and implies that the rebalancing behavior of international equity funds influence the exchange rate. We assume that the theoretical insights of the optimal competitive behavior of the two representative investors carry over to the granular investments of home and foreign equity funds. We use disaggregated fund-level holdings (quarterly frequency) for 7,940 internationally invested equity funds for the period 1999-2015 to test these predictions. The data comprise a total of 101,238 fund-quarters and 28,409,790 individual asset positions worldwide for funds domiciled in four major currency areas: the United States (U.S.), the United Kingdom (U.K.), the Eurozone (EZ), and Canada (CA). We can therefore observe portfolio rebalancing behavior in a large cross-sectional panel with different investor locations and investment destinations. Our data show a high degree of heterogeneity in the portfolio composition of institutional investors, including significant differences in the degrees of home bias. ${ }^{8}$ Importantly, we find strong evidence in favor of portfolio rebalancing strategies at the fund-level aimed at mitigating the risk exposure changes due to asset price and exchange rate changes. The key

\footnotetext{
${ }^{7}$ Empirically we also find, in accordance with intuition, that fund-level variables, such as the degree of fund diversification and its rebalancing costs, proxied by fund size, also have an impact on rebalancing behavior.

${ }^{8}$ The determinants of home bias and static portfolio allocations have been extensively studied in the literature (see e.g. the surveys of Lewis (1999) and Coeurdacier and Rey (2013)). For a detailed study of home bias at the fund level, see Hau and Rey (2008).
} 
insights are summarized as follows:

1. At the fund-level, we study the dynamics of the foreign value share of the portfolio. A higher equity return on the foreign portfolio share compared to the domestic share triggers capital repatriation, while the underperformance of foreign assets coincides with capital expatriation.

2. A high level of global FX volatility reinforces the rebalancing behavior of international equity funds.

3. Quantile regressions show that the strength of the rebalancing dynamics is non-linear in the return difference between a fund's foreign and domestic equity investments. The strength of the rebalancing increases more than proportionately as the performance difference between the foreign and domestic portfolio share increases. Transaction costs are a plausible explanation for this non-linearity.

4. Stronger fund-level rebalancing is associated with more concentrated investment in fewer stocks, as measured by the Herfindahl-Hirschman Index (HHI). Also, smaller funds exhibit stronger rebalancing, which is consistent with the transaction costs of dynamic portfolio adjustments increasing in fund size.

5. Aggregating the foreign equity investments of domestic funds and the domestic equity investments of foreign funds for each currency area, we show that net portfolio equity flows in response to differential equity returns are associated with an appreciation (a depreciation) of the domestic currency for net inflows (net outflows). The granular instrumental variable (GIV) estimator developed by Gabaix and Koijen (2020) allows us to estimate the causal effect of equity flows on exchange rate changes. 
These empirical results are consistent with the predictions of our two-country model featuring equity market segmentation and limits to intertemporal FX arbitrage, optimal portfolio choice by mean-variance investors and an equilibrium determination of the exchange rate. Our empirical study relies on more than 100,000 fund-quarter observations. This is unlike most of the existing empirical literature on capital flows which uses aggregate data, where correlation evidence between flows and returns is difficult to interpret due to thorny endogeneity issues. Bohn and Tesar (1996) analyze return chasing and portfolio rebalancing in an ICAPM framework, while Brennan and Cao (1997) and Albuquerque, Bauer, and Schneider (2007) study the effect of information asymmetries on correlations between international portfolio flows and returns. A few studies have used more granular data. Evans and Lyons (2002) show a tight correlation between order flow and exchange rate. Broner, Gelos, and Reinhart (2006) focus on country allocations of emerging market funds and look at channels of crisis transmission; Raddatz, Schmukler, and Williams (2017) study empirically how capital flows and benchmarking of funds interact. Froot and Ramadorai (2005) explore links between asset prices and equity flows at a more granular level. ${ }^{9}$ Our data allow us to get around the endogeneity issues associated with aggregate data because we observe the portfolio of each individual fund manager and estimate the portfolio weight changes induced by past realized valuation changes in our sample of heterogeneous portfolios. Those valuation changes are plausibly exogenous to each fund. Furthermore, we exploit the idiosyncratic rebalancing shocks of the large funds (GIV) to identify the aggregate effects of flows on the exchange rate. Our findings on fund rebalancing can inform a burgeoning theoretical literature in macroeconomics and finance that aims at modeling financial intermediaries. ${ }^{10}$

\footnotetext{
${ }^{9}$ In a closed economy framework, Calvet, Campbell, and Sodini (2009) investigate whether Swedish households adjust their risk exposure in response to the portfolio returns they experience during the period 1999-2002.

${ }^{10}$ See e.g. Adrian, Etula, and Shin (2015), Vayanos and Woolley (2013), Dziuda and Mondria (2012), Basak and Pavlova (2013) and Bruno and Shin (2014).
} 
The remainder of the paper is organized as follows. In Section 2 we present a simple two-country model with partially segmented asset markets. Its parsimonious microeconomic structure allows us to derive testable propositions about the joint dynamics of equity returns, exchange rates, and asset rebalancing. In Section 3 we discuss the microdata on fund asset holdings. Section 4 presents our empirical results at the fund level. Section 4.1 reports the main microevidence on portfolio rebalancing. Section 4.2 documents that such rebalancing intensifies under higher exchange rate volatility. Section 4.3 explores non-linearities in rebalancing at different quantiles of the foreign excess return distribution; and Section 4.4 shows how fund characteristics influence portfolio rebalancing. Section 5.1 is dedicated to the links between exchange rate and aggregate equity fund flows. In Sections 5.2 and 5.3 we propose a granular instrumental variable strategy to infer the supply elasticity of the exchange rate and estimate the causal effect of flows on the currency. Section 6 offers some alternative interpretations and Section 7 concludes.

\section{Model}

In this section we outline a model of dynamic portfolio rebalancing in which representative home and foreign investors optimally adjust to the endogenously determined asset prices and exchange rate fluctuations. Both investors behave competitively and are price takers. The exchange rate is determined in equilibrium between the net currency demand from portfolio rebalancing motives and the price elastic currency supply of a risk-averse global intermediary. The model builds on Hau and Rey (2002) and Hau and Rey (2006).

A key feature of the model is that the exchange rate and investors' rebalancing dynamics

are driven by the fundamental value of two dividend processes (in local currency) for home 
$(h)$ and foreign $(f)$ equity. Innovations in the fundamental value of equity in each country change stock market valuations and trigger a desire for holdings changes because the home and foreign equity markets are segmented by imperfectly traded exchange rate risk. For the home investor foreign equity is riskier whereas the opposite is true for the foreign investor. Market incompleteness resides in the realistic feature that exchange rate risk cannot be traded directly and separately between the home and foreign investors. A global intermediary is the only counterparty to the net currency demand of home and foreign equity investors. Asymmetric rebalancing desires of home and foreign investors can generate a high degree of exchange rate volatility.

To give the model a simple structure, we assume that both home and foreign investors maximize an instantaneous and linear trade-off between the expected asset return and its risk. Home and foreign investors choose portfolio weights $H_{t}=\left(H_{t}^{h}, H_{t}^{f}\right)$ and $H_{t}^{*}=\left(H_{t}^{h *}, H_{t}^{f *}\right)$ in equity markets, respectively. The superscripts $h$ and $f$ denote the home and foreign equity markets and the foreign investors are distinguished by a star (*). Alternatively, both investors can invest in a riskless domestic bond at rate $r$. The bond supply is fully price elastic. Both representative investors solve the optimization problem

$$
\begin{array}{lll}
\max _{H_{t}^{h}, H_{t}^{f}} & \mathcal{E}_{t} \int_{s=t}^{\infty} e^{-r(s-t)} & {\left[d \Pi_{t}-\frac{1}{2} \rho d \Pi_{t}^{2}\right] d s} \\
\max _{H_{t}^{f *}, H_{t}^{h *}} & \mathcal{E}_{t} \int_{s=t}^{\infty} e^{-r(s-t)} & {\left[d \Pi_{t}^{*}-\frac{1}{2} \rho d \Pi_{t}^{* 2}\right] d s}
\end{array}
$$

where $\mathcal{E}_{t}$ denotes the expectation for the stochastic profit flow $d \Pi_{t}$ from $t$ to $t+d t$ and its squared term $d \Pi_{t}^{2}$. For instantaneous excess returns $d R_{t}=\left(d R_{t}^{h}, d R_{t}^{f}\right)^{T}$ and $d R_{t}^{*}=$ $\left(d R_{t}^{h *}, d R_{t}^{f *}\right)^{T}$ expressed in terms of the currency of home and foreign investors, respectively, 
we can denote the stochastic profit flows as

$$
\begin{aligned}
d \Pi_{t} & =H_{t} d R_{t} \\
d \Pi_{t}^{*} & =H_{t}^{*} d R_{t}^{*},
\end{aligned}
$$

respectively. The investor risk aversion is denoted by $\rho$ and the domestic riskless rate is given by $r$ in each country. The linear asset demand functions abstract from intertemporal hedging motives that arise in a more general utility formulation. Investors do not take into account their price impact on asset prices or the exchange rate. The representative home and foreign investors can be thought of as aggregating a unit interval of identical atomistic individual investors without any individual price impact. Normalizing the asset supplies to one, market clearing in the equity market requires:

$$
\begin{aligned}
& H_{t}^{h}+H_{t}^{h *}=1 \\
& H_{t}^{f}+H_{t}^{f *}=1,
\end{aligned}
$$

Any selling of domestic equity by the foreign investor increases the holdings of the domestic investor. However, these purchases by domestic investors can be financed by the selling of local riskless bonds: they do not require a reduction of his foreign equity holdings. Similarly, the foreign investor may reinvest the proceeds of his equity sales in local riskless bonds and thus rebalance from equity to fixed income. The supply of bonds is fully elastic in each country and net equity flows are generally non-zero.

An additional market clearing condition applies to the foreign exchange market and its exchange rate $E_{t}$. Let $P_{t}^{h}$ and $P_{t}^{f *}$ denote the home and foreign stock prices in local stock currency, and $D_{t}^{h}$ and $D_{t}^{f *}$ the corresponding dividend flows also in local currency. We can measure the equity-related capital outflows $d Q_{t}$ of the home country (in foreign currency 
terms) as

$$
d Q_{t}=E_{t} H_{t}^{h *} D_{t}^{h} d t-H_{t}^{f} D_{t}^{f *} d t+P_{t}^{f *} d H_{t}^{f}-E_{t} P_{t}^{h} d H_{t}^{h *} .
$$

The first two terms represent the outflow if all dividends are repatriated. But investors can also increase their holdings of foreign equity assets. The net capital outflow due to changes in the foreign holdings, $d H_{t}^{f}$ and $d H_{t}^{h *}$ from $t$ to $t+d t$ are captured by the third and fourth terms. If we denote the Eurozone as the home and the U.S. as the foreign country, then $d Q_{t}$ represents the net capital outflow out of the Eurozone into the U.S. in dollar terms. An increase in $E_{t}$ (denominated in dollars per euro) corresponds to a dollar depreciation against the euro. Capital outflows are identical to a net demand in foreign currency as all investments are assumed to occur in the local currency.

The net demand for currency is met by a risk-averse global arbitrageur with a price-elastic excess supply curve with a supply elasticity parameter $\kappa>0$. For an equilibrium exchange rate $E_{t}$, the excess supply of foreign exchange is given by

$$
Q_{t}^{S}=-\kappa\left(E_{t}-\bar{E}\right)
$$

where $\bar{E}=1$ denotes the steady state exchange rate level around which the exchange rate is mean reverting. An increase in $E_{t}$ (dollar depreciation) decreases the excess supply of dollar balances. Currency speculators tend to sell dollars for euros if the dollar is expensive and buy dollars if it is cheap. The parameter $\kappa$ reflects their risk aversion or their capital constraints. The reduced form assumption in Eq. (5) could be generalized to account for interest rate differentials by adding a foreign currency supply component that increases in the differences between the home and foreign (riskless) interest rate [i.e. a term $\kappa_{2}\left(r-r^{*}\right)$ with $\left.\kappa_{2}>0\right]$. We assume zero interest rate differential $\left(r=r^{*}\right)$ for simplicity. A higher 
exchange rate level $E_{t}>1$ generates a risky arbitrage opportunity if the expected longrun exchange rate is $\mathcal{E}_{t}\left(E_{t+h}\right) \approx 1$ (for large $h$ ). In other words, risky arbitrage by bond investors with respect to uncovered interest parity violations also provides a justification for the reduced form assumption in Eq. (5). Lastly, we can relate the foreign currency supply to trade flows. Most macroeconomic models incorporate short-run nominal price rigidities and a (nominal) dollar depreciation (i.e. a higher $E_{t}$ ) tends to decrease the foreign (dollar) currency supply through a foreign (U.S.) trade surplus. At a longer horizon, the parameter $\kappa$ could also depend on the elasticity of substitution between domestic and foreign goods and the degree of nominal rigidity in the good markets.

Combining Eqs. (4) and (5), and putting aside net dividend income $N D I_{t}=E_{t} H_{t}^{h *} D_{t}^{h}-$ $H_{t}^{f} D_{t}^{f *}$, it follows that the foreign exchange rate appreciation $-d E_{t}$ (or home currency depreciation) is proportional to the foreign holding changes $d H_{t}^{f}$ by domestic funds minus the domestic holding changes $d H_{t}^{h *}$ of foreign funds as

$$
-\kappa d E_{t}=N D I_{t} d t+P_{t}^{f *} d H_{t}^{f}-E_{t} P_{t}^{h} d H_{t}^{h *}
$$

In Section 5 of the paper we explore this aggregate relationship empirically. ${ }^{11}$ Before we can solve this simple model, two more assumptions are needed. First, we have to specify the exogenous dividend dynamics in local currency. For tractability, we assume two independent Ornstein-Uhlenbeck processes with identical variance and mean reversion to a steady state value $\bar{D}$, hence

$$
\begin{aligned}
d D_{t}^{h} & =\alpha_{D}\left(\bar{D}-D_{t}^{h}\right) d t+\sigma_{D} d w_{t}^{h} \\
d D_{t}^{f *} & =\alpha_{D}\left(\bar{D}-D_{t}^{f *}\right) d t+\sigma_{D} d w_{t}^{f *}
\end{aligned}
$$

\footnotetext{
${ }^{11}$ The active rebalancing of bond funds could induce additional confounding currency demands ignored in our model. However, bond investments are usually hedged in derivative markets, which mutes their effect on exchange rates.
} 
We note that the model dynamics is invariant to the particular payout policy of firms as long as investors can reinvest dividend payouts instantaneously so that share-buybacks and reinvestments imply the same investment positions. Second, we linearize Eq. (4) as well as the foreign excess return expressed in the home currency. The model features a unique equilibrium for the joint equity price, exchange rate, and portfolio holding dynamics under these linearizations and reasonable parameter values. ${ }^{12}$

\subsection{Model Solution}

The linearized version of the model defines a system of linear stochastic differential equations in seven endogenous variables, namely the home and foreign asset prices $P_{t}^{h}$ and $P_{t}^{f *}$, the exchange rate $E_{t}$, and the home and foreign equity holdings of both investors $H_{t}=\left(H_{t}^{h}, H_{t}^{f}\right)$ and $H_{t}^{*}=\left(H_{t}^{f *}, H_{t}^{h *}\right)$, respectively. These seven variables are functions of past and current stochastic innovations $d w_{t}^{h}$ and $d w_{t}^{f}$ of the dividend processes. To characterize the equilibrium, it is useful to define a few auxiliary variables. We denote the fundamental value of equity as the expected present value of future discounted local currency dividends given by

$$
\begin{gathered}
F_{t}^{h}=\mathcal{E}_{t} \int_{s=t}^{\infty} D_{t}^{h} e^{-r(s-t)} d s=f_{0}+f_{D} D_{t}^{h} \\
F_{t}^{f *}=\mathcal{E}_{t} \int_{s=t}^{\infty} D_{t}^{f *} e^{-r(s-t)} d s=f_{0}+f_{D} D_{t}^{f *},
\end{gathered}
$$

with constant terms defined as $f_{D}=1 /\left(\alpha_{D}+r\right)$ and $f_{0}=\left(r^{-1}-f_{D}\right) \bar{D}$. Investor risk aversion and market incompleteness with respect to exchange rate risk trading imply that asset prices generally deviate from this fundamental value. We define two variables $\Delta_{t}$ and $\Lambda_{t}$ that embody the asset price dynamics around the fundamental value, that is

\footnotetext{
${ }^{12}$ More precisely, the risk aversion of the investors needs to be sufficiently low and the currency supply by the global intermediary sufficiently elastic to maintain an equilibrium where investors diversify their portfolio internationally. Otherwise we revert to a corner solution of domestic investment only.
} 


$$
\Delta_{t}=\int_{-\infty}^{t} \exp \left[-\alpha_{D}(t-s)\right] \sigma_{D} d w_{s} \quad \text { and } \quad \Lambda_{t}=\int_{-\infty}^{t} \exp \left[-\alpha_{\Lambda}(t-s)\right] d w_{s}
$$

where $d w_{s}=d w_{t}^{h}-d w_{t}^{f *}$ and $\alpha_{\Lambda}>0$. The variable $\Delta_{t}=D_{t}^{h}-D_{t}^{f *}$ simply represents the difference in the dividend level between the home and foreign equity markets, whereas $\Lambda_{t}$ aggregates past dividend innovations with a different decay factor $\alpha_{\Lambda}{ }^{13}$

We are interested in an equilibrium for which both the home and foreign investors hold positive (steady state) amounts of home and foreign equity. For such an equilibrium to exist, we impose a lower bound on the elasticity of currency $(\kappa>\underline{\kappa})$ and an upper bound on investor risk aversion $(\rho<\bar{\rho})$. Under these conditions, the following unique equilibrium exists:

\section{Proposition 1 (Portfolio Rebalancing Equilibrium):}

The unique equilibrium for the linearized model features asset prices (expressed in local currency) and an exchange rate characterized by

$$
\begin{aligned}
P_{t}^{h} & =p_{0}+F_{t}^{h}+p_{\Delta} \Delta_{t}+p_{\Lambda} \Lambda_{t} \\
P_{t}^{f *} & =p_{0}+F_{t}^{f *}-p_{\Delta} \Delta_{t}-p_{\Lambda} \Lambda_{t} \\
E_{t} & =1+e_{\Delta} \Delta_{t}+e_{\Lambda} \Lambda_{t}
\end{aligned}
$$

and dynamic portfolio holdings

$$
\left(\begin{array}{cc}
H_{t}^{h} & H_{t}^{f} \\
H_{t}^{f *} & H_{t}^{h *}
\end{array}\right)=\left(\begin{array}{cc}
1-\bar{H} & \bar{H} \\
1-\bar{H} & \bar{H}
\end{array}\right)+\left(\begin{array}{cc}
-1 & -1 \\
1 & 1
\end{array}\right) \frac{1}{2 \rho}\left(m_{\Delta} \Delta_{t}+m_{\Lambda} \Lambda_{t}\right)
$$

\footnotetext{
${ }^{13}$ We note that the variance of the process $\Lambda_{t}$ can be normalized without loss of generality as parameters $p_{\Lambda}$ and $e_{\Lambda}$ in Proposition 1 (defined below) already scale the variance of the process.
} 
where $0<\bar{H} \leq 0.5$ denotes the steady state holding of foreign assets and the coefficients $p_{0}<0, p_{\Delta}, p_{\Lambda}, e_{\Delta}, e_{\Lambda}, m_{\Delta}$, and $m_{\Lambda}$ are defined implicitly by the firstorder and market clearing conditions stated in Appendix A. These parameters are functions of the six exogenous parameters $\alpha_{D}, \sigma_{D}, \bar{D}, r, \kappa$ and $\rho$.

Proof: See Appendix A.

The home and foreign equity prices in Eqs. (10)-(11) deviate from their fundamental values $F_{t}^{h}$ and $F_{t}^{f *}$, and a constant risk premium $p_{0}<0$ by the additional stochastic term $p_{\Delta} \Delta_{t}+p_{\Lambda} \Lambda_{t}$, which moves the respective home and foreign asset prices in opposite directions. Under market incompleteness and limited international risk sharing, asset prices deviate from their fundamental values. The same stochastic processes $\Delta_{t}$ and $\Lambda_{t}$ composed of past dividend innovations also drive the exchange rate in Eq. (12) and the asset rebalancing dynamics in Eq. (13). The second $2 \times 2$ matrix in Eq. (13) describes the steady state equity holdings with the endogenous home bias $1-\bar{H}>0.5 ;^{14}$ the third term in Eq. (13) characterizes the dynamic adjustment of the equity portfolios. As the diagonal elements add up to unity, market clearing is trivially assured. Each representative investor adjusts his home and foreign equity positions by the same increment $\frac{1}{2 \rho}\left(m_{\Delta} d \Delta_{t}+m_{\Lambda} d \Lambda_{t}\right)$, but in the opposite direction of each other, which means that their rebalancing from equity into the local riskless asset occurs in opposite directions.

Limited currency supply elasticity plays a crucial role in the equilibrium. To appreciate this aspect, consider the limit case of an infinitely price elastic foreign currency supply with $\kappa \rightarrow \infty$. In this special case all exchange rate volatility disappears $\left(E_{t}=1\right)$ as $e_{\Delta} \rightarrow 0$, and $e_{\Lambda} \rightarrow 0$. Moreover, the home and foreign asset prices converge to $P_{t}^{h}=p_{0}+F_{t}^{h}$ and $P_{t}^{f *}=p_{0}+F_{t}^{f *}$, respectively, as $p_{\Delta} \rightarrow 0$, and $p_{\Lambda} \rightarrow 0$. The limit case features perfect global

\footnotetext{
${ }^{14}$ For a model in which infrequent portfolio adjustment and exchange rate volatility generates home bias see Lee (2021).
} 
risk sharing with both home and foreign investors holding half of the equity risk in each market, thus $\bar{H} \rightarrow 0.5$ and $m_{\Delta} \rightarrow 0, m_{\Lambda} \rightarrow 0$. Both equity prices are then determined only by their domestic fundamentals.

\subsection{Model Implications for Rebalancing}

The model solution in Proposition 1 implies a unique covariance structure for the joint dynamics of international equity holdings, equity returns and exchange rate. In this section we highlight the empirical implications and outline the empirical strategy for testing the model predictions.

\section{Corollary 1 (Rebalancing and Equity Return Differences):}

The domestic investor rebalances her foreign investment portfolio toward home country equity if the return on her foreign equity holdings exceeds the return on her home equity investments. Formally, the foreign equity holding change $d H_{t}^{f}$ and the excess return of the foreign equity over home equity $d r_{t}^{f}-d r_{t}^{h}=\left(d R_{t}^{f}-d R_{t}^{h}\right) / \bar{P}$ expressed in domestic currency feature a negative covariance given by

$$
\operatorname{Cov}\left(d H_{t}^{f}, d r_{t}^{f}-d r_{t}^{h}\right)=\kappa \frac{1}{\bar{P}}\left[\frac{1}{\bar{P}} f_{D} \sigma_{D}+2 p_{\Delta} \sigma_{D}+2 p_{\Lambda}+e_{\Delta} \sigma_{D}+e_{\Lambda}\right]\left(e_{\Delta} \sigma_{D}+e_{\Lambda}\right) d t<0
$$

\section{Proof: See Appendix A.}

Corollary 1 characterizes the rebalancing behavior $d H_{t}^{f}$ in foreign equity by the representative home investor under the assumption of competitive price taking behavior. Undertaking the regression analysis at the fund level considerably increases the statistical power of any

test. We measure the fund-specific foreign excess return $r_{j, t}^{f}-r_{j, t}^{h}$, which can feature cross- 
sectional heterogeneity if, for example, individual investment strategies deviate from the representative holdings due to fund-specific beliefs about future stock returns. We pursue this analysis in Section 4.1 based on a linear regression model where we regress fund $\mathrm{j}$ rebalancing $\Delta h_{j, t}^{f}$ on its fund specific return differential $\left(r_{j, t}^{f}-r_{j, t}^{h}\right)$ controlling for country-time $\eta_{c, t}$ and fund fixed effects $\varepsilon_{j}$ ( $\mu_{j, t}$ is the error term).

$$
\Delta h_{j, t}^{f}=\beta\left(r_{j, t}^{f}-r_{j, t}^{h}\right)+\varepsilon_{j}+\eta_{c, t}+\mu_{j, t}
$$

Our theory predicts a rebalancing coefficient $\beta<0$.

\subsection{Comparative Statics in FX Supply Elasticity}

The model yields additional insights into the level of FX volatility under different parameter conditions. We can derive the instantaneous volatility as

$$
V o l^{F X}=\sqrt{\frac{\mathcal{E}_{t}(d E)^{2}}{d t}}=\sqrt{2}\left|e_{\Delta} \sigma_{D}+e_{\Lambda}\right|
$$

Figure 1, Panel A plots the instantaneous volatility $\operatorname{Vol}^{F X}$ for varying scaled FX supply elasticities $\frac{\kappa}{P H} \in[10,200]$ (corresponding to $\kappa \in[100,5000]$ ). We use a risk aversion $\rho=0.02$ and the parameters of the dividend process are set at $\bar{D}=1, r=0.04, \alpha_{D}=0.015$. We show the results for four different levels of stock market volatility $\sigma_{D} \in[0.15,0.2,0.25,0.3]$. For any given level of stock market volatility $\sigma_{D}$ and risk aversion $\rho$, a lower FX supply elasticity $\kappa$ implies a larger level of FX volatility as capital flows have an increasing impact on the FX price. A lower FX market liquidity due to a decrease in available arbitrage capital at dealer banks, for example, can thus generate a higher level of FX volatility and increase the degree of equity market segmentation. We note for the empirical section that our model 
can generate observable levels of FX volatility if the (scaled) currency supply elasticity $\frac{\kappa}{\overline{P H}}$ drops below a value of 20 .

Our model does not feature any dynamic time variation in the parameter $\kappa$. Any such time variation - either deterministic or stochastic — implies that all the variance and covariance parameters of the rebalancing flows, the stock prices, and the exchange rate also become time dependent. Such an extended model is beyond the scope of this paper. But, we can nevertheless point out the results of a simple comparative statics exercise in the parameter $\kappa$ for the homoscedastic model. This solution describes a good approximation to a heteroscedastic model if the transition dynamics between different levels of volatility is slow relative to the dividend dynamics governing the system. ${ }^{15}$

\section{Corollary 2 (Comparative Statics in FX Supply Elasticity):}

The home investor rebalances the foreign investment portfolio toward the home country more strongly under higher foreign excess return $d r_{t}^{f}-d r_{t}^{h}$ if the level of FX volatility is larger due to a lower elasticity parameter $\kappa$. Formally, the rebalancing coefficient $\beta$ decreases in $\mathrm{FX}$ volatility, that is, ${ }^{16}$

$$
\frac{d \beta}{d \operatorname{Vol}^{F X}}<0, \quad \text { where } \beta=\frac{\operatorname{Cov}\left[d H_{t}^{f}, d r_{t}^{f}-d r_{t}^{h}\right]}{\operatorname{Var}\left[d r_{t}^{f}-d r_{t}^{h}\right]}
$$

\section{Numerical simulation: See Appendix A.}

Figure 1, Panel B, plots the rebalancing coefficient $\beta$ as a function of the instantaneous FX volatility for variations of the supply elasticity parameter $\kappa \in[100,5000]$. Lower supply elasticities - equivalent to higher FX volatility in Panel B - imply ceteris paribus a higher

\footnotetext{
${ }^{15}$ The effect of changing volatility levels on the equilibrium characteristics tends to be small if changes in $\kappa(t)$ occur slowly relative to the short (myopic) horizon of the investors.

${ }^{16}$ We compute $\beta$ in Appendix A.
} 
FX volatility level and a more negative rebalancing coefficient. In other words, we predict more intense rebalancing under higher FX volatility. We show the results for four different levels of stock market volatility $\sigma_{D} \in[0.15,0.2,0.25,0.3]$.

Corollary 2 suggests that episodes of higher FX volatility should coincide with a stronger and more negative rebalancing coefficient $\beta$. We can explore this prediction at the fund level by regressing foreign holding changes $\Delta h_{j, t}^{f}$ over period $t$ of fund $j$ on the interaction terms $\left(r_{j, t}^{f}-r_{j, t}^{h}\right) \times V o l_{t}^{F X}$ between a fund foreign excess return $r_{j, t}^{f}-r_{j, t}^{h}$ and the the level of FX volatility $\operatorname{Vol}_{t}^{F X}$. Controlling for fund fixed effects and time-country fixed effects, we expect the linear regression

$$
\Delta h_{j, t}^{f}=\beta\left(r_{j, t}^{f}-r_{j, t}^{h}\right)+\gamma V o l_{t}^{F X}+\delta\left(r_{j, t}^{f}-r_{j, t}^{h}\right) \times V o l_{t}^{F X}+\varepsilon_{j}+\eta_{c, t}+\mu_{j, t}
$$

to yield a negative rebalancing/volatility interaction coefficient $\delta<0$. In other words, rebalancing toward home equity increases in periods of higher FX volatility. Intuitively, higher exchange rate volatility renders foreign equity positions more risky in domestic currency terms and strengthens the profit repatriation motive for any foreign excess return. We pursue this analysis in Section 4.2 .

\section{Data}

For data on global equity holdings we use FactSet/LionShares. ${ }^{17}$ The data report individual mutual fund and other institutional holdings at the stock level. For investors in the U.S., the data are collected by the Securities and Exchange Commission (SEC) based on 13-F filings

\footnotetext{
${ }^{17}$ Ferreira and Matos (2008) examine the representativeness of the FactSet/LionShares dataset, by comparing the cross-border equity holdings in it with the aggregate cross-country holdings data of the Coordinated Portfolio Investment Survey (CPIS) of the IMF. The CPIS data have been systematically collected since 2001 and constitute the best measures of aggregate crosscountry asset holdings. The values reported in FactSet are lower than those in the CPIS but still representative of foreign equity positions in the world economy.
} 
(fund family level) and N-SAR filings (individual fund level). Outside the U.S., the sources are national regulatory agencies, fund associations, and fund management companies. The sample period covers the 17 years from 1999 to 2015 and has therefore not only a large cross-sectional coverage, but also a reasonably long time dimension to investigate portfolio dynamics. $^{18}$

The FactSet/LionShares dataset comprises fund identifier, stock identifier, country code of the fund incorporation, management company name, stock position (number of stocks held), reporting dates for which holding data are available, and security prices on the reporting date. We complement these data with the total return index (including the reinvested dividends) in local currency for each stock using CRSP (for U.S./Canadian stocks) and Datastream (for non-U.S./non-Canadian stocks). Most funds report quarterly, which suggests that the analysis is best carried out at a quarterly frequency. Reporting dates differ somewhat, but more than $90 \%$ of the reporting occurs in the last 30 days of each quarter. A limitation of the data is that they do not include any information on a fund's cash holdings, financial leverage, investments in fixed income instruments, or investments in derivative contracts. All the portfolio characteristics we calculate therefore concern only the equity proportion of a fund's investment. We believe that missing cash holdings in home currency or financial leverage is not a major concern for our analysis, since (positive or negative) leverage simply implies a scaling of the absolute risk by a leverage factor. All our analysis is based on portfolio shares and therefore not affected by constant leverage or time variations in leverage, as long as these are independent of the excess return on foreign assets. ${ }^{19}$ A more serious concern is

\footnotetext{
${ }^{18}$ Other papers use disaggregated data on international institutional investors holdings, albeit with a different focus. Chan, Covrig, and $\mathrm{Ng}$ (2005) look at the determinants of static allocations at the country level. Froot, O'Connell, and Seasholes (2001) high-frequency study is based on the transaction data of one global custodian (State Street Bank \& Trust). The authors look at the effect of aggregate cross-country flows on MSCI country returns. For a high-frequency study linking exchange rates to aggregated institutional investors flows using State Street Bank \& Trust data, see Froot and Ramadorai (2005). Our study focuses on a different time scale (quarterly instead of daily) and uses a whole cross-section of fund-specific investment decisions and stock level data.

${ }^{19}$ This argument is only valid for home currency cash and cannot be maintained if cash is held in foreign currency. In the
} 
that funds may carry out additional hedging operations that escape our inference. However, as documented in previous surveys (Levich, Hayt, and Ripston (1998)), most equity funds do not engage in any derivative trading and their equity position may therefore represent an accurate representation of their risk-taking. We also note that any additional hedging is likely to attenuate rebalancing and therefore bias the predicted negative correlation toward zero.

We focus our analysis on funds domiciled in four geographic regions, namely the United States (U.S.), the United Kingdom (U.K.), the Eurozone, and Canada. ${ }^{20}$ These fund locations represent $92 \%$ of all quarterly fund reports in our data and constitute $97 \%$ of all reported positions by value. Funds in the Eurozone are pooled because of their common currency after 1999. To reduce data outliers and limit the role of reporting errors, a number of data filters are employed:

- We retain holding data only from the last reporting date of a fund in each quarter. A fund has to feature in two consecutive quarters to be retained. Consecutive reporting dates are a pre-requisite for the dynamic inference in this paper. Our sample starts at the first quarter of 1999.

- Funds are retained if their total asset holding exceeds $\$ 10$ million. Smaller funds might represent incubator funds and other non-representative entities.

- We retain only international funds that hold at least five stocks in the domestic currency and at least five stocks in another currency area. This excludes all fund-quarters with fewer than 10 stock positions and also funds with only domestic or only international positions. Our focus on international rebalancing between foreign and domestic stocks

\footnotetext{
latter case the exchange rate risk alters the risk features of the portfolio.

${ }^{20}$ The Eurozone countries included in the sample are Austria, Belgium, Finland, France, Germany, Ireland, Italy, Luxembourg, the Netherlands, Portugal, and Spain.
} 
renders funds with a narrow foreign or domestic investment mandate less interesting.

- Non-diversified funds with extreme investment biases in very few stocks are also ignored. We consider a fund diversified if fund stock weights produce a Herfindahl-Hirschman Index below $20 \%$.

- We discard funds if their return on combined equity holdings exceed $200 \%$ or if they lose more than $50 \%$ of their equity holdings value over a quarter. Individual stock observations are ignored if they feature extreme quarterly returns that exceed $500 \%$ or are below $-80 \% .^{21}$

- We trim the percentage fund rebalancing statistics at the $2.5 \%$ and $97.5 \%$ quantile. ${ }^{22}$

In Table 1, Panel A, we report summary statistics on fund holdings at the fund-quarter level for the sample period 1999-2015. An international fund has on average $\$ 1$ billion in total equity assets, out of which $\$ 677$ million are invested in home equity and $\$ 325$ million in foreign equity. The data on internationally invested funds show a modest home bias, as the average domestic share of a fund portfolio is $54.0 \%$. While the average quarterly rebalancing between foreign and domestic equity investments is small at $0.064 \%$, its standard deviation is substantial at $4.6 \%$ of the total (equity) value of the portfolio. The number of international funds in the raw sample increases steadily over time from only 167 funds reporting at the end of 1999 to 5,683 funds reporting at the end of 2014. While the European fund sample comprises a larger number of fund periods and stock positions than the U.S. fund sample, the latter amounts to a larger aggregate value throughout the sample period. For example, at the end of 2006, we count 889 (international) equity funds domiciled in the U.S. with a

\footnotetext{
${ }^{21}$ We discard very few observations this way. Extreme return values may be attributable to data errors.

${ }^{22}$ Extreme rebalancing is concentrated in very small equity funds and its trimming has only a small impact on aggregate portfolio flows. We check robustness of our results using alternative trimming assumptions.
} 
total of 156,086 stock positions valued at $\$ 1,690$ billion. For the same quarter, the European equity fund sample comprises 2,744 funds with a total of 293,718 stock positions and an aggregate value of $\$ 732$ billion. Table 1 , Panel B presents the aggregate statistics at the quarterly level. The variables are the (effective) exchange rate change of currency area $c$ relative to the 10 other most important investment destinations, the aggregate rebalancing $\Delta H_{c, t}^{f}$ from home to foreign investments for all funds domiciled within currency area $c$, and the reciprocal aggregate rebalancing $\Delta H_{c, t}^{h *}$ into currency area $c$ for funds domiciled outside currency area $c$. It also reports the summary statistics for the FX volatility variable and for the granular instrumental variables used to identify the causal effect of portfolio flows on the exchange rate in Section 5.

\section{Evidence on Portfolio Rebalancing}

The model in Section 2 illustrates that imperfect exchange rate risk trading can generate exchange rate volatility that segments the foreign and domestic equity markets. The foreign investment component of an international portfolio is exposed to additional exchange rate risk and generates a rebalancing motive whenever its value grows relative to the domestic equity share in the portfolio. Such differential exposure to exchange rate risk implies that equity investments are repatriated to the home country whenever the foreign equity market outperforms the domestic market. The rebalancing behavior reflects the investor's desire to partly offset exogenous changes in exchange rate risk exposure. These rebalancing flows in turn create a feedback effect on exchange rate volatility. The repatriated equity investments lead to appreciation of the domestic currency. We explore the role of FX volatility in Section 4.2, plausible non-linearities in rebalancing in Section 4.3, and the role of fund heterogeneity 
in Section 4.4. Our fund-level rebalancing variable $\Delta h_{j, t}^{f}$ compares the observed foreign equity weights $w_{j, t}^{f}$ of fund $j$ at the end of period (quarter) $t$ to the implied weights $\widehat{w}_{j, t}^{f}$ from a simple holding strategy that does not engage in any buy or sell activity with respect to foreign equity investment. Formally, we define rebalancing of foreign asset holdings as any deviation from the simple holding strategy given by

$$
\Delta h_{j, t}^{f}=w_{j, t}^{f}-\widehat{w}_{j, t}^{f} \quad \text { with } \quad \widehat{w}_{j, t}^{f}=w_{j, t-1}^{f}\left[\frac{1+r_{j, t}^{f}}{1+r_{j, t}^{P}}\right]
$$

where $r_{j, t}^{P}$ represents the total portfolio return and $r_{j, t}^{f}$ the return on the foreign component of the portfolio of fund $j$ between dates $t-1$ and $t$, all expressed in the currency of the fund domicile. Furthermore,

$$
w_{j, t}^{f}=\sum_{s=1}^{N_{j}} 1_{s=f} \times w_{s, j, t},
$$

where $1_{s=f}$ is a dummy variable that is 1 if stock $s$ is a foreign stock and 0 otherwise.

Figure 2 illustrates the distribution of the rebalancing measure for each of the four fund domiciles. We graph the realized foreign portfolio share $w_{j, t}^{f}$ of each fund on the y-axis against the implied share $\widehat{w}_{j, t}^{f}$ under a passive holding strategy on the x-axis. The dispersion of points along the 45-degree line shows the difference in the foreign investment share across funds in the different domiciles. The vertical distance of any fund observation from the 45-degree line measures active portfolio rebalancing of foreign asset holdings $\Delta h_{j, t}^{f}=w_{j, t}^{f}-\widehat{w}_{j, t}^{f}$ in percent of total assets for the respective fund. Fund rebalancing at the quarterly frequency has a standard deviation of $4.6 \%$ for the full sample of 101,238 fund periods as stated in Table 1. It is highest for Eurozone funds at $5.2 \%$ and lowest for the U.K. and U.S. funds at $3.9 \%$ and 3.8\%, respectively. We also highlight a larger average foreign investment share for U.K. funds and the stronger home bias for U.S. funds. By contrast, the Eurozone fund sample is 
more uniformly distributed in terms of its foreign investment share.

The total portfolio return $r_{j, t}^{P}$ on fund $j$ is defined as

$$
r_{j, t}^{P}=\sum_{s=1}^{N_{j}} w_{s, j, t-1} r_{s, t}
$$

where $r_{s, t}$ is the return on security $s$ expressed in the currency of the fund domicile and $N_{j}$ is the total number of stocks in the portfolio of fund $j$. The foreign and domestic return components of the portfolio expressed in the currency of the fund domicile are given by

$$
r_{j, t}^{f}=\sum_{s=1}^{N_{j}} \frac{w_{s, j, t-1}}{w_{j, t-1}^{f}} r_{s, t} \times 1_{s=f} \quad r_{j, t}^{h}=\sum_{s=1}^{N_{j}} \frac{w_{s, j, t-1}}{w_{j, t-1}^{h}} r_{s, t} \times 1_{s=h} .
$$

\subsection{Main Results}

As a test of the rebalancing hypothesis, we regress the portfolio rebalancing measure on the excess return of the foreign part of the portfolio over the home part of the portfolio, that is

$$
\Delta h_{j, t}^{f}=\sum_{l=0,1,2} \beta_{l}\left(r_{j, t-l}^{f}-r_{j, t-l}^{h}\right)+\eta_{c, t}+\varepsilon_{j}+\mu_{j, t}
$$

where $\beta_{l}<0$ with $l=0$ captures instantaneous rebalancing and $\beta_{l}<0$ with $l=1,2$ captures delayed portfolio reallocations with a time lag of $l$ quarters. ${ }^{23}$ The specification includes interacted investor country and time fixed effects $\eta_{c, t}$ to capture common (macroeconomic) reallocations between home and foreign equity pertaining to all funds domiciled in the same country. To allow for a time trend in the foreign portfolio allocation of funds we also include fund fixed effects $\varepsilon_{j}$ in most specifications. We note that a passive buy and hold strategy of an index produces $\Delta h_{j, t}^{f}=0$ and should imply a zero coefficient. Passive

\footnotetext{
${ }^{23}$ The excess return of the foreign part of the portfolio over the home part of the portfolio $r_{j, t-l}^{f}-r_{j, t-l}^{h}$ is measured in the currency of the fund domicile. Results are robust to an alternative specification where $r_{j, t-l}^{f}-r_{j, t-l}^{h}$ is measured in local stock
currency.
} 
index investment will bias the coefficients $\beta_{l}$ toward zero.

Table 2 reports the baseline results on the rebalancing behavior of international equity funds. Column (1) includes only the contemporaneous excess return $r_{j, t}^{f}-r_{j, t}^{h}$ and does not include any fixed effects. The 101,238 fund-quarters yield the predicted negative coefficient at -1.839 , which is statistically highly significant. As some of the rebalancing is likely to occur only with a time lag, we include in Column (2) the lagged excess return on foreign equity. The inclusion of lagged excess returns also presents a useful control of reverse causality. If a fund increases (decreases) its positions in illiquid foreign stocks, this may increase (decrease) their stock price, generate a positive (negative) foreign excess return $r_{j, t}^{f}-r_{j, t}^{h}$ and thus bias the contemporaneous coefficient toward a positive value $\beta_{0}>0$. The same logic does not apply to lagged foreign excess returns. Column (2) also includes interacted time and investor country fixed effects which control for all macroeconomic effects such as common equity fund inflows in the investor domicile. The contemporaneous coefficient $\beta_{0}$ and the lagged coefficient $\beta_{1}$ are both negative at high levels of statistical significance. Adding fund fixed effects in Column (3) can absorb any positive or negative growth trend in a fund's foreign equity position, but their inclusion does not qualitatively affect the rebalancing evidence. Column (4) shows that even the second quarterly lag of foreign excess returns $r_{j, t-2}^{f}-r_{j, t-2}^{h}$ has some explanatory power for fund rebalancing, although the economic magnitude is weaker at -0.998 .

Adding the three coefficients in Column (4) implies a combined rebalancing effect of -5.099. A relative quarterly excess return of two standard deviations (or 0.140) therefore implies a reduction in the foreign equity weight by 0.714 percentage points for the representative (foreign-invested) institutional investor. ${ }^{24}$ In light of the large size of foreign equity positions valued at $\$ 6.7$ trillion for U.S. investors in December 2015, this amounts to econom-

\footnotetext{
${ }^{24}$ We note that the dependent variable $\Delta h_{j, t}^{f}$ is scaled by a factor of 100 .
} 
ically significant equity flows of $\$ 48$ billion per quarter for U.S. equity investors alone. ${ }^{25}$ We also explore asymmetries in the rebalancing behavior of international investors by splitting the sample into negative and positive excess returns. Formally, we have

$$
\Delta h_{j, t}^{f}=\sum_{l=0,1} \beta_{l}^{+}\left(r_{j, t-l}^{f}-r_{j, t-l}^{h}\right) \times 1_{\Delta r \geq 0}+\sum_{l=0,1} \beta_{l}^{-}\left(r_{j, t-l}^{f}-r_{j, t-l}^{h}\right) \times 1_{\Delta r<0}+\eta_{c, t}+\varepsilon_{j}+\mu_{j, t},
$$

where $1_{\Delta r \geq 0}$ represents a dummy that is equal to 1 whenever the foreign excess return $\Delta r=r_{j, t}^{f}-r_{j, t}^{h} \geq 0$ and 0 otherwise. The complementary dummy marking negative foreign excess returns is given by $1_{\Delta r<0}$. The regression coefficients for the positive and negative components of the excess return reported in Column (5) show similar overall rebalancing for positive and negative excess returns when the significant coefficients for the contemporaneous and lagged rebalancing behavior are summed up. We conclude that rebalancing occurs symmetrically for both positive and negative foreign excess returns. We also split the excess return into a separate foreign and home market return components, namely $r_{j, t-l}^{f}$ and $r_{j, t-l}^{h}$. Again no evidence for an asymmetric rebalancing is found in these unreported regression results. Finally, we split the sample into a pre-crisis period up to June 2008 (Period I) and a crisis and post-crisis period (Period II) thereafter. Columns (6) and (7) show the respective regression results and suggest that portfolio rebalancing in response to foreign excess returns is of roughly similar economic significance in the pre-crisis period 1999-2008 and thereafter.

\subsection{Rebalancing and FX Market Volatility}

Higher FX market volatility increases segmentation between the domestic and foreign equity markets. This reinforces portfolio rebalancing under incomplete FX risk trading in accordance with Corollary 2. To obtain measures of exchange rate volatility at a quarterly

\footnotetext{
${ }^{25}$ Source: U.S. Portfolio Holdings of Foreign Securities as of December 3, 2015, U.S. Department of Treasury.
} 
frequency, we first calculate the effective daily exchange rate $E_{c, d}$ for currency area $c$ on trading day $d$ as the weighted average of bilateral exchange rates $E_{c, i, d}$ with the $N$ most important investment destinations indexed by $i$. Formally,

$$
E_{c, d}=\sum_{i=1}^{N} \omega_{c, i} E_{c, i, d}
$$

where the weights $\omega_{c, i}$ are chosen to be the average foreign portfolio shares of all domestic funds in currency area $c$. For simplicity, we limit $N$ to the ten most important equity investment destinations, which account for more than $95 \%$ of foreign equity investment of all funds in each of the four currency areas $c$. The (realized) exchange rate volatility $V O L_{c, t}^{F X}$ for quarter $t$ is defined as the standard deviation of the daily return $r_{c, d}^{F X}=\ln E_{c, d}-\ln E_{c, d-1}$ calculated for all trading days $d$ of quarter $t .{ }^{26}$ Figure 3 shows the realized effective exchange rate volatility of the four fund locations for the period January 1999-December 2015. To test for the FX volatility sensitivity of portfolio rebalancing, we interact the excess return on foreign equity $r_{j, t}^{f}-r_{j, t}^{h}$ with the contemporaneous measure of realized exchange rate volatility $V O L_{c, t}^{F X}$. The extended regression specification follows as

$$
\Delta h_{j, t}^{f}=\sum_{l=0,1} \beta_{l}\left(r_{j, t-l}^{f}-r_{j, t-l}^{h}\right)+\gamma V O L_{c, t}^{F X}+\sum_{l=0,1} \delta_{l}\left(r_{j, t-l}^{f}-r_{j, t-l}^{h}\right) \times V O L_{c, t}^{F X}+\eta_{c, t}+\varepsilon_{j}+\mu_{j, t}
$$

where $\beta_{l}$ captures the volatility-independent component of fund rebalancing at lags $l=0,1$ and $\delta_{l}$ the sensitivity of rebalancing to changes in FX volatility. The coefficient $\gamma$ measures any increase in the foreign bias of fund allocation related to changes in the level of FX

\footnotetext{
${ }^{26}$ For a total of $D$ trading days in a given quarter $t$, realized volatility is calculated as follows

$$
V O L_{c, t}^{F X}=100 \times \sqrt{\frac{66}{D} \sum_{d=1}^{D}\left(r_{c, d}^{F X}\right)^{2}} .
$$
}


volatility. We include fund fixed effects $\varepsilon_{j}$ in the regression, and for specifications $(3)$ and (4) only (where the level of volatility is not included as a regressor) also the interacted time and investor country fixed effects as we seek to identify the role of time variation in the rebalancing channel.

Table 3 presents the regression results for the extended specification. Column (1) includes only the contemporaneous component of excess returns (lag $l=0)$ and its interaction with exchange rate volatility $V O L_{c, t}^{F X}$, whereas Column (2) also includes lagged excess returns (lag $l=1$ ). In Columns (3)-(4) we also add interacted time-country fixed effects, which absorb any portfolio rebalancing related to macroeconomic phenomena and unrelated to fund-specific excess return on foreign equity holdings.

We find that the rebalancing behavior in response to differential equity returns is stronger under higher levels of exchange rate volatility as predicted in Corollary 2. For a quarterly foreign excess return of $10 \%$, any increase of the contemporaneous FX volatility by one standard deviation $(=1.73)$ generates an additional rebalancing flow towards home equity of $0.126 \%$ of funds under management $(=-0.728 \times 0.1 \times 1.73)$. The insignificant coefficient for the term $r_{j, t}^{f}-r_{j, t}^{h}$ suggests that the intensity of rebalancing is approximately proportional to the realized volatility measure $V O L_{c, t}^{F X}$. Higher FX volatility increases the riskiness of the foreign equity share in the fund portfolio and thus strengthens the rebalancing motive. In Column (4) the interaction term $\left(r_{j, t-1}^{f}-r_{j, t-1}^{h}\right) \times V O L_{c, t}^{F X}$ for lagged excess returns is also statistically significant and adds to the overall rebalancing flow. As noted before, fund rebalancing can occur with some time delay. We conclude that higher exchange rate volatility reinforces the rebalancing channel of international equity investment. 


\subsection{Rebalancing by Quantiles}

The linear regression model captures an average effect for the rebalancing channel. Yet the propensity to rebalance could be heterogeneous across fund characteristics. The elasticity of fund flows to differentials in returns could be different, for example, for large and small rebalancing flows, which could in turn reflect more active or passive strategies. We allow for a non-linear relationship between foreign excess returns and the intensity of rebalancing by using quantile regressions. The slope coefficient of the quantile regression represents the incremental change in rebalancing for a one-unit change in returns differentials at the quantile of the rebalancing variable. For the baseline regression in Table 2, Column (2) we undertake 10 different quantile regressions at the (interior) quantiles $\tau=0.05,0.15,0.25, \ldots$, $0.85,0.95$ of the distribution of holding changes. ${ }^{27}$ Figure 4 plots the quantile coefficients $\beta_{0}^{\tau}$ and $\beta_{1}^{\tau}$ at lags 0 and 1 , respectively. The gray shaded area shows a $95 \%$ confidence interval around the point estimate. Both the contemporaneous and delayed rebalancing reactions show an inverted U-shaped pattern where the edges of the distribution show more negative and therefore stronger rebalancing behavior. All quantiles have both $\beta_{0}^{\tau}<0$ and $\beta_{1}^{\tau}<0$, hence funds across all quantiles rebalance their portfolios.

Figure 4 shows that the propensity to rebalance as a function of returns differentials is strongest whenever we observe large absolute rebalancing. Modest (positive or negative) rebalancing at more central quantiles features a weaker association between rebalancing and the returns differentials $r_{j, t-l}^{f}-r_{j, t-l}^{h}$, whereas strong rebalancing in absolute terms at low quantiles $\tau=0.05,0.15,0.25$ or high quantiles $\tau=0.75,0.85,0.95$ covaries more negatively with the returns differentials on foreign and domestic equity positions. Hence, particularly large changes $\Delta h_{j, t}^{f}$ at the edge of the rebalancing distribution contribute most

\footnotetext{
${ }^{27}$ We do not include time interacted with investor country fixed effects in the quantile regression specifications.
} 
to the average rebalancing effect captured by the OLS regressions. For comparison, we add the OLS estimate as a blue dashed line together with its $95 \%$ confidence interval (dotted line). This evidence is consistent with periodic (rather than continuous) fund rebalancing where the likelihood of rebalancing increases as the discrepancy between desired and actual fund holdings grows. Similar to index funds pursuing a trade-off between tracking error and transaction costs, international funds rebalance more vigorously if the imbalance relative to the desired equity position becomes large.

\subsection{Fund Heterogeneity}

We now investigate potential factors behind the heterogeneous rebalancing responses of funds reported in Section 4.3. Could the stronger rebalancing behavior shown in the tails of the $\Delta h_{j, t}^{f}$ distribution be explained by differences in fund characteristics? The three dimensions of fund heterogeneity we examine more closely are (i) fund size measured as log assets under management, (ii) a fund's foreign investment share $w_{j, t}^{f}$, and (iii) the fund investment concentration as measured by the Herfindahl-Hirschman Index (HHI) of all fund stock position weights $w_{s, j, t}$. Fund size may represent an obstacle to frequent rebalancing if average transaction costs increase with the size of the position change. Large funds are also likely to be more diversified so that large differences between foreign and domestic equity returns occur less frequently. Greater fund diversification is likely to attenuate the need for rebalancing. We therefore expect funds with more concentrated holdings to feature stronger rebalancing behavior.

We calculate the average and median values of these three fund characteristics for all observations in the direct vicinity of the regression line for 10 quantiles $\tau=0.05,0.15$, $0.25, \ldots, 0.85,0.95$. Vicinity means that observations associated with quantile $\tau$ fall into a 
space around the quantile slope $\beta(\tau)$ delimited from above by the quantile slope $\beta(\tau-.05)$ and from below by the quantile slope $\beta(\tau+.05)$. Formally, such observations $\left(x_{j, t}, \Delta h_{j, t}^{f}\right)$ fulfill the conditions $\Delta h_{j, t}^{f}-x_{j, t} \beta(\tau-.05)<0$ and $\Delta h_{j, t}^{f}-x_{j, t} \beta(\tau+.05) \geq 0$. The regressors $x_{j, t}$ are the same as in the quantile regressions in Section 4.3 and include the excess return at lags $l=0,1$; that is $x_{j, t}=\left(r_{j, t}^{f}-r_{j, t}^{h}, r_{j, t-1}^{f}-r_{j, t-1}^{h}\right) \in \mathbb{R}^{2}$. In other words, the vicinity space for each quantile $\tau$ is delimited by the two (two-dimensional) hyperplanes $y_{j, t}=x_{j, t} \beta(\tau-.05$ ) and $y_{j, t}=x_{j, t} \beta(\tau+.05)$ through the origin of the space $\mathbb{R}^{3}$.

Figure 5, Panels A and B characterize the average and median fund size, foreign portfolio share and portfolio concentration along the various quantile regressions lines, respectively. The average (median) fund size is less than one-third (one-half) at the edge of the distribution for the rebalancing statistics $\Delta h_{j, t}^{f}$ than at its center. The strongest propensity to rebalance in reaction to returns differentials is therefore observed for smaller funds. The smaller price impact makes portfolio adjustment less costly for these smaller institutional investors, which seems to make them more sensitive to returns differentials. The foreign portfolio share plotted in Panels $\mathrm{C}$ and D does not suggest any strong heterogeneity in the intensity of rebalancing behavior across funds with different home biases. Only a slightly larger foreign investment share is associated with larger rebalancing propensities at low quantiles (large repatriation flows). By contrast, the intensity of rebalancing is strongly related to the Herfindahl-Hirschman Index (HHI) of a fund's investment stock concentration. Its median value in Panel $\mathrm{F}$ is almost twice as large at the edges of the rebalancing distribution in which the portfolio adjustment to excess returns is most pronounced. Unlike index tracking funds, concentrated equity funds contribute strongly to the rebalancing evidence. This is not surprising as these funds are also more likely to feature diverging performance on their domestic and foreign equity portfolios. Funds with concentrated equity positions feature 
stronger rebalancing behavior. The more diversified and largest funds tend in contrast to be associated with moderate rebalancing levels and low rebalancing propensities. They are more likely to follow more passive strategies.

\section{Exchange Rate Effects of Portfolio Rebalancing}

A key element of the equilibrium model developed in Section 2 is that equity portfolio rebalancing influences a country's exchange rate. While foreign productivity gains relative to the home country should depreciate the home currency in a real business cycle model, the associated higher foreign equity returns can reinforce rebalancing toward the home country, with the opposite effect on the exchange rate. To what extent the portfolio flow effect dominates at a given horizon is largely an empirical matter. We start by exploring the correlation structure between rebalancing flows and exchange rate in Section 5.1. We then proceed to estimate the causal effect of flows on the currency in Section 5.2 using a granular instrumental variable approach.

\subsection{Aggregate Flow Measurement}

To explore the links between aggregate equity fund flows and exchange rate dynamics, we define as $D_{c}$ the set of all home funds domiciled in one of four currency areas $c \in\{$ U.S., U.K., Eurozone, Canada\}, and $F_{c}$ as the complementary set of all foreign funds domiciled in currency areas $c^{\prime} \in\{$ U.S., U.K., Eurozone, Canada $\} \backslash\{c\}$, but with equity investment in currency area $c$. Let the market value of all foreign equity positions of fund $j \in D_{c}$ at the end

of quarter $t-1$ be denoted by $a_{j, t-1}^{f}$ and the value of all equity positions in currency area $c$ by a foreign fund $j \in F_{c}$ be given by $a_{j, t-1}^{h *}$. We can then define the value weighted (average) 
aggregate rebalancing (in terms of portfolio shares) of all home and foreign domiciled funds with respect to currency area $c$ as

$$
\begin{aligned}
& \Delta H_{c, t}^{f}=\frac{1}{A_{c, t-1}^{f}} \sum_{j \in D_{c}} \Delta h_{j, t}^{f} \times a_{j, t-1}^{f} \quad \text { with } \quad A_{c, t-1}^{f}=\sum_{j \in D_{c}} a_{j, t-1}^{f} \\
& \Delta H_{c, t}^{h *}=\frac{1}{A_{c, t-1}^{h *}} \sum_{j \in F_{c}} \Delta h_{j, t}^{h *} \times a_{j, t-1}^{h *} \quad \text { with } \quad A_{c, t-1}^{h *}=\sum_{j \in F_{c}} a_{j, t-1}^{h *}
\end{aligned}
$$

respectively, where $\Delta h_{j, t}^{f}$ denotes the fund-level rebalancing of home funds (domiciled in currency area $c$ ) toward foreign equity (i.e., portfolio outflows from currency area $c$ ) and $\Delta h_{j, t}^{h *}$ the rebalancing of foreign domiciled funds from foreign equity positions into equity in currency area $c$ (i.e., portfolio inflows into currency area $c$ ). Similar to the fund level terms $\Delta h$, the aggregate rebalancing flows $\Delta H$ represent percentage changes in the aggregate foreign equity position and therefore are not denominated in any currency. ${ }^{28}$ Our model captures net aggregate flows as the last two terms in Eq.(6). For percentage aggregate holding changes $\Delta H_{c, t+d t}^{f}=d H_{c, t}^{f} / H_{c, t}^{f}$ and $\Delta H_{c, t+d t}^{h *}=d H_{c, t}^{h *} / H_{c, t}^{h *}$, and asset positions $A_{c, t}^{f}=P_{c, t}^{f *} H_{t}^{f}$ and $A_{c, t}^{h *}=E_{c, t} P_{c, t}^{h} H_{c, t}^{h *}$, respectively, we restate net aggregate equity flows as ${ }^{29}$

$$
\begin{aligned}
P_{c, t}^{f *} d H_{c, t}^{f}-E_{c, t} P_{c, t}^{h} d H_{c, t}^{h *} & =A_{c, t}^{f} \Delta H_{c, t+d t}^{f}-A_{t}^{h *} \Delta H_{c, t+d t}^{h *}= \\
& =\frac{1}{2}\left[A_{c, t}^{f}+A_{c, t}^{h *}\right]\left[2 \mu_{c, t} \Delta H_{c, t+d t}^{f}-2\left(1-\mu_{c, t}\right) \Delta H_{c, t+d t}^{h *}\right] \approx \overline{P H} \Delta H_{c, t+d t}^{N e t}
\end{aligned}
$$

with percentage net flows defined as $\Delta H_{c, t+d t}^{N e t} \equiv 2 \mu_{c, t} \Delta H_{c, t+d t}^{f}-2\left(1-\mu_{c, t}\right) \Delta H_{c, t+d t}^{h *}$. The parameter $\mu_{c, t} \equiv A_{c, t}^{f} /\left(A_{c, t}^{f}+A_{c, t}^{h *}\right)$ denotes the size of the outbound equity investments relative to the sum of outbound and inbound investments. Empirically, the time-averaged

\footnotetext{
${ }^{28}$ We ignore rebalancing events below the $2.5 \%$ and above the $97.5 \%$ percentile of the rebalancing statistics. This filter eliminates extremely large position changes that could originate in data errors. As extreme rebalancing events concern mostly smaller funds, we effectively discard only $1.58 \%$ of the aggregate asset value under management. We check robustness of the results with respect to $1 \%, 2 \%, 3 \%, 4 \%$ and $5 \%$ trimming thresholds at Internet Appendix Table A2. Our estimates are qualitatively robust.

${ }^{29}$ In the discrete time framework, we give the percentage rebalancing $\Delta h$ and $\Delta H$ from (the end of) period $t-1$ to $t$ the time index $t$, which corresponds to $t+d t$ in continuous time.
} 
value of $\mu_{c, t}$ is $84.6 \%, 17.1 \%, 42.3 \%$, and $18.9 \%$ for the U.S., U.K., Eurozone, and Canada, respectively. The correlation between aggregate equity rebalancing outflows and inflows and the quarterly effective (log) foreign currency appreciation $-\Delta E_{c, t}=-\left[\ln E_{c, t}-\ln E_{c, t-1}\right]$ can be evaluated by the linear regressions

$$
-\Delta E_{c, t}=\alpha \Delta H_{c, t}^{N e t}+\epsilon_{c, t}
$$

where we pool observations across the four currency areas U.S., U.K., Eurozone, and Canada. We only include quarterly observations for a currency area if at least 20 fund observations are recorded. ${ }^{30}$ Each currency area is in turn considered the home country with home funds accounting for aggregate rebalancing flows $\Delta H_{c, t}^{f}$ and oversea funds contributing an aggregate rebalancing flow $\Delta H_{c, t}^{h *}$. The effective foreign currency appreciation $-\Delta E_{c, t}$ (i.e., the relative depreciation of currency area $c$ ) is calculated based on fixed weights for the 10 most important outbound equity investment destinations as stated by Eq. (25).

In Table 4, Column (1), we pool the data over the four currency areas and show the OLS coefficients separately for the aggregate foreign holding change $\Delta H_{c, t}^{f}$ of funds incorporated in the home country and for the home country holding change $\Delta H_{c, t}^{h *}$ of foreign funds. Column (2) reports corresponding results for the net flows $\Delta H_{c, t}^{N e t}$, which takes into account the relative size of inbound and outbound equity markets by currency area. The aggregate foreign holding increase $\Delta H_{c, t}^{f}>0$ (or investment expatriation) indeed correlates with an appreciation of the foreign currency and a decrease in foreign fund investment at home $\Delta H_{c, t}^{h *}<0$ also correlates with an appreciation of the foreign currency. However, statistical significance at the conventional one percent level is obtained only for the net flows in Column

\footnotetext{
${ }^{30} \mathrm{As}$ a consequence, we record 36 currency area quarters with aggregate inflow and outflow data for the period 1999-2007, and 107 currency area quarters for the period 2008-2015.
} 
(2) with a point estimate of 1.046 . The overall explanatory power of the regression is modest, as illustrated by the regression $R^{2}$ of approximately $5.7 \%$.

Comparing the data period 1999-2007 to 2008-2015, we find that the regression fit almost doubles from an $R^{2}$ of 0.042 in Column (4) to 0.083 in Column (6). This increase in explanatory power is likely to reflect the more comprehensive reporting of institutional fund positions in the later subsample. We also note that a subsample of U.S. and U.K. observations features a higher $R^{2}$ of $8.0 \%$ compared to $4.4 \%$ for Canada and the Euro area, which may also be explained by a more comprehensive reporting by institutional investors in the former countries. ${ }^{31}$

Lilley et al. (2020) use quarterly portfolio flows from the IMF's balance of payments data (BPM6), which includes investor types other than the institutional investors we focus on. They focus on the 2007-2019 period. Using their data, simple correlations between equity flows and exchange rate tend to be unstable over subsamples. But correlations between bond flows (particularly US purchases of foreign bonds) and the exchange rate are very strong on any subsample where the financial crisis dominates. As argued by Lilley et al. (2020), during the 2007-2012 period, the status of the dollar as a safe haven currency drives exchange rate correlations. For the crisis period, they capture a very strong link between US bond outflows and the exchange rate (with a R-squared of $32 \%$ ). This correlation weakens as the sample increases. In contrast, we capture the long-run phenomenon of equity rebalancing behavior by institutional investors, which entails a more stable relationship with exchange rates. Yet, all OLS regressions suffer from endogeneity issues, and this motivates our use of granular instrument.

There are three considerations for why equity flows should generally move exchange rates

\footnotetext{
${ }^{31}$ For the respective subsample analysis we refer to Table A4 in the Internet Appendix.
} 
more than bond flows: (i) the higher volatility of relative equity returns, (ii) the generally unhedged investment character of equity positions, whereas bond positions tend to be hedged, and (iii) the larger size of foreign equity positions in developed markets. For example, using CPIS data, we calculate that of all foreign equity and debt held by U.S. institutional investors in 2015 , the share of equity is $72 \%$ and the share of debt is $28 \%$, respectively.

The strong correlation between exchange rates and some bond flows during the crisis is interesting and requires more analysis. Conceptually, hedged bond flows should matter far less for the exchange rate dynamics as spot rate transactions are offset by forward rate transactions. However, recent work by Liao and Zhang (2020) on the "hedging channel" of exchange rate dynamics suggests that the hedge ratio on foreign bond positions itself may undergo large variations depending on the investor type, and thereby influences the exchange rates. A more integrated analysis of bond and FX derivative transactions represents a promising avenue for future research.

Lastly, we highlight that simple OLS regressions do not control for any of the common factors that may be driving equity flows and exchange rates. This certainly limits their meaningful interpretation of supply elasticities. We take up this challenge in the next section.

\subsection{A Granular Instrumental Variables Approach}

The assumption of a price elastic supply of foreign exchange is at the heart of our theoretical model and embodied in the positive parameter $\kappa$. To quantify this supply elasticity, we use our disaggregate fund-level data and the granular instrumental variable (GIV) methodology proposed by Gabaix and Koijen (2020). While the theoretical model in Section 2 adopts a representative agent perspective and features no exogenous aggregate currency demand shocks, such shocks arise naturally in an empirical model of fund-level rebalancing. In such 
a model rebalancing can be characterized not only by the fund's response to its own foreign excess return, but also by common and idiosyncratic rebalancing shocks originating in belief changes about future stock returns. A fund-level framework implies that the quantitatively most important portfolio flows can be traced to large funds. If net aggregate flows and their exchange rate impact are mostly influenced by the rebalancing of large funds, we can construct GIV instruments, which extract the idiosyncratic component of rebalancing by large funds relative to the average rebalancing of all funds and use it as an instrument.

For the aggregate currency supply change we build on Eq. (5) and assume

$$
\Delta Q_{c, t}^{S}=-\kappa \Delta E_{c, t}+\varepsilon_{t}
$$

The error term $\epsilon_{t}$ allows for additional (liquidity) supply shocks that are not part of the theoretical model in Section 2. The currency demand is generated by the rebalancing behavior of individual funds domiciled at home $\left(j \in D_{c}\right)$ or abroad $\left(j \in F_{c}\right)$ given by

$$
\begin{aligned}
\Delta h_{j, t}^{f} & =\beta\left(r_{j, t}^{f}-r_{j, t}^{h}\right)+\eta_{c, t}+u_{j, t} \quad \text { for } j \in D_{c} \\
\Delta h_{j, t}^{h *} & =\beta\left(r_{j, t}^{h *}-r_{j, t}^{f *}\right)+\eta_{c, t}^{*}+u_{j, t}^{*} \quad \text { for } j \in F_{c}
\end{aligned}
$$

respectively. The terms $\eta_{c, t}$ and $u_{j, t}$ embody the common and idiosyncratic belief shocks at the fund level, respectively. We assume that the idiosyncratic fund-level errors are orthogonal to the common error and the supply shock, that is $\mathcal{E}_{t}\left[u_{j, t} \eta_{c, t}\right]=\mathcal{E}_{t}\left[u_{j, t}^{*} \eta_{c, t}^{*}\right]=\mathcal{E}_{t}\left[u_{j, t} \varepsilon_{t}\right]=$ $\mathcal{E}_{t}\left[u_{j, t}^{*} \varepsilon_{t}\right]=0$. In Appendix $\mathrm{C}$, we then provide the conditions under which fund-level rebalancing aggregates to a net currency demand

$$
\Delta Q_{c, t}^{D}=\overline{P H} \Delta H_{c, t}^{N e t}=\overline{P H} \beta \bar{\theta} \Delta E_{c, t}+\overline{P H} \widetilde{\eta}_{c, t}^{N e t}+\overline{P H} \widetilde{u}_{j, t}^{N e t}
$$


where $\widetilde{\eta}_{c, t}^{N e t}$ represents an aggregate error term, $\widetilde{u}_{j, t}^{N e t}$ the linear combination of idiosyncratic fund-level error terms, $\beta<0$ the rebalancing parameter and $\bar{\theta}>0$ a constant. Identification of the supply elasticity via granular instruments relies on the orthogonality of the error term $\widetilde{u}_{j, t}^{N e t}$ capturing only idiosyncratic rebalancing with the aggregate error terms $\widetilde{\eta}_{c, t}^{N e t}$ and with the FX supply shocks $\varepsilon_{t}$, that is

$$
\mathcal{E}_{t}\left[\widetilde{u}_{j, t}^{N e t} \widetilde{\eta}_{c, t}^{N e t}\right]=\mathcal{E}_{t}\left[\widetilde{u}_{j, t}^{N e t} \varepsilon_{t}\right]=0
$$

Following Gabaix and Koijen (2020), our instrument is based on netting the fund-size based idiosyncratic variation of both equity fund outflows and inflows from their common components. Let $z_{c, t}^{\text {Outflows }}$ denote the granular instrumental variable for the foreign investments of funds domiciled in currency area $c$; and $z_{c, t}^{\text {Inflows }}$ represent the granular instrumental variable for the domestic investments by funds domiciled outside currency area $c$ :

$$
\begin{aligned}
z_{c, t}^{\text {Outflows }} & =\frac{1}{A_{c, t-1}^{f}} \sum_{j \in D_{c}} \Delta h_{j, t}^{f} \times a_{j, t-1}^{f}-\frac{1}{N_{D_{c}}} \sum_{j \in D_{c}} \Delta h_{j, t}^{f} \\
z_{c, t}^{\text {Inflows }} & =\frac{1}{A_{c, t-1}^{h *}} \sum_{j \in F_{c}} \Delta h_{j, t}^{h *} \times a_{j, t-1}^{h *}-\frac{1}{N_{F_{c}}} \sum_{j \in F_{c}} \Delta h_{j, t}^{h *}
\end{aligned} .
$$

In other words, $z_{c, t}^{\text {Outflows }}$ is defined as the difference between the fund-size weighted and average weighted equity outflows by domestic funds in currency area $c$ and $z_{c, t}^{\text {Inflows }}$ is defined analogously as the difference between fund-size weighted and average equity inflows from the foreign funds into currency area $c$. As the rebalancing terms $\Delta h_{j, t}$ are expressed in terms of percentages of total assets, we still have to account for differences in the relative importance of inflows and outflows for each currency area $c$ by using $\mu_{c, t}$ as the proportion of outflows relative to the sum of outflows and inflows. This allows us to define the granular instrument for the net equity flows $\Delta H_{c, t}^{N e t}$ as 


$$
z_{c, t}^{\text {Net }} \equiv 2 \mu_{c, t-1} z_{c, t}^{\text {Outflows }}-2\left(1-\mu_{c, t-1}\right) z_{c, t}^{\text {Inflows }}
$$

The parameters $\mu_{c, t-1} \equiv A_{c, t-1}^{f} /\left(A_{c, t-1}^{f}+A_{c, t-1}^{h *}\right)$ and $1-\mu_{c, t-1}$ denote again the relative size of outbound and inbound equity investments. The instrument $z_{c, t}^{N e t}$ captures the idiosyncratic flows of large funds relative to general rebalancing flows of the average fund; it has at 0.448 a $45 \%$ lower standard deviation than the aggregate net flows $\Delta H_{c, t}^{N e t}$. However, this idiosyncratic net flow component is still highly variable and represents a strong instrument for the aggregate net flows in a first stage regression

$$
\Delta H_{c, t}^{N e t}=\alpha z_{c, t}^{N e t}+\epsilon_{c, t}
$$

The predicted component $\Delta \widehat{H}_{c, t}^{N e t}$ from the first-stage regression then identifies in the secondstage regression

$$
-\Delta \widehat{E}_{c, t}=\frac{\overline{P H}}{\kappa} \Delta \widehat{H}_{c, t}^{N e t}+\zeta_{c, t}
$$

the inverse of the supply elasticity parameter given by $\frac{\overline{P H}}{\kappa}>0 .{ }^{32}$

In our baseline approach called GIV1, we use the portfolio rebalancing flows $\Delta h_{j, t}^{f}$ and $\Delta h_{j, t}^{h *}$ to construct our instrument $z_{c, t}^{\text {Net }}$ according to Eqs. (34)-(35). The differencing of value- and equally-weighted flows eliminates all rebalancing components $\eta_{c, t}$ and $\eta_{c, t}^{*}$ in Eq. (31), which influence fund flows independently of fund characteristics. However, the evidence in Section 4.4 shows fund heterogeneity in rebalancing that may not be purged by simple differencing based on granularity. This motivates an augmented approach called GIV2, which filters additional predictable components based on fund characteristics $C_{j, t}$ and fund fixed

\footnotetext{
${ }^{32} \mathrm{Using} z_{c, t}$ as an instrument for $\Delta H_{c, t}^{N e t}$ is the intuitive approach. Alternatively, we could also instrument $-\Delta E_{c, t}$ first and then identify $\kappa / \overline{P H}$ regression directly (instead of its inverse) in the second-stage regression $H_{c, t}^{N e t}=\frac{\kappa}{\overline{P H}}\left[-\Delta \widehat{E}_{c, t}\right]+\epsilon_{c, t}$. Both approaches yield the same elasticity estimate.
} 
effects $\alpha_{j}$ from the raw fund flows. We then use the residual portfolio flows $\Delta h_{j, t}^{f}-C_{j, t} \beta-\alpha_{j}$ and $\Delta h_{j, t}^{h *}-C_{j, t} \beta-\alpha_{j}$, to construct our instrument. As control variables $C_{j, t}$ we use the $\log$ fund size, the HHI of fund concentration, and their interaction with a fund's foreign excess return $r_{j, t}^{f}-r_{j, t}^{h}$. The fund fixed effects $\alpha_{j}$ take out all trend growth in foreign investment shares.

As an additional robustness check, we extract from the fund flows principal components and include them as additional control variables in the two-stage least square estimation. For GIV1, we use the raw portfolio rebalancing flows $\Delta h_{j, t}^{f}$ and $\Delta h_{j, t}^{h *}$ and extract the first ten principal components $\eta_{t}^{\text {Net }}{ }^{33}$ As our initial panel is unbalanced, we select for the principal component extraction only funds with at most seven missing time observations. We then use the alternating least squares algorithm to obtain a balanced panel for the principal component analysis. ${ }^{34}$ For GIV2, we proceed along the same lines, but use the residual portfolio flows $\Delta h_{j, t}^{f}-C_{j, t} \beta-\alpha_{j}$ and $\Delta h_{j, t}^{h *}-C_{j, t} \beta-\alpha_{j}$ to extract the principal components. As an illustration, we present in Table A5 of the Internet Appendix the time series of GIV1 for the U.S. and the Eurozone. We check that the largest shocks correspond to underlying idiosyncratic inflows and outflows shocks of certain large funds. We then go further and look for narratives behind the biggest idiosyncratic shocks. Following the methodology described in Gabaix and Koijen (2020) we run regressions of the rebalancing at the fund level on a constant and collect the residuals. Adjusting with the relevant size variable, we pick the 10 largest shocks for each of the geographical regions. We then look for news that can explain the shocks experienced by the funds selected above on the relevant quarter and check that

\footnotetext{
${ }^{33}$ We compute principal components $\eta_{t}^{\text {Outflows }}$ and $\eta_{t}^{\text {Inflows }}$ from the raw flows $\Delta h_{j, t}^{f}$ and $\Delta h_{j, t}^{h *}$, respectively, and then define $\eta_{t}^{\text {Net }}=2 \mu_{c, t-1} \eta_{t}^{\text {Outflows }}-2\left(1-\mu_{c, t-1}\right) \eta_{t}^{\text {Inflows }}$.

${ }^{34}$ We use the Matlab command pca.m and its built-in alternating least squares algorithm to compute the principal components. We retain the first ten principal components as additional control variables. For GIV2, we follow the same procedure, but use the residual portfolio flows.
} 
these shocks are indeed idiosyncratic. We gather information on the shocks by analyzing the Factiva dataset. For example, in 2003q4, the largest shock related to U.S. outflows concerns Janus Capital Management LLC. This corresponds to the following legal event, described in the Financial Times in December 2003: "Janus Capital, one of the first fund groups to become embroiled in New York attorney-general Eliot Spitzer's crackdown on mutual fund trading scandals, has offered to return $\$ 31.5 \mathrm{~m}$ to its investors as compensation for the improper trading that took place in its funds." For Eurozone (EZ) outflows, one of the largest shocks occurred for Deutsche Asset Management Investment GmbH. Reuters reports that "The U.S. asset management arm of Deutsche Bank AG has agreed to pay $\$ 19.3$ million to settle a case involving directed brokerage and the Scudder Funds, U.S. regulators and the company said on Thursday." We provide the Factiva link, the date, and the news source for the shocks in Table A5 of the Internet Appendix.

\subsection{FX Supply Elasticity Estimates}

Table 5 reports our results for the four specifications, namely GIV1 and GIV2 — each with and without the principal components as control variables, respectively. Columns (1)-(4) provide the first-stage regression results for Eq. (36), and Columns (6)-(9) the second-stage estimates for Eq. (37). ${ }^{35}$ The Montiel-Pflueger F-statistics suggest very strong instruments in all four cases — although GIV1 features the strongest instruments with values of 53.6 and 70.3, respectively. This is not surprising as GIV2 applies more filters to the flow statistics entering the instrument construction.

The point estimate in Column (6) for the GIV1 is 0.928, and statistically significant at the $5 \%$ level. It implies that an exogenous outflow shock given by one standard deviation

\footnotetext{
${ }^{35}$ For the specifications with principal components, we have $\Delta H_{c, t}^{N e t}=\alpha z_{c, t}+\eta_{t}^{N e t}+\epsilon_{c, t}$ as the first stage and $-\Delta \widehat{E}_{c, t}=\frac{\overline{P H}}{\kappa}$ $\Delta \widehat{H}_{c, t}^{N e t}+\eta_{t}^{N e t}+\zeta_{c, t}$ as the second stage.
} 
of aggregate percentage flows (i.e. 0.813) depreciates the home currency by $0.754 \%(=$ $0.928 \% \times 0.813)$. This represents an economically significant effect. The implied currency supply elasticity follows as $\frac{\widehat{\kappa}}{\overline{P H}}=1.078$. In other words, a $1 \%$ effective quarterly foreign exchange rate appreciation is associated with a net currency demand shock of $1.078 \%$ of the average aggregate foreign fund positions in a currency. For the U.S., this amounts to approximately US\$7.1bn (=1.078\% $\times$ US $\$ 658 \mathrm{bn})$ at the end of 2014 (as $\overline{P H} \approx \mathrm{US} \$ 658 \mathrm{bn})$. Allowing for the possibility of common factors has the effect of decreasing the elasticity to $\frac{\widehat{\kappa}}{\overline{P H}}=0.806$, implying that a $1 \%$ effective quarterly foreign exchange rate appreciation is associated to slightly lower inflows of US\$5.3bn $(=0.806 \% \times \mathrm{US} \$ 658 \mathrm{bn})$. Some caution is required when translating the elasticity estimate into a currency inflow quantity required to produce a currency appreciation by 1 percentage point. The latter estimate depends on the correct measurement of the total capital $\overline{P H}$ involved in rebalancing. Since the FactSet data may not contain all institutional investors and excludes private portfolio investors, the total capital $\overline{P H}$ is underestimated. If these excluded equity positions participate to some extent in international equity rebalancing, we have to scale the above quantity estimates accordingly. In other words: these quantities are best interpreted as a lower bound for the inflows needed to trigger an appreciation by one percentage point. Furthermore, it would not be correct to assume that net trade flows translate automatically into net currency demand. Trade imbalances need not generate any net currency demand from the real sector if the invoicing domestic entities convert foreign balances into net foreign asset holdings denominated and settled in foreign currency. Symmetrically, trade imbalances can be invoiced in domestic currency and bypass the foreign exchange market via an adjustment of the domestic currency assets of the foreign trading partner.

Table 5, Columns (8)-(9) report the second-stage results for the more robust (residual- 
based) granular instrument, without and with ten principal components as controls, respectively. The point estimates for the supply elasticity $\frac{\widehat{\kappa}}{\frac{P H}{P}}$ are 1.080 and 0.806 for GIV2 without principal components and GIV2 with principal components, respectively. The GIV2 estimate without principal components is very close to the baseline result for GIV1 without principal components, given by 1.078, but, just as before, the elasticity estimated with principal components is lower.

From a theoretical perspective, the stylized model in Section 2 can generate a realistic level of exchange rate volatility for a scaled supply elasticity parameter $\frac{\widehat{\kappa}}{P H}$ below 20 . Hence, our lower point estimate for the currency supply elasticity is consistent with high levels of exchange rate volatility. Our currency supply elasticity estimates can be compared to previous estimates in the literature. Hau, Massa, and Peress (2009) use a major exogenous change in MSCI's global index weights in 2001 to estimate the elasticity of currency supply to rebalancing flows. For a six-day window around the announcement of the index reweighting, the authors estimate for 33 mostly down-weighted emerging market currencies an average supply elasticity of 0.4 . This suggests that on average US $\$ 2.6 \mathrm{bn}$ are needed for a $1 \%$ change of the bilateral dollar rate. ${ }^{36}$ The elasticity estimates in Hau, Massa, and Peress (2009) are pooled over a large set of currency markets which includes many Emerging Market currencies and small open economies all relative to the US dollar. These estimates are therefore likely to provide a lower bound for the supply elasticity of FX liquidity. Indeed our estimates are somewhat higher and correspond to a more elastic currency supply.

\footnotetext{
${ }^{36}$ The point estimate of 2.49 on page 1699 corresponds to a supply elasticity of $0.4[=1 / 2.49]$. An average US $\$ 0.66 \mathrm{bn}$ of equity outflows for every $10 \%$ country weight decrease in the MSCI index then implies the US $\$ 2.6 \mathrm{bn}[=0.4 \times 0.66 \mathrm{bn} / 0.1]$ in currency flows for a $1 \%$ exchange rate change.
} 


\section{Alternative Interpretations}

Our empirical results provide strong support in favor of portfolio rebalancing. Can the observed rebalancing result from a simple behavioral hypothesis? One such behavioral hypothesis concerns "profit-taking" on appreciating stocks. Fund managers might sell stocks once a certain target price is reached. The evidence presented here reflects the decisions of investment professionals who should be less prone to behavioral biases compared to households. But we can identify two additional aspects of the data that cannot be easily reconciled with a "profit-taking motive" as an explanatory alternative. First, this behavioral hypothesis does not explain why funds buy foreign equity shares when these assets underperform domestic holdings, as documented in Section 4.1. Second, the "profit-taking motive" evaluates each stock in isolation from the other portfolio assets, unlike our risk-based paradigm, which looks at the portfolio of all foreign equity holdings. Third, we also show that higher exchange rate risk interacts with the rebalancing motive, while it is unclear why it should matter for a "profit-taking motive".

A second alternative interpretation concerns exogenous investment policies and mandates for the funds. Could the observed rebalancing behavior result from investment policies that commit a fund to a certain range of foreign stock ownership? French and Poterba (1991) note that fund mandates are an unlikely explanation for the home bias in equity. This does not preclude their greater importance for the rebalancing dynamics documented in this paper. To the extent that such mandates exist, we can interpret them as reflecting the risk management objectives of the ultimate fund investors. As such they can be interpreted as direct evidence for limited asset substitutability and support, rather than contradict, the main message of our study. But rationalizing such mandates in the context of agency 
problems is beyond the scope of this paper. Distinguishing between mandated rebalancing and autonomous fund-based rebalancing presents an interesting issue for future research. To make progress on these issues we doubtless need a better theoretical understanding of delegated investment strategies and one that is compatible with the stylized facts that we uncover in this paper. Modeling financial intermediaries more realistically is an important agenda for future research. ${ }^{37}$

\section{Conclusion}

This paper documents a pervasive feature of the international equity portfolios of institutional investors, namely that they repatriate capital after making an excess return on their foreign portfolio share relative to their domestic equity investment. We interpret such rebalancing behavior as a consequence of investor risk aversion in an equity market partially segmented by exchange rate risk and present a simple model characterizing the joint dynamics of stock prices, the exchange rate, and international portfolio holdings. Limited international tradability of exchange rate risk implies that foreign equity investments are riskier than home country equity investments. International investors reduce their foreign equity share if excess returns in the foreign market increase their FX exposure.

We document a rich set of new empirical facts that support this interpretation. First, higher exchange rate risk (measured by realized FX volatility) reinforces the risk rebalancing channel. Second, the largest correlation between rebalancing and foreign excess returns is found at the tails of the rebalancing distribution — suggesting a non-linear relationship. In other words, the rebalancing motive of equity funds increases as their return differential

\footnotetext{
${ }^{37}$ Important progress has been made in that direction: see, for example, Gabaix and Maggiori (2015), Coimbra and Rey (2017), Koijen and Yogo (2019) and Koijen and Yogo (2020).
} 
between foreign and domestic fund positions becomes more extreme. Third, we find that smaller funds and funds with a higher concentration of their investments in fewer stocks have the largest rebalancing propensity in reaction to return differentials. By contrast, rebalancing is observed equally across funds with very heterogeneous foreign investment shares. To estimate aggregate effects of rebalancing flows on the exchange rate, we use the disaggregated structure of fund flows to construct a granular instrumental variable as in Gabaix and Koijen (2020). This allows us to estimate the elasticity of supply of foreign exchange and the causal effect from rebalancing flows to exchange rate movements. We speculate that our evidence casts some light on international financial linkages. Gourinchas and Rey (2007) show that current account adjustments go through a trade channel and a financial adjustment channel, the latter becoming more important over the recent years. In the presence of a foreign asset market boom which is usually associated with a real foreign currency appreciation and a current account deficit, domestic investors will at some point repatriate their funds, thereby depreciating the foreign currency with a stabilizing effect. Much remains to be done to better comprehend the complexity of international links across financial asset markets. 


\section{References}

Adrian, T., E. Etula, and H. S. Shin. 2015. Risk appetite and exchange rates. FRB of New York Staff Report 361.

Albuquerque, R., G. H. Bauer, and M. Schneider. 2007. International equity flows and returns: a quantitative equilibrium approach. The Review of Economic Studies 74:1-30.

Bacchetta, P., M. Davenport, E. van Wincoop, et al. 2021. Can sticky portfolios explain international capital flows and asset prices? NBER Chapters .

Bacchetta, P., and E. Van Wincoop. 2010. Infrequent portfolio decisions: A solution to the forward discount puzzle. American Economic Review 100:870-904.

Basak, S., and A. Pavlova. 2013. Asset prices and institutional investors. American Economic Review 103:1728-58.

Benetrix, A. S., P. R. Lane, and J. C. Shambaugh. 2015. International currency exposures, valuation effects and the global financial crisis. Journal of International Economics 96:S98S109.

Blanchard, O., F. Giavazzi, and F. Sá. 2005. International investors, the us current account, and the dollar. Brookings Papers on Economic Activity 1:1-65.

Bohn, H., and L. L. Tesar. 1996. Us equity investment in foreign markets: portfolio rebalancing or return chasing? The American Economic Review 86:77-81.

Branson, W. H., and D. W. Henderson. 1985. The specification and influence of asset markets. Handbook of international economics 2:749-805. 
Brennan, M. J., and H. H. Cao. 1997. International portfolio investment flows. The Journal of Finance 52:1851-80.

Broner, F. A., R. G. Gelos, and C. M. Reinhart. 2006. When in peril, retrench: Testing the portfolio channel of contagion. Journal of International Economics 69:203-30.

Bruno, V., and H. S. Shin. 2014. Cross-border banking and global liquidity. The Review of Economic Studies 82:535-64.

Caballero, R. J., and A. Simsek. 2020. A model of fickle capital flows and retrenchment. Journal of Political Economy 128:2288-328.

Calvet, L. E., J. Y. Campbell, and P. Sodini. 2009. Fight or flight? portfolio rebalancing by individual investors. The Quarterly journal of economics 124:301-48.

Chan, K., V. Covrig, and L. Ng. 2005. What determines the domestic bias and foreign bias? evidence from mutual fund equity allocations worldwide. The Journal of Finance $60: 1495-534$.

Coeurdacier, N. 2009. Do trade costs in goods market lead to home bias in equities? Journal of international Economics 77:86-100.

Coeurdacier, N., and H. Rey. 2013. Home bias in open economy financial macroeconomics. Journal of Economic Literature 51:63-115.

Coimbra, N., and H. Rey. 2017. Financial cycles with heterogeneous intermediaries. Working Paper, National Bureau of Economic Research.

Della Corte, P., L. Sarno, and G. Sestieri. 2012. The predictive information content of external imbalances for exchange rate returns: how much is it worth? Review of Economics and Statistics 94:100-15. 
Devereux, M. B., and A. Sutherland. 2010. Valuation effects and the dynamics of net external assets. Journal of international Economics 80:129-43.

- 2011. Country portfolios in open economy macro-models. Journal of the european economic Association 9:337-69.

Dou, W. W., and A. Verdelhan. 2015. The volatility of international capital flows and foreign assets. Working Paper, MIT.

Driskill, R., and S. McCafferty. 1980. Exchange-rate variability, real and monetary shocks, and the degree of capital mobility under rational expectations. The Quarterly Journal of Economics 95:577-86.

Dziuda, W., and J. Mondria. 2012. Asymmetric information, portfolio managers, and home bias. The Review of Financial Studies 25:2109-54.

Evans, M. D., and R. K. Lyons. 2002. Order flow and exchange rate dynamics. Journal of political economy 110:170-80.

Ferreira, M. A., and P. Matos. 2008. The colors of investors' money: The role of institutional investors around the world. Journal of Financial Economics 88:499-533.

Frankel, J. A. 1982a. In search of the exchange risk premium: A six-currency test assuming mean-variance optimization. Journal of international Money and finance 1:255-74.

- 1982b. A test of perfect substitutability in the foreign exchange market. Southern Economic Journal (pre-1986) 49:406-.

Fratzscher, M., L. Juvenal, and L. Sarno. 2010. Asset prices, exchange rates and the current account. European Economic Review 54:643-58. 
French, K. R., and J. M. Poterba. 1991. Investor diversification and international equity markets. The American Economic Review 81:222-6.

Froot, K. A., P. G. O'Connell, and M. S. Seasholes. 2001. The portfolio flows of international investors. Journal of financial Economics 59:151-93.

Froot, K. A., and T. Ramadorai. 2005. Currency returns, intrinsic value, and institutionalinvestor flows. The Journal of Finance 60:1535-66.

Gabaix, X., and R. S. Koijen. 2020. Granular instrumental variables. Working Paper, National Bureau of Economic Research.

Gabaix, X., and M. Maggiori. 2015. International liquidity and exchange rate dynamics. The Quarterly Journal of Economics 130:1369-420.

Gourinchas, P.-O., and H. Rey. 2007. International financial adjustment. Journal of political economy 115:665-703.

Hau, H., M. Massa, and J. Peress. 2009. Do demand curves for currencies slope down? evidence from the msci global index change. The Review of Financial Studies 23:1681717.

Hau, H., and H. Rey. 2002. Exchange rate, equity prices and capital flows. National Bureau of Economic Research.

- 2006. Exchange rates, equity prices, and capital flows. Review of Financial Studies 19:273-17.

- 2008. Home bias at the fund level. American Economic Review 98:333-38. 
Jeanne, O., and D. Sandri. 2020. Global financial cycle and liquidity management. Working Paper, National Bureau of Economic Research.

Koijen, R. S., and M. Yogo. 2019. A demand system approach to asset pricing. Journal of Political Economy 127:1475-515.

— 2020. Exchange rates and asset prices in a global demand system. Working Paper .

Kouri, P. 1982. Balance of payment and the foreign exchange market: A dynamic partial equilibrium model. Bhandari). S., Bluford H. Putnam,(eds.) Economic Interdependence and Flexible Exchange Rates 116-56.

Kouri, P. J. 1976. The exchange rate and the balance of payments in the short run and in the long run: A monetary approach. The Scandinavian Journal of Economics 280-304.

Kouri, P. J., J. B. De Macedo, W. S. Salant, and M. v. N. Whitman. 1978. Exchange rates and the international adjustment process. Brookings Papers on Economic Activity 111-57.

Lane, P. R., and G. M. Milesi-Ferretti. 2007. A global perspective on external positions. In G7 current account imbalances: sustainability and adjustment, 67-102. University of Chicago Press.

- 2017. International financial integration in the aftermath of the global financial crisis. International Monetary Fund Working Paper .

Lane, P. R., and J. C. Shambaugh. 2010. Financial exchange rates and international currency exposures. American Economic Review 100:518-40.

Lee, A. S. 2021. Implications of infrequent portfolio adjustment for international portfolio choices. Available at SSRN 3929737. 
Levich, R. M., G. S. Hayt, and B. A. Ripston. 1998. Survey of derivatives and risk management practices by us institutional investors. Leonard N. Stern School of Business Working Paper.

Lewis, K. K. 1999. Trying to explain home bias in equities and consumption. Journal of economic literature 37:571-608.

Liao, G., and T. Zhang. 2020. The hedging channel of exchange rate determination. FRB International Finance Discussion Paper .

Lilley, A., M. Maggiori, B. Neiman, and J. Schreger. 2020. Exchange rate reconnect. The Review of Economics and Statistics 1-28.

Maggiori, M., B. Neiman, and J. Schreger. 2020. International currencies and capital allocation. Journal of Political Economy 128:2019-66.

Portes, R., and H. Rey. 2005. The determinants of cross-border equity flows. Journal of international Economics 65:269-96.

Raddatz, C., S. Schmukler, and T. Williams. 2017. International asset allocations and capital flows: The benchmark effect. Journal of international Economics 108:413-30.

Rogoff, K. 1984. On the effects of sterilized intervention: An analysis of weekly data. journal of Monetary Economics 14:133-50.

Sandulescu, M., F. Trojani, and A. Vedolin. 2021. Model-free international stochastic discount factors. The Journal of Finance 76:935-76.

Stavrakeva, V., and J. Tang. 2019. The dollar during the great recession: US monetary policy signaling and the flight to safety. Working Paper, London Business School . 
. 2020. Deviations from fire and exchange rates: a GE theory of supply and demand. Working Paper, London Business School .

Tille, C. 2008. Financial integration and the wealth effect of exchange rate fluctuations. Journal of International Economics 75:283-94.

Tille, C., and E. Van Wincoop. 2010. International capital flows. Journal of international Economics 80:157-75.

Vayanos, D., and P. Woolley. 2013. An institutional theory of momentum and reversal. The Review of Financial Studies 26:1087-145. 


\section{Appendix A: Model Solution}

To solve the model we conjecture a linear solution for asset returns. The existence and uniqueness of equilibrium in the class of linear equilibria can be shown following the same steps as Hau and Rey (2002). Asset price for the home and foreign equity processes are indexed by $h$ and $f$ as $P_{t}^{h}$ as $P_{t}^{f}$, respectively, if expressed in the currency of the home investor; and indexed by $h *$ and $f *$ as $P_{t}^{h *}$ and $P_{t}^{f *}$, respectively, if expressed in the currency of the foreign investor. We define the corresponding (instantaneous) excess returns (on one unit of asset) as $d R_{t}=\left(d R_{t}^{h}, d R_{t}^{f}\right)^{T}$ and $d R_{t}^{*}=\left(d R_{t}^{h *}, d R_{t}^{f *}\right)^{T}$ in terms of the currency of the home and foreign investors, respectively. Indices $h, f *$ then refer to home and foreign country variables expressed in local stock currency and $h *, f$ to the same variables expressed in the currency of the overseas investor.

Next, we conjecture for excess returns a solution in two state variables $\Psi_{t}^{h}=\left(1, D^{h}, \Delta_{t}, \Lambda_{t}\right)^{T}$ and $\boldsymbol{\Psi}_{t}^{f *}=\left(1, D_{t}^{f *}, \Delta_{t}, \Lambda_{t}\right)^{T}$ with $\Delta_{t} \equiv D_{t}^{h}-D_{t}^{f *}$ and the stochastic process $\Lambda_{t}$. Let $\mathbf{d w}_{t}^{h}=\left(d w_{t}^{h}, d w_{t}\right)^{T}=\left(d w_{t}^{h}, d w_{t}^{h}-d w_{t}^{f *}\right)^{T}$ and $\mathbf{d} \mathbf{w}_{t}^{f *}=\left(d w_{t}^{f *}, d w_{t}\right)^{T}=\left(d w_{t}^{f *}, d w_{t}^{h}-d w_{t}^{f *}\right)^{T}$ denote two $(1 \times 2)$ vectors of innovations. Vectors $\alpha_{\Psi}^{i}=\left(\alpha_{0}^{i}, \alpha_{D}^{i}, \alpha_{\Delta}^{i}, \alpha_{\Lambda}^{i}\right)$ and $\mathbf{b}_{\Psi}^{i}=\left(f_{D} \sigma_{D}, b_{\Delta}^{i}\right)$ , $(i \in\{h, f *, h *, f\})$ with $f_{D}=1 /\left(\alpha_{D}+r\right)$ allow us to express excess returns as

$$
\left[\begin{array}{cc}
d R_{t}^{h} & d R_{t}^{f *} \\
d R_{t}^{h *} & d R_{t}^{f}
\end{array}\right]=\left[\begin{array}{cc}
\alpha_{\Psi}^{h} & \alpha_{\Psi}^{f *} \\
\alpha_{\Psi}^{h *} & \alpha_{\Psi}^{f}
\end{array}\right]\left[\begin{array}{c}
\Psi_{t}^{h} d t \\
\Psi_{t}^{f *} d t
\end{array}\right]+\left[\begin{array}{cc}
\mathbf{b}_{\Psi}^{h} & \mathbf{b}_{\Psi}^{f *} \\
\mathbf{b}_{\Psi}^{h *} & \mathbf{b}_{\Psi}^{f}
\end{array}\right]\left[\begin{array}{c}
\mathbf{d} \mathbf{w}_{t}^{h} \\
\mathbf{d w}_{t}^{f *}
\end{array}\right] .
$$

All coefficients are functions of six exogenous model parameters $\alpha_{D}, \sigma_{D}, \bar{D}, r, \kappa$ and $\rho$. The first-order conditions for the optimal asset demand functions follow as

$$
\left[\begin{array}{c}
H_{t}^{h} \\
H_{t}^{f}
\end{array}\right]=\frac{1}{\rho} \boldsymbol{\Omega}^{-1} \mathcal{E}_{t}\left[\begin{array}{c}
\alpha_{\Psi}^{h} \boldsymbol{\Psi}_{t}^{h} \\
\alpha_{\Psi}^{f} \boldsymbol{\Psi}_{t}^{f *}
\end{array}\right] \text { and } \quad\left[\begin{array}{c}
H_{t}^{f *} \\
H_{t}^{h *}
\end{array}\right]=\frac{1}{\rho} \boldsymbol{\Omega}^{-1} \mathcal{E}_{t}\left[\begin{array}{c}
\alpha_{\Psi}^{f *} \boldsymbol{\Psi}_{t}^{f *} \\
\alpha_{\Psi}^{h *} \boldsymbol{\Psi}_{t}^{h}
\end{array}\right]
$$

for the home and foreign investors, respectively. The matrix $\Omega$ denotes the $(2 \times 2)$ covariance matrix of instantaneous returns and $\Omega^{-1}$ its inverse matrix. We approximate excess returns (around steady state values $\bar{P}^{h}=\bar{P}^{f *}=\bar{P}$ and $\bar{E}=1$ ) as

$$
\begin{aligned}
d R_{t}^{h} & =d P_{t}^{h}-r P_{t}^{h} d t+D_{t}^{h} d t \\
d R_{t}^{f} & \approx-d E_{t} \bar{P}+d P_{t}^{f *}-d E_{t} d P_{t}^{f *}-r\left[P_{t}^{f *}-\bar{P}\left(E_{t}-1\right)\right] d t+\left[D_{t}^{f *}-\bar{D}\left(E_{t}-1\right)\right] d t \\
d R_{t}^{f *} & =d P_{t}^{f *}-r P_{t}^{f *} d t+D_{t}^{f *} d t \\
d R_{t}^{h *} & \approx d E_{t} \bar{P}+d P_{t}^{h}+d E_{t} d P_{t}^{h}-r\left[P_{t}^{h}+\bar{P}\left(E_{t}-1\right)\right] d t+\left[D_{t}^{h}+\bar{D}\left(E_{t}-1\right)\right] d t .
\end{aligned}
$$

Substitution of the linear equations in Proposition 1 into Eqs. (A3)-(A6) yields the representation in Eq. (A1) and determines the vectors $\alpha_{\Psi}^{j}, \alpha_{\Psi}^{i}, \mathbf{b}_{\Psi}^{j}, \mathbf{b}_{\Psi}^{i}$. For the covariance elements 
we obtain

$$
\begin{aligned}
& \Omega_{11}=\left(f_{D} \sigma_{D}\right)^{2}+2\left[p_{\Delta} \sigma_{D}+p_{\Lambda}\right]^{2}+2 f_{D} \sigma_{D}\left[p_{\Delta} \sigma_{D}+p_{\Lambda}\right] \\
& \Omega_{12}=-2\left(p_{\Delta} \sigma_{D}+p_{\Lambda}\right)^{2}-\left[2\left(p_{\Delta} \sigma_{D}+p_{\Lambda}\right)+f_{D} \sigma_{D}\right] \bar{P}\left(e_{\Delta} \sigma_{D}+e_{\Lambda}\right)-2\left(p_{\Delta} \sigma_{D}+p_{\Lambda}\right) f_{D} \sigma_{D} \\
& \Omega_{22}=\left(f_{D} \sigma_{D}\right)^{2}+2\left[\bar{P}\left(e_{\Delta} \sigma_{D}+e_{\Lambda}\right)+p_{\Delta} \sigma_{D}+p_{\Lambda}\right]^{2}+2 f_{D} \sigma_{D}\left[\bar{P}\left(e_{\Delta} \sigma_{D}+e_{\Lambda}\right)+p_{\Delta} \sigma_{D}+p_{\Lambda}\right] .
\end{aligned}
$$

Market clearing in the two stock markets implies $H_{t}^{h}+H_{t}^{h *}=1$ and $H_{t}^{f *}+H_{t}^{f}=1$. Market clearing in the FX market requires $Q_{t}^{D}=Q_{t}^{S}=-\kappa\left(E_{t}-1\right)$ or in the linearized version (around foreign asset holding $\bar{H}$ )

$$
-\kappa d E_{t}=\left(E_{t}-1\right) \overline{H D} d t+\left(H_{t}^{h *}-H_{t}^{f}\right) \bar{D} d t+\left(D_{t}^{h}-D_{t}^{f *}\right) \bar{H} d t+\left(d H_{t}^{f}-d H_{t}^{h *}\right) \bar{P},
$$

where the last term $d H^{N e t} \bar{P}=\left(d H_{t}^{f}-d H_{t}^{h *}\right) \bar{P}$ denotes the net portfolio rebalancing (or net equity outflow), $-d E_{t}$ the associated foreign currency appreciation, and $\kappa$ the currency supply elasticity. The first three terms account for asymmetric dividend incomes between the home and foreign investors.

The six endogenous parameters $p_{0}, p_{\Delta}, p_{\Lambda}, e_{\Delta}, e_{\Lambda}$, and $\alpha_{\Lambda}$ are determined by the equity market clearing condition (implying A11-A13) and by compliance with the flow constraint in A10 (implying A14-A16):

$$
\begin{gathered}
p_{0}=\frac{-\rho \operatorname{det} \Omega-\mathcal{E}_{t}\left(d E_{t} d P_{t}^{f *}\right)\left(-\Omega_{12}+\Omega_{11}\right)}{r\left(\Omega_{11}-2 \Omega_{12}+\Omega_{22}\right)} \\
p_{\Delta}=-e_{\Delta} \frac{\left[\left(\alpha_{D}+r\right) \bar{P}-\bar{D}\right]\left(\Omega_{21}+\Omega_{11}\right)}{\left(\alpha_{D}+r\right)\left(\Omega_{11}+2 \Omega_{21}+\Omega_{22}\right)} \\
p_{\Lambda}=-e_{\Lambda} \frac{\left[\left(\alpha_{\Lambda}+r\right) \bar{P}-\bar{D}\right]\left(\Omega_{21}+\Omega_{11}\right)}{\left(\alpha_{\Lambda}+r\right)\left(\Omega_{11}+2 \Omega_{21}+\Omega_{22}\right)} \\
0=e_{\Delta}\left(\overline{H D}-\kappa \alpha_{D}\right)+m_{\Delta} \frac{1}{\rho}\left(\bar{D}+\alpha_{D} \bar{P}\right)+\bar{H} \\
0=e_{\Lambda}\left(\overline{H D}+\kappa \alpha_{\Lambda}\right)+m_{\Lambda} \frac{1}{\rho}\left(\bar{D}-\alpha_{\Lambda} \bar{P}\right) \\
0=\kappa\left[e_{\Delta} \sigma_{D}+e_{\Lambda}\right]-\frac{1}{\rho} \bar{P}\left[m_{\Delta} \sigma_{D}+m_{\Lambda}\right] \\
0=\left[\left(\alpha_{\Lambda}+r\right) \bar{P}-\bar{D}\right]\left(\bar{D}-\alpha_{\Lambda} \bar{P}\right)-\frac{\rho}{2}\left(\overline{H D}+\kappa \alpha_{\Lambda}\right)\left[\Omega_{11}+2 \Omega_{21}+\Omega_{22}\right] .
\end{gathered}
$$


The expressions $m_{\Delta}, m_{\Lambda}$, and $\operatorname{det} \Omega$ are defined as

$$
\begin{aligned}
m_{\Delta} & =2 p_{\Delta}\left(\alpha_{D}+r\right)\left(\Omega_{12}^{-1}-\Omega_{22}^{-1}\right)-2\left[\left(\alpha_{D}+r\right) \bar{P}-\bar{D}\right] e_{\Delta} \Omega_{22}^{-1} \\
m_{\Lambda} & =2 p_{\Lambda}\left(\alpha_{\Lambda}+r\right)\left(\Omega_{12}^{-1}-\Omega_{22}^{-1}\right)-2\left[\bar{P}\left(\alpha_{\Lambda}+r\right)-\bar{D}\right] e_{\Lambda} \Omega_{22}^{-1} \\
\operatorname{det} \Omega & =\Omega_{11} \Omega_{22}-\Omega_{21} \Omega_{21}
\end{aligned}
$$

where $\Omega_{i j}^{-1}$ denotes element $(i, j)$ of the inverse matrix $\Omega^{-1}$.

For the steady state values $\bar{P}>0, \bar{D}>0, \bar{\Lambda}=0$ and $0<\bar{H}<1$ we require

$$
\begin{aligned}
\bar{P} & =p_{0}+\frac{\bar{D}}{r}+p_{\Lambda} \bar{\Lambda}=p_{0}+\frac{\bar{D}}{r} \\
\bar{H} & =\frac{\rho\left[\Omega_{11}-\Omega_{21}\right]-\mathcal{E}_{t}\left(d E_{t} d P_{t}^{f *}\right)}{\rho\left(\Omega_{11}-2 \Omega_{21}+\Omega_{22}\right)} .
\end{aligned}
$$

and

$$
\mathcal{E}_{t}\left(d E_{t} d P_{t}^{h}\right) / d t=-\mathcal{E}_{t}\left(d E_{t} d P_{t}^{f *}\right) / d t=\left(e_{\Delta} \sigma_{D}+e_{\Lambda}\right)\left[f_{D} \sigma_{D}+2\left(p_{\Delta} \sigma_{D}+p_{\Lambda}\right)\right]<0 .
$$

For the rebalancing dynamics of home investors in foreign assets we obtain

$$
d H_{t}^{f}=-\frac{1}{2 \rho} m_{\Delta} d \Delta_{t}-\frac{1}{2 \rho} m_{\Lambda} d \Lambda_{t}=-\frac{1}{2 \rho} m_{\Delta}\left[-\alpha_{D} \Delta_{t} d t+\sigma_{D} d w_{t}\right]-\frac{1}{2 \rho} m_{\Lambda}\left[-\alpha_{\Lambda} \Delta_{t} d t+d w_{t}\right],
$$

where we define $d w_{t}=d w_{t}^{h}-d w_{t}^{f *}$ and $\mathcal{E}_{t}\left(d w_{t} d w_{t}^{\prime}\right) / d t=2$. The excess returns (relative to the steady state price $\bar{P}$ ) follow as $d r_{t}^{h}=d R_{t}^{h} / \bar{P}, d r_{t}^{f *}=d R_{t}^{f *} / \bar{P}, d r_{t}^{f}=d R_{t}^{f} / \bar{P}$, and $d r_{t}^{h *}=d R_{t}^{h *} / \bar{P}$.

\section{Corollary 1 (Rebalancing and Foreign Excess Returns):}

Ignoring terms of order $d t^{2}$, we find:

(i) a negative correlation between foreign equity holdings and excess returns expressed in investor currency, hence

$$
\operatorname{Cov}\left(d H_{t}^{f}, d r_{t}^{f}-d r_{t}^{h}\right) / d t=\kappa \frac{1}{\bar{P}}\left[\frac{1}{\bar{P}} f_{D} \sigma_{D}+2 p_{\Delta} \sigma_{D}+2 p_{\Lambda}+e_{\Delta} \sigma_{D}+e_{\Lambda}\right]\left[e_{\Delta} \sigma_{D}+e_{\Lambda}\right]<0,
$$

(ii) a negative correlation between foreign equity holdings and excess returns expressed in stock currency, hence

$$
\operatorname{Cov}\left(d H_{t}^{f}, d r_{t}^{f *}-d r_{t}^{h}\right) / d t=\kappa \frac{1}{\bar{P}}\left[\frac{1}{\bar{P}} f_{D} \sigma_{D}+2 p_{\Delta} \sigma_{D}+2 p_{\Lambda}\right]\left[e_{\Delta} \sigma_{D}+e_{\Lambda}\right]<0 .
$$

This follows from $\left[e_{\Delta} \sigma_{D}+e_{\Lambda}\right]<0$ and $\frac{1}{P} f_{D} \sigma_{D}+2 p_{\Delta} \sigma_{D}+2 p_{\Lambda}+e_{\Delta} \sigma_{D}+e_{\Lambda}>0$. 


\section{Corollary 2 (Rebalancing for different FX Supply Elasticities):}

The instantaneous variance of the excess return process can be derived as

$$
\begin{aligned}
\operatorname{Var}\left(d r_{t}^{f}-d r_{t}^{h}\right) & =\frac{1}{\bar{P}^{2}} \mathcal{E}_{t}\left(d R_{t}^{f}-d R_{t}^{h}\right)\left(d R_{t}^{f}-d R_{t}^{h}\right)= \\
& =\frac{2}{\bar{P}^{2}}\left[\bar{P}\left(e_{\Delta} \sigma_{D}+e_{\Lambda}\right)+f_{D} \sigma_{D}+2 p_{\Delta} \sigma_{D}+2 p_{\Lambda}\right]^{2} d t
\end{aligned}
$$

Using the covariance term in Eq. (A25), we obtain for the OLS regression coefficient

$$
\beta=\frac{\operatorname{Cov}\left(d H_{t}^{f}, d r_{t}^{f}-d r_{t}^{h}\right)}{\operatorname{Var}\left(d r_{t}^{f}-d r_{t}^{h}\right)}=\frac{\kappa\left(e_{\Delta} \sigma_{D}+e_{\Lambda}\right)}{2\left[\bar{P}\left(e_{\Delta} \sigma_{D}+e_{\Lambda}\right)+f_{D} \sigma_{D}+2 p_{\Delta} \sigma_{D}+2 p_{\Lambda}\right]}<0 .
$$

We note that the endogenous terms $\bar{P}, p_{\Delta}, p_{\Lambda}, e_{\Delta}$, and $e_{\Lambda}$ in Eq. (A28) generally depend on the exogenous parameter $\kappa$. We verify

$$
\frac{d \beta}{d V o l^{F X}}<0
$$

numerically for a large variety of exogenous parameters. Figure 1, Panel B, provides a parametric plot of $\beta(\kappa)$ and $d \operatorname{Vol}^{F X}(\kappa)$ for $\kappa \in[100,5000]$. 


\section{Appendix B: Data}

FactSet/LionShares provides three different data files: (i) the "holding master file", (ii) the "fund file", and (iii) the "entity (institution) file". The first file provides the fund positions on a quarterly frequency, while the other two give information on fund and institutional investor characteristics. For our analysis we only use the "holding master file", which reports the FactSet fund identifier, the CUSIP stock identifier, the number of stock positions, the reporting date, the country domicile of the fund, the stock price on the reporting date, and the number of shares outstanding at the reporting date. We complement the FactSet/LionShares data with data from Datastream, which provides the total stock return index (assuming dividends are reinvested and correcting for stock splits) for each stock, the country of stock domicile/listing, the currency of the stock listing, and the exchange rate. In a first step, we match holding data for each fund with holding data in the same fund in the two previous quarters. Holding data for which no holding date is reported in the previous quarter are discarded. Additional holding data from quarter $t-2$ are matched whenever available. For each fund we retain only the latest reporting date within a quarter. The stock price, total return index, and exchange rate data are matched for the same reporting date as stated in the holding data. Similar to Calvet, Campbell, and Sodini (2009), we use a sequence of data filters to eliminate the role of reporting errors in the data. We focus on the four largest fund domiciles, namely the U.S., the U.K., the Eurozone, and Canada. ${ }^{38}$ All small funds with a capitalization of less than $\$ 10$ million are deleted. These small funds might represent incubator funds or other non-representative entities. Funds with a growth in total assets over the quarter of more than $200 \%$ or less than $-50 \%$ are also discarded. Finally we treat as missing those stock observations for which the return exceeds $500 \%$ or is below $-80 \%$ over the quarter. Missing observations do not enter into the calculation of the stock weights or the foreign excess returns. We use filters discarding potential reporting errors and typos such as (i) positions with negative holdings, (ii) positions with missing or negative prices, (iii) positions larger than $\$ 30$ billion, and (iv) positions for which the combined stock capitalization (in this dataset) exceeds $\$ 300$ billion. Two additional selection criteria guarantee a minimal degree of fund diversification. First, we ignore funds with fewer than five foreign and five domestic stocks in their portfolio. Pure country funds or pure domestic funds are therefore excluded from the sample. Second, all funds with a Herfindahl-Hirschman Index over all stock weights above $20 \%$ are discarded. This fund concentration threshold is surpassed if a fund holds more than $\sqrt{0.2} \approx 0.447 \%$ in a single stock. Funds with such extreme stock weights are unlikely to exhibit much consideration for risk diversification. The latter criterion eliminates approximately $0.1 \%$ of fund-quarters from the sample.

\footnotetext{
${ }^{38}$ As previously stated, we define the Eurozone as the original 11 members in 1999: Austria, Belgium, Finland, France, Germany, Ireland, Italy, Luxembourg, the Netherlands, Portugal and Spain.
} 


\section{Appendix C: Granular Instruments}

This section outlines the conditions under which the granular instrumental variable (GIV) estimator discussed in Section 5.2 provides consistent estimates for the FX supply elasticity parameter. Our exposition follows closely Section 2.3 in Gabaix and Koijen (2020). For the aggregate currency supply change for country $c$ (relative to the rest of the world) we assume a linear function

$$
\Delta Q_{c, t}^{S}=-\kappa \Delta E_{c, t}+\varepsilon_{t}
$$

in analogy to Eq. (24) in Gabaix and Koijen (2020) with $\kappa>0$. The term $\epsilon_{t}$ allows for additional supply shocks which where ignored in the theoretical model in Section 2.

The demand side in the FX market is composed of a set of home funds $\left(j \in D_{c}\right)$ with foreign equity positions $\left(\Delta h_{j, t}^{f}>0\right.$ implies home outflows and a positive foreign currency demand) and a set of oversea funds $\left(j \in F_{c}\right)$ invested in the home country $\left(\Delta h_{j, t}^{h *}>0\right.$ implies home inflows and a negative foreign currency demand). The respective rebalancing is characterized by

$$
\begin{aligned}
& \Delta h_{j, t}^{f}=\beta\left(r_{j, t}^{f}-r_{j, t}^{h}\right)+\eta_{c, t}+u_{j, t} \text { for } j \in D_{c} \\
& \Delta h_{j, t}^{h *}=\beta\left(r_{j, t}^{h *}-r_{j, t}^{f *}\right)+\eta_{c, t}^{*}+u_{j, t}^{*} \quad \text { for } j \in F_{c}
\end{aligned},
$$

where $r_{j, t}^{f}-r_{j, t}^{h}$ and $r_{j, t}^{h *}-r_{j, t}^{f *}$ denote the foreign excess returns in the fund domicile currency, respectively, and $\beta<0$ characterizes rebalancing away from the location of excess returns. Here $\eta_{c, t}$ and $u_{j, t}$ denote the common and idiosyncratic component of rebalancing not captured by the excess return, respectively. We assume that the idiosyncratic fund-level errors are orthogonal to the common error and the supply shock; that is $\mathcal{E}_{t}\left[u_{j, t} \eta_{c, t}\right]=\mathcal{E}_{t}\left[u_{j, t}^{*} \eta_{c, t}^{*}\right]=\mathcal{E}_{t}\left[u_{j, t} \varepsilon_{t}\right]=\mathcal{E}_{t}\left[u_{j, t}^{*} \varepsilon_{t}\right]=0$.

Next, we express the fund excess returns on foreign equity as deviations from the aggregate excess returns, that is

$$
\begin{aligned}
& r_{j, t}^{f}-r_{j, t}^{h}=r_{t}^{f}-r_{t}^{h}+v_{j, t} \quad \text { for } j \in D \\
& r_{j, t}^{h *}-r_{j, t}^{f *}=r_{t}^{h *}-r_{t}^{f *}+v_{j, t}^{*} \quad \text { for } j \in F_{c}
\end{aligned}
$$

Again, we assume that idiosyncratic fund-level error terms $v_{j, t}$ and $v_{j, t}^{*}$ are orthogonal to the aggregate error terms $\eta_{c, t}, \eta_{c, t}^{*}$, and $\varepsilon_{t}$. From Hau and Rey (2006), the aggregate excess returns in turn relate to the exchange rate change as follows

$$
r_{t}^{f}-r_{t}^{h}=-\left(r_{t}^{h *}-r_{t}^{f *}\right)=\theta \Delta E_{c, t}+\vartheta_{c, t},
$$

where $\vartheta_{c, t}$ denotes an aggregate error term orthogonal to the fund-level shocks; that is $\mathcal{E}_{t}\left[u_{j, t} \vartheta_{c, t}\right]=\mathcal{E}_{t}\left[u_{j, t}^{*} \vartheta_{c, t}\right]=\mathcal{E}_{t}\left[v_{j, t} \vartheta_{c, t}\right]=\mathcal{E}_{t}\left[v_{j, t}^{*} \vartheta_{c, t}\right]=0$. A foreign stock excess return $\left(r_{t}^{f}-r_{t}^{h}>\right.$ 0 ) often coincides with a home currency appreciation $\left(\Delta E_{c, t}>0\right)$, hence $\theta>0$. For empirical 
evidence on this uncovered equity parity condition see Hau and Rey (2006):

Substitution of Eqs. (C3)-(C4) into Eqs. (C2) yields

$$
\begin{array}{lll}
\Delta h_{j, t}^{f}= & \beta \theta \Delta E_{c, t}+\widetilde{\eta}_{c, t}+\widetilde{u}_{j, t} & \text { for } j \in D_{c} \\
\Delta h_{j, t}^{h *}=-\beta \theta \Delta E_{c, t}+\widetilde{\eta}_{c, t}^{*}+\widetilde{u}_{j, t}^{*} & \text { for } j \in F_{c}
\end{array},
$$

where we define linear combinations of errors as $\widetilde{\eta}_{c, t}=\beta \vartheta_{c, t}+\eta_{c, t}, \widetilde{\eta}_{c, t}^{*}=-\beta \vartheta_{c, t}+\eta_{c, t}^{*}$ and $\widetilde{u}_{j, t}=\beta v_{j, t}+u_{j, t}, \widetilde{u}_{j, t}^{*}=\beta v_{j, t}^{*}+u_{j, t}^{*}$. The new idiosyncratic (fund-level) errors $\widetilde{u}_{j, t}$ and $\widetilde{u}_{j, t}^{*}$ are orthogonal to the aggregate errors $\widetilde{\eta}_{c, t}, \widetilde{\eta}_{c, t}^{*}$, and $\varepsilon_{t}$ because their components are orthogonal.

It is useful to define a value-weighted aggregation operator (with superscript $N e t$ ) for any fund-level variable $y_{j, t}$ as

$$
y_{c, t}^{N e t}=\frac{2 \mu_{c}}{A_{c, t-1}^{f}} \sum_{j \in D_{c}} y_{j, t} \times a_{j, t-1}^{f}-\frac{2\left(1-\mu_{c}\right)}{A_{c, t-1}^{c *}} \sum_{j \in F_{c}} y_{j, t}^{*} \times a_{j, t-1}^{h *}
$$

where we denote fund capitalizations as $a_{j, t-1}^{f}, a_{j, t-1}^{h *}$, and their respective country aggregates as $A_{c, t-1}^{f}, A_{c, t-1}^{h *}$, respectively. The aggregate currency demand from investor rebalancing in currency $c$ follows as

$$
\Delta Q_{c, t}^{D}=\overline{P H} \Delta H_{c, t}^{N e t}=\overline{P H} \beta \theta \Delta E_{c, t}+\overline{P H} \widetilde{\eta}_{c, t}^{N e t}+\overline{P H} \widetilde{u}_{j, t}^{N e t}
$$

where we find for the (aggregate) common error $\widetilde{\eta}_{c, t}^{N e t}=2 \mu_{c} \widetilde{\eta}_{c, t}-2\left(1-\mu_{c}\right) \widetilde{\eta}_{c, t}^{*}$. The previous orthogonality conditions imply $\mathcal{E}_{t}\left[\widetilde{u}_{j, t}^{N e t} \widetilde{\eta}_{c, t}^{N e t}\right]=\mathcal{E}_{t}\left[\widetilde{u}_{j, t}^{N e t} \varepsilon_{t}\right]=0$. We note that the currency demand $\Delta Q_{c, t}^{D}$ is (like the supply) an increasing function in $-\Delta E_{c, t}$ because $-\overline{P H} \beta \theta>0$. As a stability condition we impose $\kappa>\bar{\kappa}=-\overline{P H} \beta \theta$.

Equating changes in currency demand and supply $\left(\Delta Q_{c, t}^{D}=\Delta Q_{c, t}^{S}\right)$ implies for the equilibrium exchange rate change

$$
-\Delta E_{c, t}=\frac{\overline{P H} \widetilde{\eta}_{c, t}^{N e t}+\overline{P H} \widetilde{u}_{j, t}^{N e t}-\varepsilon_{t}}{\kappa+\overline{P H} \beta \theta} .
$$

Eq. (C8) has the same structure as Eq. (25) in Gabaix and Koijen (2020). The elasticity of supply is $\frac{\kappa}{\overline{P H}}$ and the elasticity of demand is $\beta \theta$.

Eqs. (34)-(35) define the granular instrumental variable $z_{c, t} \equiv G I V\left(\Delta H_{c, t}^{N e t}\right)$. By construction, $z_{c, t}$ is a linear (size-weighted) linear combination of idiosyncratic fund-level errors only, which are by assumption orthogonal to $\widetilde{\eta}_{c, t}^{\text {Net }}$ and $\varepsilon_{t}$, hence

$$
\mathcal{E}_{t}\left[\widetilde{\eta}_{c, t}^{N e t} z_{c, t}\right]=\mathcal{E}_{t}\left[\varepsilon_{t} z_{c, t}\right]=0
$$


The relevance of the instrument follows from

$$
\mathcal{E}_{t}\left[-\Delta E_{c, t} z_{c, t}\right]=\frac{1}{\frac{\kappa}{\overline{P H}}+\beta \theta} \mathcal{E}_{t}\left[\widetilde{u}_{j, t}^{N e t} z_{c, t}\right] \neq 0 .
$$

The moment condition $\mathcal{E}_{t}\left[\left(\Delta Q_{c, t}^{S}+\kappa \Delta E_{c, t}\right) z_{c, t}\right]=0$ implies that the inverse of the supply elasticity parameter is characterized by

$$
\frac{1}{\kappa}=\frac{\mathcal{E}_{t}\left[-\Delta E_{c, t} z_{c, t}\right]}{\mathcal{E}_{t}\left[\left(\Delta Q_{c, t}^{S} z_{c, t}\right]\right.}=\frac{\mathcal{E}_{t}\left[-\Delta E_{c, t} z_{c, t}\right]}{\overline{P H} \mathcal{E}_{t}\left[\Delta H_{c, t}^{N e t} z_{c, t}\right]}
$$

and the corresponding IV estimator follows as

$$
\frac{\widehat{P H}}{\kappa}=\frac{\frac{1}{T} \sum_{c, t}-\Delta E_{c, t} z_{c, t}}{\frac{1}{T} \sum_{c, t} \Delta H_{c, t}^{N e t} z_{c, t}}
$$

is consistent. Eq. (C11) corresponds to Eq. (30) in Gabaix and Koijen (2020). In Section 5.2, we describe the equivalent two-step estimator in Eqs. (36)-(37) which projects first the net equity flows $\Delta H_{c, t}^{N e t}$ onto $z_{c, t}$ and then the exchange rate change $-\Delta E_{c, t}$ onto the predicted values $\Delta \widehat{H}_{c, t}^{N e t}$. 


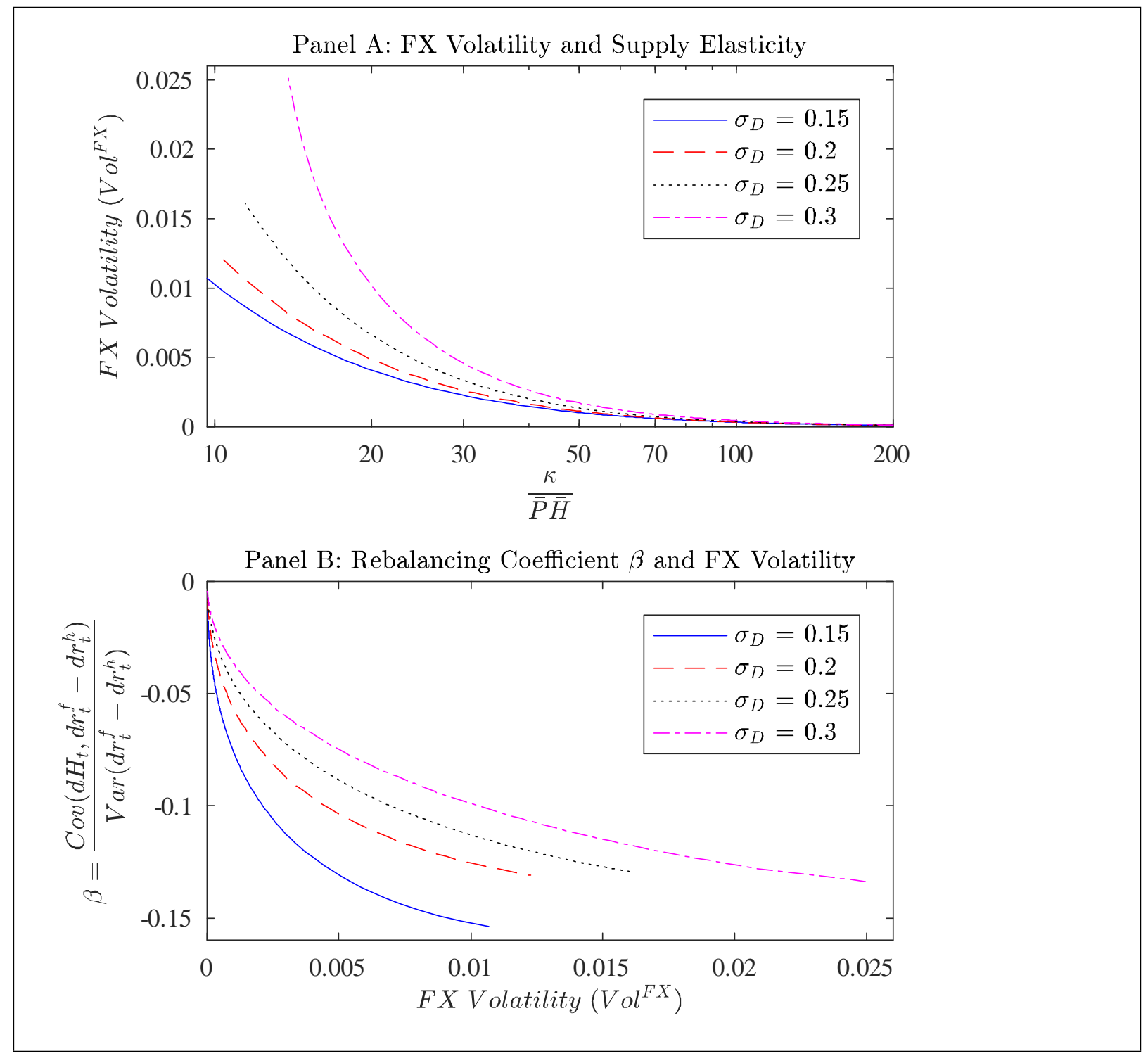

Figure 1: In Panel A, we plot FX volatility as a function of the scaled supply elasticity parameter $\frac{\kappa}{P H}$ for different stock volatility values $\sigma_{D} \epsilon\{0.15,0.20,0.25,0.30\}$ and the parameter range $\kappa \epsilon[100,5000]$. In Panel B, we plot the rebalancing coefficient $\beta=\frac{\operatorname{Cov}\left(H_{t}^{f}, d r_{t}^{f}-d r_{t}^{h}\right)}{\operatorname{Var}\left(d r_{t}^{f}-d r_{t}^{h}\right)}$ as a function of FX volatility for different stock volatility values $\sigma_{D} \epsilon\{0.15,0.20,0.25,0.30\}$. For both panels, we use parameters $\rho=0.02, r=0.04$, $\alpha_{D}=0.015$, and $\bar{D}=1$. 


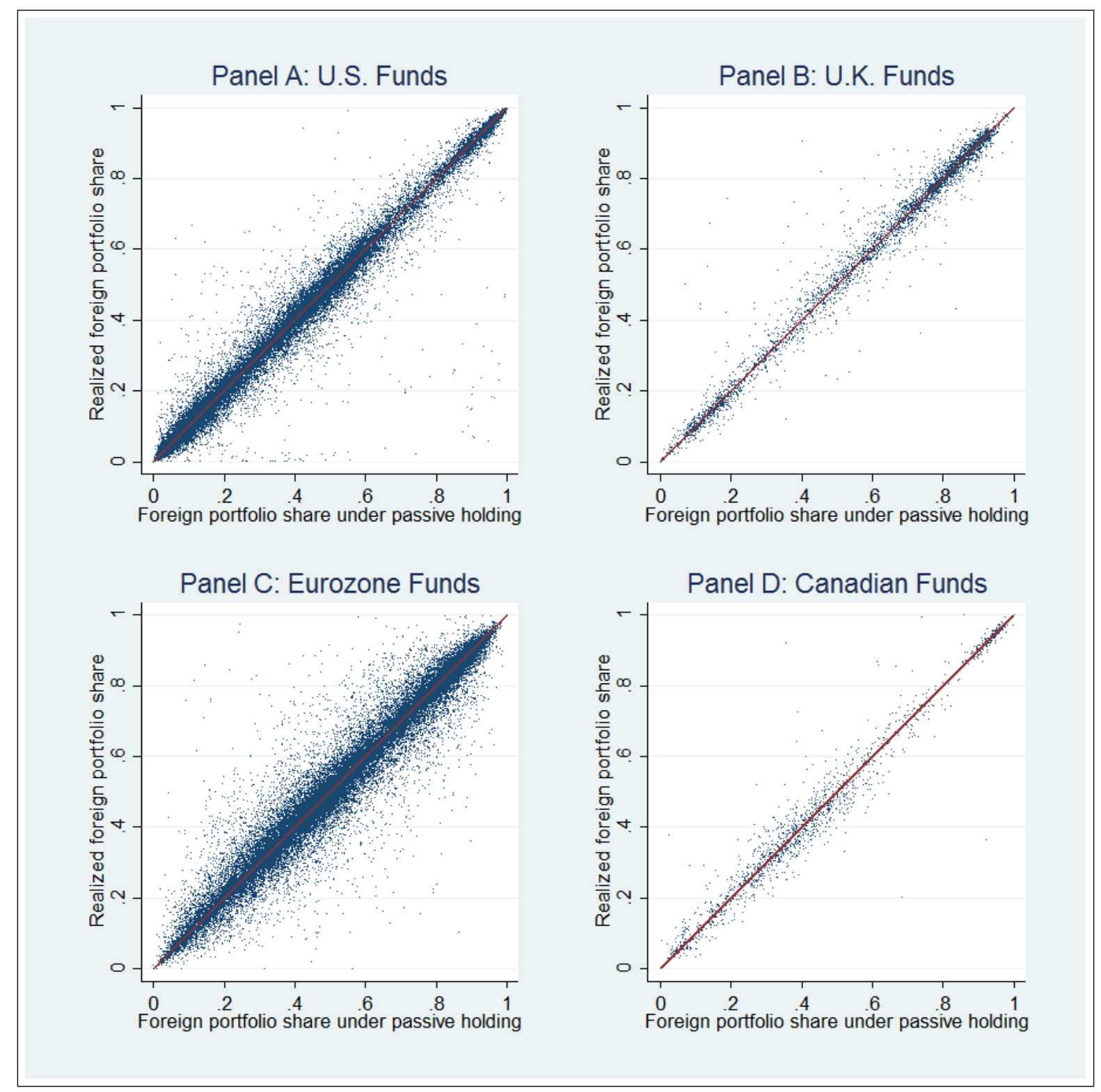

Figure 2: We plot the realized foreign portfolio share $w_{j, t}^{f}$ (y-axis) relative to the portfolio share implied by a passive holding strategy $\widehat{w}_{j, t}^{f}$ (x-axis) of funds domiciled in the U.S. (Panel A), the U.K. (Panel B), the Eurozone (Panel C), and Canada (Panel D). The vertical distance to the 45-degree line is proportional to the active rebalancing measure $\Delta h_{j, t}^{f}=w_{j, t}^{f}-\widehat{w}_{j, t}^{f}$. 


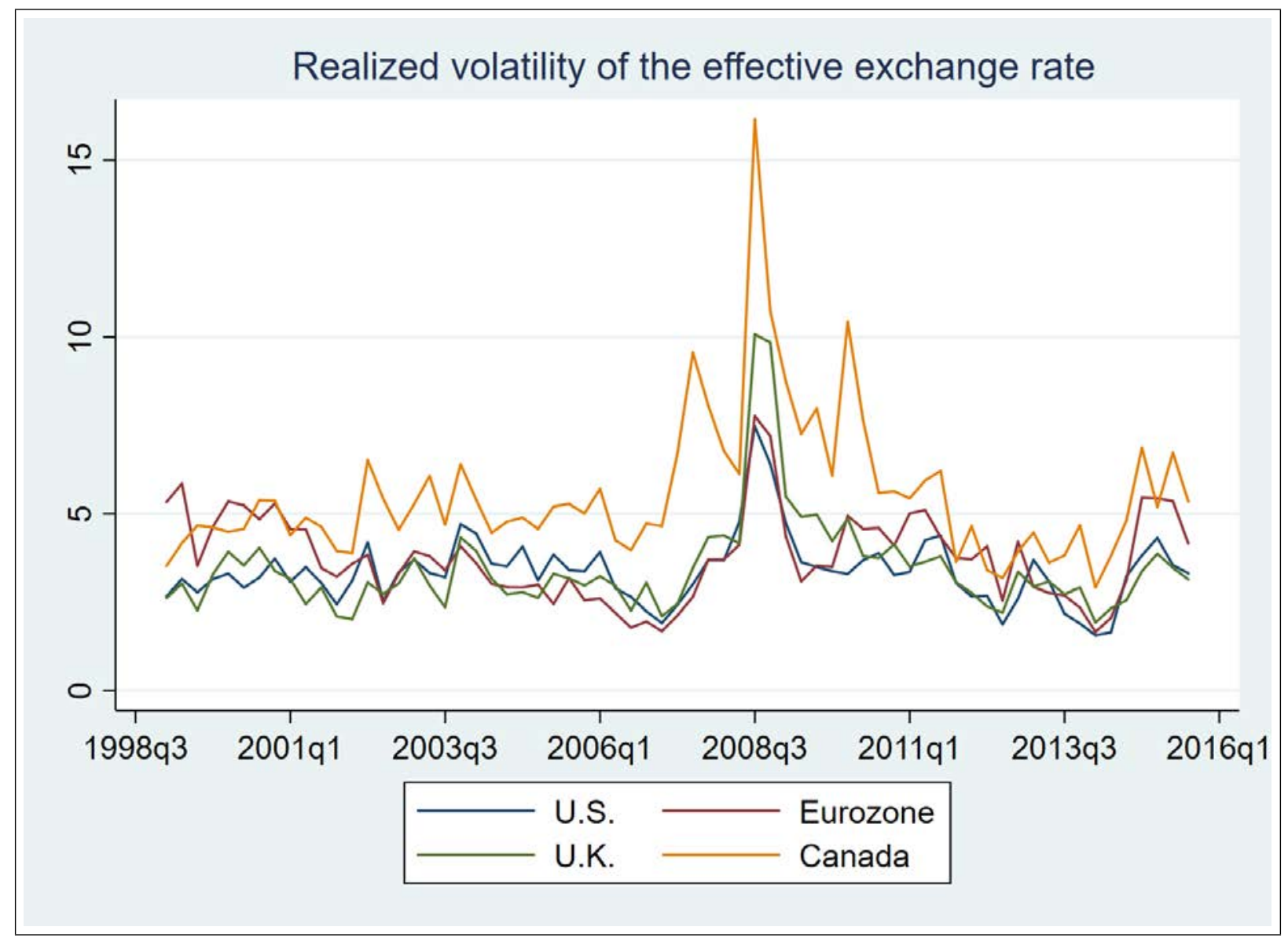

Figure 3: We plot the quarterly realized volatility $V O L_{c, t}^{F X}$ of the effective exchange rate for the U.S., U.K., Eurozone, and Canada, respectively for the period January 1999-December 2015. For a total of $D$ trading days in a given quarter $t$, realized volatility is calculated as

$$
V O L_{c, t}^{F X}=100 \times \sqrt{\frac{66}{D} \sum_{d=1}^{D}\left(r_{c, d}^{F X}\right)^{2}}
$$

where $r_{c, d}^{F X}$ is the log daily return of the effective exchange rate of currency area c. 


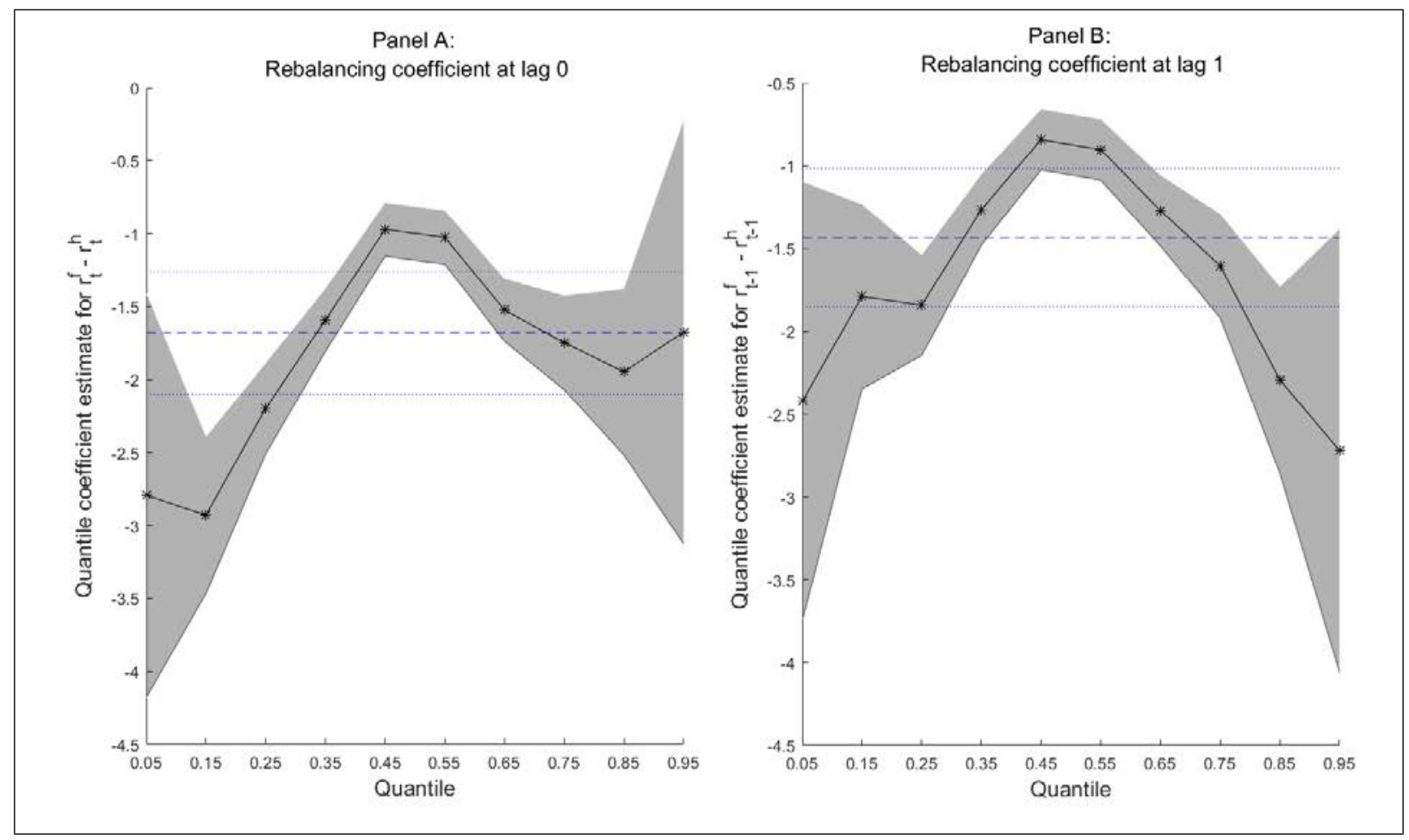

Figure 4: Panels $\mathrm{A}$ and $\mathrm{B}$ show the rebalancing coefficients $\beta_{0}$ and $\beta_{1}$ in the regression

$$
\Delta h_{j, t}^{f}=\alpha+\beta_{0}\left(r_{j, t}^{f}-r_{j, t}^{h}\right)+\beta_{1}\left(r_{j, t-1}^{f}-r_{j, t-1}^{h}\right)+\mu_{j, t}
$$

for the foreign excess return and the lagged foreign excess return, respectively, for the 10 quantile regressions at quantiles $\tau=0.05,0.15,0.25, \ldots, 0.95$ together with a confidence interval of two standard deviations. The horizontal dashed blue line represents the point estimate of the OLS coefficient surrounded by its $95 \%$ confidence interval (dotted blue lines). We do not include time interacted with investor country fixed effects in the quantile regression specifications. 


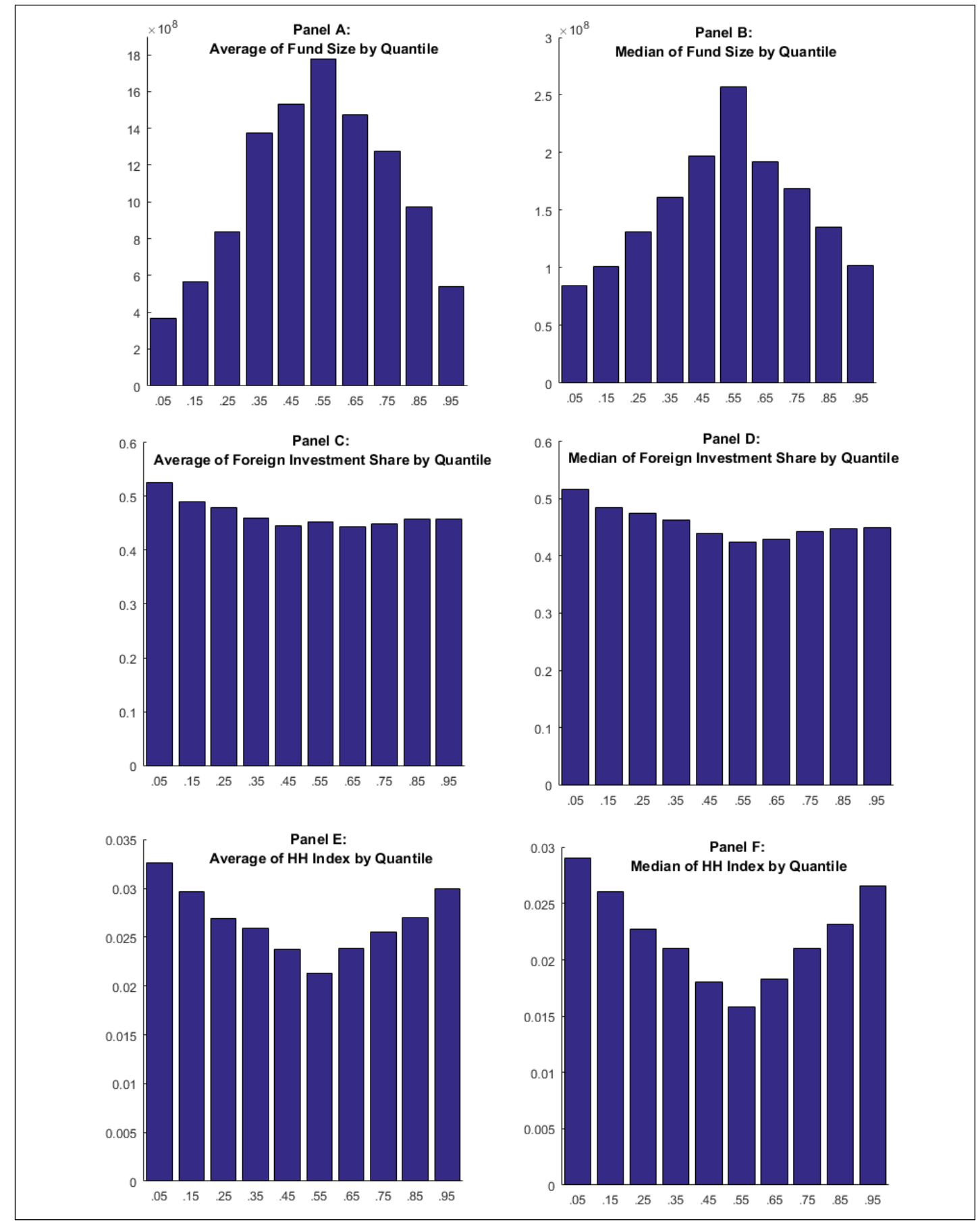

Figure 5: Panels A and B characterize the mean and median fund size around a quantile regression at the quantiles $\tau=0.05,0.15,0.25, \ldots, 0.95$, where the interquantile range of mean and median calculation is from $\tau-0.05$ to $\tau+0.05$. Panels $\mathrm{C}$ and $\mathrm{D}$ show the mean and median estimates for the foreign fund share and Panels E and F for the Herfindahl-Hirschman Index (HHI) of investment shares concentration across stocks. 
Table 1: Summary Statistics

We use the FactSet dataset (available at WRDS) to calculate in Panel A fund-level statistics for 101,238 fund-quarter observations for the period 1999-2015. We consider all funds domiciled in four different currency areas $c$, namely the U.S., the U.K., the Eurozone, and Canada. Reported are total fund assets, the fund assets invested in equity at home $(h)$ (i.e., the fund domicile) and in any foreign country $(f)$ (i.e., anywhere outside the fund domicile), respectively; the portfolio shares held in the home $\left(w_{j}^{h}\right)$ and foreign country $\left(w_{j}^{f}\right)$ equity, respectively; the active equity rebalancing $\left(\Delta h_{j, t}^{f}\right)$ in quarter $t$ of the foreign investment share toward the home country by fund $j$ domiciled in $c$ (scaled by the factor of 100); the fund-level excess returns on foreign minus home-country investment positions $\left(r_{j, t}^{f}-r_{j, t}^{h}\right)$ (expressed in fund domicile currency) in quarter $t$; and the positive $\left(\times 1_{\geq 0}\right)$ or negative $\left(\times 1_{<0}\right)$ component of these foreign excess returns. Panel B provides aggregate summary statistics for the four currency areas. The effective quarterly home currency appreciation $\left(\Delta E_{c, t}\right)$ of currency area $c$ is based on weights calculated from the aggregate foreign investment position of domestic funds in the 10 most important foreign investment destinations. The aggregate rebalancing flows $\Delta H_{c, t}^{f}\left(\Delta H_{c, t}^{h *}\right)$ measure the aggregate change in foreign (domestic) investment positions held by all domestic (foreign) equity funds domiciled in (outside) currency area $c$. The aggregate net equity flows $H_{c, t}^{N e t}=2 \mu_{c, t-1} \Delta H_{c, t}^{f}-2\left(1-\mu_{c, t-1}\right) \Delta H_{c, t}^{h *}$ are calculated based on the ratio $\mu_{c, t-1}$ of aggregate outbound equity holdings relative to the sum of outbound and inbound equity holdings. We denote $V o l_{c, t}^{F X}$ the quarterly realized volatility of the effective exchange rate in currency $c$. Following Gabaix and Koijen (2020), we report in the last three rows different "granular instrument variables" defined as either the fund-size weighted net equity flows minus equally weighted net flows (GIV1), or fund-size weighted filtered net flows minus equally-weighted filtered net flows (GIV2).

\begin{tabular}{cccccccc} 
Obs. & Mean & STD & Min & 10th & 50 th & 90 th & Max \\
\hline$(1)$ & $(2)$ & $(3)$ & $(4)$ & $(5)$ & $(6)$ & $(7)$ & $(8)$ \\
\hline
\end{tabular}

Panel A: Pooled fund-level statistics

\begin{tabular}{|c|c|c|c|c|c|c|c|c|c|}
\hline Fund assets & Mio USD & 101,238 & 1,002 & 4,794 & 10 & 19 & 130 & 1,489 & 145,289 \\
\hline Fund assets at home & Mio USD & 101,238 & 677 & 3,679 & 0 & 7 & 53 & 902 & 109,235 \\
\hline Fund assets abroad & Mio USD & 101,238 & 325 & 1,966 & 0 & 6 & 45 & 489 & 122,816 \\
\hline Home asset share & $w_{j}^{h}$ & 101,238 & 0.540 & 0.290 & 0.000 & 0.123 & 0.546 & 0.932 & 1.000 \\
\hline Foreign asset share & $w_{j}^{f}$ & 101,238 & 0.460 & 0.290 & 0.000 & 0.068 & 0.454 & 0.877 & 1.000 \\
\hline Fund rebalancing & $\Delta h_{j, t}^{f}$ & 101,238 & 0.064 & 4.557 & -89.015 & -3.495 & 0.017 & 3.686 & 72.833 \\
\hline \multicolumn{10}{|c|}{ Excess returns (expressed in the fund domicile currency) } \\
\hline$r_{j, t}^{f}-r_{j, t}^{h}$ & (quarterly) & 101,238 & -0.001 & 0.070 & -0.554 & -0.082 & -0.002 & 0.082 & 0.766 \\
\hline$\left(r_{j, t}^{f}-r_{j, t}^{h}\right) \times 1_{<0}$ & (quarterly) & 101,238 & -0.026 & 0.041 & -0.554 & -0.082 & -0.002 & 0.000 & 0.000 \\
\hline$\left(r_{j, t}^{f}-r_{j, t}^{h}\right) \times 1_{\geq 0}$ & (quarterly) & 101,238 & 0.026 & 0.043 & 0.000 & 0.000 & 0.000 & 0.082 & 0.766 \\
\hline
\end{tabular}

Panel B: Aggregate statistics

$\begin{array}{llllllllll}\text { Exchange rate change } & \Delta E_{c, t} & 143 & 0.001 & 0.036 & -0.082 & -0.045 & -0.004 & 0.047 & 0.102 \\ \text { Observed rebalancing } & & & & & & & & & \\ \text { All fund in } c & \Delta H_{c, t}^{f} & 143 & -0.024 & 0.582 & -2.270 & -0.749 & -0.052 & 0.571 & 2.230 \\ \quad \text { All funds outside } c & \Delta H_{c, t}^{h *} & 143 & -0.081 & 0.549 & -3.840 & -0.630 & -0.026 & 0.419 & 1.380 \\ \quad \text { Net flows } & \Delta H_{c, t}^{N e t} & 143 & 0.070 & 0.813 & -1.910 & -0.768 & 0.017 & 0.920 & 5.500 \\ \text { FX volatility } & V o l_{c, t}^{F X} & 259 & 4.050 & 1.730 & 1.560 & 2.440 & 3.690 & 5.940 & 16.200 \\ \text { GIV1 } & z_{c, t} & 143 & -0.015 & 0.448 & -1.330 & -0.455 & -0.016 & 0.486 & 2.230 \\ \text { GIV2 } & z_{c, t} & 143 & 0.102 & 0.446 & -1.122 & -0.346 & 0.085 & 0.573 & 2.248 \\ & & & & & & & & & \end{array}$


Table 2: Equity Fund Rebalancing

Fund rebalancing of the foreign investment share $\Delta h_{j, t}^{f}$ of fund $j$ in quarter $t$ (measured in percentages) is regressed on the excess return of the foreign over the domestic investment share, $r_{j, t}^{f}-r_{j, t}^{h}$, and its lagged values $r_{j, t-l}^{f}-r_{j, t-l}^{h}$ for lags $l=1,2$. In Column (1) we report OLS regression results without fixed effects, Columns (2)-(7) add interacted time and fund domicile fixed effects and Columns (3)-(7) add additional fund fixed effects. Column (5) splits the excess return on the foreign portfolio share into positive and negative realizations to test for symmetry of the rebalancing behavior. In Columns (6)-(7) we report the baseline regression of Column (3) for the subsample until June 2008 (Period I) and thereafter (Period II). We report robust standard errors clustered at the fund level for specification $(1)$ and use ${ }^{* * *},{ }^{* *}$, and ${ }^{*}$ to denote statistical significance at the $1 \%, 5 \%$, and $10 \%$ level respectively.

Dependent variable:

Fund Level Rebalancing $\Delta h_{j, t}^{f}$

$\begin{array}{lllllll}(1) & (2) & (3) & (4) & (5) & \text { (6) }\end{array}$

$r_{j, t}^{f}-r_{j, t}^{h}$

$\begin{array}{cccc}-1.839^{* * *} & -2.463^{* * *} & -2.405^{* * *} & -2.461^{* * *} \\ (0.239) & (0.250) & (0.263) & (0.278) \\ & -1.595^{* * *} & -1.439^{* * *} & -1.640^{* * *} \\ & (0.249) & (0.262) & (0.276) \\ & & & -0.998^{* * *} \\ & & & (0.274)\end{array}$

$\left(r_{j, t}^{f}-r_{j, t}^{h}\right) \times 1_{\geq 0}$

$-3.567^{* * *}$

$(0.454)$

$\left(r_{j, t}^{f}-r_{j, t}^{h}\right) \times 1_{<0}$

$-1.196^{* *}$

(0.468)

$\left(r_{j, t-1}^{f}-r_{j, t-1}^{h}\right) \times 1_{\geq 0}$

$-0.295$

$(0.447)$

$\left(r_{j, t-1}^{f}-r_{j, t-1}^{h}\right) \times 1_{<0}$

$\begin{array}{cc}-1.995^{* * *} & -2.435^{* * *} \\ (0.554) & (0.305) \\ -1.651^{* * *} & -1.355^{* * *} \\ (0.578) & (0.301)\end{array}$

$-2.702^{* * *}$

(0.471)

Time $\times$ Fund Domicile FEs

$\begin{array}{ccc}\text { No } & \text { Yes } & \text { Yes } \\ \text { No } & \text { No } & \text { Yes } \\ 59.105 & 10.865 & 10.294 \\ 101,238 & 89,175 & 89,175 \\ 0.001 & 0.066 & 0.134 \\ \text { Full } & \text { Full } & \text { Full }\end{array}$

Yes

Yes

Yes

Yes

Fund FEs

Yes

Yes

Yes

Yes

$F$-statistic

Full

10.267

10.297

4.300

12.888

79, 432

89,175

15, 984

73, 191

Adjusted $R^{2}$

0.143

0.134

0.170

0.142

Sample

Full

Full

Full

Until June 2008 After June 2008 
Table 3: Fund Rebalancing and Exchange Rate Volatility

Fund rebalancing of the foreign investment share $\Delta h_{j, t}^{f}$ of fund $j$ in quarter $t$ (measured as percentage) is regressed on the excess return of the foreign over the domestic investment share, $r_{j, t}^{f}-r_{j, t}^{h}$, the realized (daily) FX volatility $V o l_{c, t}^{F X}$ of the effective exchange rate of the fund domicile country in the current quarter $t$, and the interaction between foreign excess return and volatility, $\left(r_{j, t}^{f}-r_{j, t}^{h}\right) \times V o l_{c, t}^{F X}$. In Columns (2) and (4) we also add lagged excess returns, $r_{j, t-1}^{f}-r_{j, t-1}^{h}$, and their interaction with the volatility measure as additional regressors. We report robust standard errors clustered at the fund level for specifications (1) and (2) and use ***, **, and * to denote statistical significance at the $1 \%, 5 \%$, and $10 \%$ level, respectively.

\begin{tabular}{|c|c|c|c|c|}
\hline \multirow[t]{2}{*}{ Dependent variable: } & \multicolumn{4}{|c|}{ Fund Level Rebalancing $\Delta h_{j, t}^{f}$} \\
\hline & $(1)$ & $(2)$ & $(3)$ & $(4)$ \\
\hline \multirow[t]{2}{*}{$V o l_{c, t}^{F X}$} & 0.001 & -0.009 & & \\
\hline & $(0.013)$ & $(0.013)$ & & \\
\hline \multirow[t]{2}{*}{$r_{j, t}^{f}-r_{j, t}^{h}$} & -0.025 & -0.148 & 0.259 & 0.102 \\
\hline & $(0.904)$ & $(0.953)$ & $(0.743)$ & $(0.786)$ \\
\hline \multirow[t]{2}{*}{$\left(r_{j, t}^{f}-r_{j, t}^{h}\right) \times V o l_{c, t}^{F X}$} & $-0.434^{*}$ & -0.397 & $-0.728^{* * *}$ & $-0.680^{* * *}$ \\
\hline & $(0.246)$ & $(0.261)$ & $(0.184)$ & $(0.195)$ \\
\hline \multirow[t]{2}{*}{$r_{j, t-1}^{f}-r_{j, t-1}^{h}$} & & 0.944 & & 0.501 \\
\hline & & $(0.760)$ & & $(0.798)$ \\
\hline \multirow{2}{*}{$\left(r_{j, t-1}^{f}-r_{j, t-1}^{h}\right) \times V o l_{c . t}^{F X}$} & & $-0.610^{* * *}$ & & $-0.525^{* * *}$ \\
\hline & & $(0.193)$ & & $(0.201)$ \\
\hline Time FEs $\times$ Fund Domicile FEs & No & No & Yes & Yes \\
\hline Fund FEs & Yes & Yes & Yes & Yes \\
\hline$F$-statistic & 13.830 & 16.139 & 20.889 & 22.781 \\
\hline Observations & 101,238 & 89,175 & 101,238 & 89,175 \\
\hline Adjusted $R^{2}$ & 0.079 & 0.074 & 0.119 & 0.121 \\
\hline
\end{tabular}


Table 4: Aggregate Equity Rebalancing and the Exchange Rate

The effective (log) foreign currency appreciation $-\Delta E_{c, t}$ in quarter $t$ (scaled by a factor of 100) for the four currency areas $c$ (i.e., U.S., U.K., Eurozone, Canada) is regressed on the net equity rebalancing flows (expressed in percentages of the average foreign equity positions). In Columns (1)-(2) we use the full sample and in Columns (3)-(6) we present subsample results. In Column (1), we report OLS regression coefficients for the aggregate rebalancing $\Delta H_{c, t}^{f}$ of the foreign portfolio share of all funds domiciled in $c$ and the aggregate rebalancing $\Delta H_{c, t}^{h *}$ of the portfolio share invested in $c$ by equity funds domiciled outside $c$. Column (2) combines both terms to the net aggregate equity outflow $\Delta H_{c, t}^{N e t}=2 \mu_{c, t-1} \Delta H_{c, t}^{f}-2\left(1-\mu_{c, t-1}\right) \Delta H_{c, t}^{h *}$ from currency area $c$, where $\mu_{c, t-1}$ denotes the ratio of aggregate outbound to the sum of aggregate outbond and inbound equity investments. Columns (3)-(6) repeat the regressions in Columns (1)-(2) for a pre-crisis 1999-2007 subsample amd a crisis/post-crisis 2008-2015 subsample. We use ***, $* *$, and $*$ to denote statistical significance at the $1 \%, 5 \%$, and $10 \%$ level, respectively.

Dependent var.: $\quad$ Effective Quarterly Foreign Currency Appreciation, $-\Delta E_{c, t}$

\begin{tabular}{|c|c|c|c|c|c|}
\hline \multicolumn{2}{|c|}{ Full Sample } & \multicolumn{2}{|c|}{ Period 1999-2007 } & \multicolumn{2}{|c|}{ Period 2008-2015 } \\
\hline OLS & OLS & OLS & OLS & OLS & OLS \\
\hline (1) & $(2)$ & (3) & (4) & $(5)$ & (6) \\
\hline
\end{tabular}

\begin{tabular}{lcccccc}
$\Delta H_{c, t}^{f}$ & 0.547 & & 1.363 & & 0.196 & \\
& $(0.541)$ & & $(0.906)$ & & $(0.660)$ & \\
$\Delta H_{c, t}^{h *}$ & $-1.085^{*}$ & & -0.214 & & $-2.097^{* *}$ & \\
& $(0.574)$ & & $(0.711)$ & & $(0.906)$ & \\
$\Delta H_{c, t}^{N e t}$ & & $1.046^{* * *}$ & & 0.538 & & $1.700^{* * *}$ \\
& & $(0.357)$ & & $(0.438)$ & & $(0.551)$ \\
& & & & & & \\
$F$-statistic & 3.458 & 8.567 & 1.818 & 1.508 & 3.206 & 9.532 \\
Observations & 143 & 143 & 36 & 36 & 107 & 107 \\
Adjusted $R^{2}$ & 0.047 & 0.057 & 0.099 & 0.042 & 0.058 & 0.083 \\
& & & & & & \\
\hline
\end{tabular}


Table 5: Currency Supply Elasticity to Equity Flows

We estimate the exchange rate supply elasticity to net equity flows using different Granular Instrumental Variable (GIV) estimators (Gabaix and Koijen, 2020). Columns (1)-(4) report the first-stage regressions with the net equity outflows $\Delta H_{c, t}^{N e t}$ as the dependent (instrumented) variable. Column (5) reports the OLS regression of the effective (log) foreign currency appreciation $-\Delta E_{c, t}(\times 100)$ of currency area $c$ regressed on the observed net equity outflows $\Delta H_{c, t}^{\text {Net }}$. The second-stage regressions in Columns (6)-(9) have the effective $(\log )$ foreign currency appreciation $-\Delta E_{c, t}(\times 100)$ of currency area $c$ as the dependent variable and predicted net flows $\Delta \widehat{H}_{c, t}^{N e t}$ from the first-stage regression as their regressor. For GIV1 in Columns (1) and (6), we construct granular instruments $z_{c, t}^{N e t}$ directly from the raw fund-level portfolio flows $\Delta h_{j, t}^{f}$ and $\Delta h_{j, t}^{h *}$ as described in Eqs. (34)-(35). In Columns (2) and (7), we add as control variables the first ten principal components of the net flows (not reported) extracted from the raw fund-level portfolio flows $\Delta h_{j, t}^{f}$ and $\Delta h_{j, t}^{h *}$, respectively. For GIV2 in Columns (3) and (8), we construct granular instruments based on the residual portfolio flows $\Delta h_{j, t}^{f}-C_{j, t} \beta-\alpha_{j}$ or $\Delta h_{j, t}^{h *}-C_{j, t} \beta-\alpha_{j}$ where the predictable flow component $C_{j, t} \beta$ is subtracted along with fund fixed effects $\alpha_{j}$. The control variables $C_{j, t}$ consist of the $\log$ fund size, the HHI of fund concentration, and the interaction terms of log fund size and HHI with a fund's foreign excess returns $r_{j, t}^{f}-r_{j, t}^{h}$. In Columns (4) and (9), we report the corresponding regressions with the first ten principal components added as controls. The latter are extracted from the residual portfolio flows $\Delta h_{j, t}^{f}-C_{j, t} \beta-\alpha_{j}$ or $\Delta h_{j, t}^{h *}-C_{j, t} \beta-\alpha_{j}$. The coefficient for the predicted net equity outflows $\Delta \widehat{H}_{c, t}^{N e t}$ identifies the inverse of the supply elasticity parameter, namely $\overline{P H} / \kappa$. We use ${ }^{* * *},{ }^{* *}$, and $*^{*}$ to denote statistical significance at the $1 \%, 5 \%$, and $10 \%$ level, respectively.

\begin{tabular}{|c|c|c|c|c|c|c|c|c|c|}
\hline \multirow[t]{2}{*}{ Dependent variables: } & \multicolumn{4}{|c|}{$\begin{array}{l}\text { Net Equity Outflows } \\
\qquad \Delta H_{c, t}^{N e t}\end{array}$} & \multicolumn{5}{|c|}{$\begin{array}{l}\text { Effective Quarterly Foreign Currency Appreciation } \\
\qquad-\Delta E_{c, t}\end{array}$} \\
\hline & GIV1 & GIV1 & GIV2 & GIV2 & OLS & GIV1 & GIV1 & GIV2 & GIV2 \\
\hline \multirow[t]{2}{*}{ Stage: } & First & First & First & First & - & Second & Second & Second & Second \\
\hline & $(1)$ & $(2)$ & $(3)$ & $(4)$ & $(5)$ & $(6)$ & $(7)$ & $(8)$ & $(9)$ \\
\hline$\Delta H_{c, t}^{N e t}$ & & & & & $\begin{array}{c}1.046^{* * *} \\
(0.357)\end{array}$ & & & & \\
\hline$\Delta \widehat{H}_{c, t}^{N e t}$ & & & & & & $\begin{array}{l}0.928^{* *} \\
(0.445)\end{array}$ & $\begin{array}{l}1.009^{* *} \\
(0.466)\end{array}$ & $\begin{array}{l}0.926^{* *} \\
(0.453)\end{array}$ & $\begin{array}{c}1.240^{* * *} \\
(0.479)\end{array}$ \\
\hline$z_{c, t}^{N e t}$ & $\begin{array}{c}1.448^{* * *} \\
(0.092)\end{array}$ & $\begin{array}{c}1.393^{* * *} \\
(0.088)\end{array}$ & $\begin{array}{c}1.429^{* * *} \\
(0.095)\end{array}$ & $\begin{array}{c}1.403^{* * *} \\
(0.092)\end{array}$ & & & & & \\
\hline First ten PCs as controls & No & Yes & No & Yes & - & No & Yes & No & Yes \\
\hline Implied estimate $\kappa / \overline{P H}$ & & & & & - & 1.078 & 0.991 & 1.080 & 0.806 \\
\hline Montiel-Pflueger $F$-stat. & & & & & - & 53.594 & 70.343 & 48.627 & 101.921 \\
\hline Observations & 143 & 143 & 143 & 143 & 143 & 143 & 143 & 143 & 143 \\
\hline Adjusted $R^{2}$ & 0.638 & 0.707 & 0.615 & 0.715 & 0.057 & 0.057 & 0.096 & 0.057 & 0.135 \\
\hline
\end{tabular}




\section{Theoretical Internet Appendix}

Global Portfolio Rebalancing and Exchange Rates

December 15, 2021 


\section{Appendix A: Model and Propositions}

\section{A.1. Model Asumptions}

The world has two countries and a home and a foreign investor. Both investors are risk averse and can invest in risky home and risky foreign equity and a riskless domestic asset. The riskless asset (bond) is in fully price elastic supply and features for both countries a constant return (in local currency) given by $r=r^{*}$. Purchase of foreign assets by the home investor requires the acquisition of foreign balances as equity prices are purchased and sold in local currency. Similarly all foreign dividend income of the home investors is repatriated and generates a demand in the currency market. Investors do not hold any monetary balances and all their wealth is invested either in equity or their riskless (domestic) bond. The exchange rate is determined through a flow constraint which balances the currency demand of the two representative investors with a price elastic supply of forex balances on the part of financial institutions. The net currency demand by the two investors generates an exchange rate response and allows the liquidity suppliers to make an intertemporal trading profit.

The following 4 assumptions provide more detail on each element of the model structure. We start with the asset market structure:

\section{Assumption 1: Asset Market Structure}

A home $(h)$ and a foreign $(f *)$ stock market provide exogenous stochastic dividend flows $D_{t}^{h}$ and $D_{t}^{f *}$ in local currency. Home and foreign investors can invest in both stock markets. In addition, each investor can invest in a domestic riskless storage technology providing a riskless constant return $r$.

The domestic investor cannot access the foreign riskless investment opportunity. In particular they cannot acquire a short position in the foreign riskless storage investment. Markets are therefore incomplete and risk trading opportunities are generally not fully exploited. In particular, foreign exchange exposure from foreign stock investment is not fully eliminated as it would be in a complete market setting. We believe that incomplete hedging of foreign investment is the more realistic description compared to a world of full international exchange rate risk sharing. ${ }^{1}$

Investors in our model are risk averse and their objective is to find an optimal trade-off between expected profit flow of their asset position and the instantaneous profit risk. Each investor measures profits in home currency.

\section{Assumption 2: Investor Behavior}

Home and foreign investor are risk averse and maximize (in local currency terms) a myopic meanvariance objective for the profit flow. The home investors chooses portfolio weights $H_{t}=\left(H_{t}^{h}, H_{t}^{f}\right)$ and the foreign investor choose $H_{t}^{*}=\left(H_{t}^{f *}, H_{t}^{h *}\right)$ so as to solve the two optimization problems

$$
\begin{array}{lll}
\max _{H_{t}^{h}, H_{t}^{f}} & \mathcal{E}_{t} \int_{s=t}^{\infty} e^{-r(s-t)} & {\left[d \Pi_{t}-\frac{1}{2} \rho d \Pi_{t}^{2}\right] d s} \\
\max _{H_{t}^{f *}, H_{t}^{h *}} & \mathcal{E}_{t} \int_{s=t}^{\infty} e^{-r(s-t)} & {\left[d \Pi_{t}^{*}-\frac{1}{2} \rho d \Pi_{t}^{* 2}\right] d s}
\end{array},
$$

\footnotetext{
${ }^{1}$ See State Street Bank hedging ratios data.
} 
where $\mathcal{E}_{t}$ denotes the rational expectation operator. Let $d R_{t}=\left(d R_{t}^{h}, d R_{t}^{f}\right)^{T}$ and $d R_{t}^{*}=\left(d R_{t}^{f *}, d R_{t}^{h *}\right)^{T}$ denote the excess returns (in local currency) for home and foreign investors, respectively.

We define the excess stochastic profit flows for the domestic and foreign investor as

$$
\begin{aligned}
d \Pi_{t} & =H_{t} d R_{t} \\
d \Pi_{t}^{*} & =H_{t}^{*} d R_{t}^{*},
\end{aligned}
$$

respectively. The investor risk aversion is given by $\rho$ and the local discount rate is given by $r$.

The myopic investor behavior simplifies the asset demand equations to linear functions in the fundamentals. Hedging demand components are ignored under this utility specification. We highlight that both stock markets have to clear under the optimal asset demand. For simplicity we normalize the quantity of outstanding equity to one. This implies

$$
\begin{aligned}
& H_{t}^{h}+H_{t}^{h *}=1 \\
& H_{t}^{f}+H_{t}^{f *}=1
\end{aligned}
$$

as the two asset market clearing conditions.

An additional market clearing condition applies to the foreign exchange market with an exchange rate $E_{t}$ It is denominated as units of foreign per unit of home currency. We can measure the capital outflows $d Q_{t}$ from the home country (in foreign currency terms) as

$$
d Q_{t}=E_{t} H_{t}^{h *} D_{t}^{h} d t-H_{t}^{f} D_{t}^{f} d t+d H_{t}^{f} P_{t}^{f}-E_{t} d H_{t}^{h *} P_{t}^{h}
$$

The first two terms capture the outflow if all dividends are repatriated. But they can also increase their holdings of foreign equity assets. The net capital outflow due to changes in the foreign holdings, $d H_{t}^{f}$ and $d H_{t}^{h *}$ are captured by the third and fourth term. Let us for example denote the euro area as the home and the U.S. as the foreign country. Then $d Q_{t}$ represents the net capital outflow out of the Eurozone into the US in dollar terms. It corresponds to a demand for dollar balances. An increase in $E_{t}$ (denominated in dollars per euro) corresponds to a dollar depreciation against the euro. Any capital outflow in our model is identical to a net demand in foreign currency as all investment is assumed to occur in local currency. We can therefore also identify $d Q_{t}$ with the demand for foreign currency in the foreign exchange (forex) market. Furthermore, the above investor capital outflow can be linearly approximated by

$$
d Q_{t}^{D}=\left(E_{t}-\bar{E}\right) \overline{H D} d t+\left(H_{t}^{h *}-H_{t}^{f}\right) \bar{D} d t+\left(D_{t}^{h}-D_{t}^{f *}\right) \bar{H} d t+\left(d H_{t}^{f}-d H_{t}^{h *}\right) \bar{P}
$$

where the upper bar variables denote the unconditional means of the stochastic variables. We normalize $\bar{E}$ to 1 . The linearization allows for a linear model and makes the analysis tractable.

The forex demand of the investors is absorbed by liquidity supplying banks which can buffer foreign exchange imbalances. $^{2}$ The following assumption characterizes the liquidity supply.

\footnotetext{
${ }^{2} \mathrm{~A}$ generalization of the model consists in allowing for additional current account imbalances given by $C A_{t} d t=\gamma\left(\bar{E}-E_{t}\right) d t$. The current account of the euro area is in deficit when the euro is strong and vice versa ( $\gamma$ is the exchange rate elasticity of the current account). This generalization is straightforward.
} 


\section{Assumption 3: Price Elastic Excess Supply of Foreign Exchange}

The foreign exchange market clears for a price elastic excess supply curve with elasticity parameter $\kappa$.

For an equilibrium exchange rate $E_{t}$, the excess supply of foreign exchange is given by

$$
Q_{t}^{S}=-\kappa\left(E_{t}-\bar{E}\right)
$$

where $\bar{E}$ denotes the steady state exchange rate level.

A increase in $E_{t}$ (dollar depreciation) increases the excess supply of dollar balances. This exchange rate elastic excess supply may be generated by the intertemporal arbitrage of risk averse forex market makers, who sell dollars for euros when the exchange rate is high and buy dollars when the exchange rate is low. While it is possible to endogenize the elasticity parameter $\kappa$, we content here with the simpler parametric representation.

Market clearing in the forex market then requires $Q_{t}^{S}=Q_{t}^{D}$ and the foreign exchange rate is subject to the constraint

$$
-\kappa d E_{t}=\left(E_{t}-\bar{E}\right) \overline{H D} d t+\left(H_{t}^{h *}-H_{t}^{f}\right) \bar{D} d t+\left(D_{t}^{h}-D_{t}^{f *}\right) \bar{H} d t+\left(d H_{t}^{f}-d H_{t}^{h *}\right) \bar{P} .
$$

The exchange rate level is therefore tied to the relative dividend flows, $D_{t}^{h}-D_{t}^{f *}$, the relative level of foreign asset holdings $H_{t}^{h *}-H_{t}^{f}$, and their relative changes $d H_{t}^{h *}-d H_{t}^{f}$. Foreign asset holdings follow from the optimal foreign asset demand and depend on the stochastic characteristics of the exchange rate.

It is straightforward to express the payoff on a unit of domestic asset investment over the interval $d t$ as $d R_{t}^{h}$. To characterize the foreign asset payoff $d R_{t}^{f}$ in domestic currency we use a linear approximation around the steady state exchange rate $\bar{E}$ and the steady state price $\bar{P}$. The gross excess returns in home currency (of a unit of asset) are therefore

$$
\begin{aligned}
& d R_{t}^{h}=d P_{t}^{h}-r P_{t}^{h} d t+D_{t}^{h} d t \\
& d R_{t}^{f} \approx-d E_{t} \bar{P}+d P_{t}^{f *}-d E_{t} d P_{t}^{f *}-r\left[P_{t}^{f *}-\bar{P}\left(E_{t}-1\right)\right] d t+\left[D_{t}^{f *}-\bar{D}\left(E_{t}-1\right)\right] d t
\end{aligned}
$$

for the domestic and foreign asset returns, respectively. The return contribution of the exchange rate change $d E_{t}$ on the foreign asset return is approximated by $-\bar{P} d E_{t}$.

Finally, we have to specify the stochastic structure of the state variables spelled out in the following assumption:

\section{Assumption 5: Divident Structure}

The home and foreign dividends follow independent Ornstein-Uhlenbeck processes with identical variance and mean reversion given by

$$
\begin{aligned}
d D_{t}^{h} & =\alpha_{D}\left(\bar{D}-D_{t}^{h}\right) d t+\sigma_{D} d w_{t}^{h} \\
d D_{t}^{f *} & =\alpha_{D}\left(\bar{D}-D_{t}^{f *}\right) d t+\sigma_{D} d w_{t}^{f *},
\end{aligned}
$$

The innovations $d w_{t}^{h}$ and $d w_{t}^{f *}$ in local currencies are independent. 
The mean reversion of all stochastic processes simplify the analysis considerably. We can now introduce variables $F_{t}^{h}$ and $F_{t}^{f *}$ which denote the expected present value of the future discounted dividend flow,

$$
\begin{aligned}
F_{t}^{h} & =\mathcal{E}_{t} \int_{s=t}^{\infty} D_{t}^{h} e^{-r(s-t)} d s=f_{0}+f_{D} D_{t}^{h} \\
F_{t}^{f *} & =\mathcal{E}_{t} \int_{s=t}^{\infty} D_{t}^{f *} e^{-r(s-t)} d s=f_{0}+f_{D} D_{t}^{f *},
\end{aligned}
$$

with constant terms defined as $f_{D}=1 /\left(\alpha_{D}+r\right)$ and $f_{0}=\left(r^{-1}-f_{D}\right) \bar{D}$. The risk aversion of the investors and the endogenous exchange rate variability and the prediction errors imply that the asset price will generally differ from this fundamental value.

\section{A.2. Exchange Rate Dynamics}

Next we discuss the exchange rate dynamics under incomplete markets. Two principle equilibrium forces shape this dynamics. The first equilibrium tendency is governed by the inelastic liquidity supply for forex order flow. Forex order flow $d Q_{t}^{D}$ in equation (5) is accommodated by financial institutions which finance these home outflows according to an upward sloped supply curve. The elasticity of forex liquidity supply certainly influences the implact of net order flow on the exchange rate and indirectly the adjustment speed towards the steady state exchange rate, $\bar{E}$. We associate the supply induced mean reversion with a first characteristic root (labeled $z=-\alpha_{\Lambda}$ ). A second important parameter for the exchange rate dynamics is the mean reversion of the dividend processes. This mean reversion $\alpha_{D}>0$ is exogenous and any feedback effect from the exchange rate dynamics to the dividend process is ruled out by assumption.

An important simplifying feature of our model is its symmetry between the home and foreign country. Symmetry implies that the exchange rate can depend only on differences between home and foreign country variables, but not on country specific variables itself. Otherwise the symmetry would be broken. The symmetry requirement also implies that the exchange rate can only be a function of current and past relative dividend innovations, $d w_{s}=w_{s}^{h}-w_{s}^{f *}$. These relative innovations are the only exogenous source of exchange rate dynamics.

Finally, we highlight the linearity of the model structure. The forex order flow constraint is linearized and the exogenous dividend dynamics is linear by assumption. Moreover, we have assumed a myopic mean-variance utility function which translates linear dividend, price and return processes into linear asset demands. It therefore seems justified to restrict attention to the class of linear exchange rate and price processes. The argument for two fundamental equilibrium forces justifies why we focus on two state variables $\Delta_{t}$ and $\Lambda_{t}$, both of which depend for reasons of model symmetry on current and past relative dividend innovations $d w_{s}$ only.

The following proposition 4 states the conjectured exchange rate process and derives its implications for order flow constraint (7).

\section{Proposition A1 (Exchange Rate Dynamics):}

Assume that equity prices $P=\left(P_{t}^{h}, P_{t}^{f *}\right)$ denominated in local currency and the exchange rate $E_{t}$ have 
the following linear representation

$$
\begin{aligned}
P_{t}^{h} & =p_{0}+p_{F} F_{t}^{h}+p_{\Delta} \Delta_{t}+p_{\Lambda} \Lambda_{t} \\
P_{t}^{f *} & =p_{0}+p_{F} F_{t}^{f *}-p_{\Delta} \Delta_{t}-p_{\Lambda} \Lambda_{t} \\
E_{t} & =1+e_{\Delta} \Delta_{t}+e_{\Lambda} \Lambda_{t}
\end{aligned}
$$

with

$$
\begin{aligned}
\Delta_{t} & =D_{t}^{h}-D_{t}^{f *}=\int_{-\infty}^{t} \exp \left[-\alpha_{D}(t-s)\right] \sigma_{D} d w_{s} \\
\Lambda_{t} & =\int_{-\infty}^{t} \exp [z(t-s)] d w_{s}
\end{aligned}
$$

where $z<0$ and $d w_{s}=d w_{s}^{h}-d w_{s}^{f *}{ }^{3}$ Then the order flow constraint (7) implies for the exchange rate dynamics the following simple form

$$
d E_{t}=k_{1} \Delta_{t} d t+k_{2}\left(E_{t}-1\right) d t+k_{3} d w_{t}
$$

where $k_{1}, k_{2}=z$ and $k_{3}$ represent undetermined coefficients.

Proof of Proposition A1: We have to show that for a linear price and exchange rate equilibrium investor utility maximization implies optimal asset demands $H_{t}^{h}, H_{t}^{f}, d H_{t}^{f *}, d H_{t}^{h *}$ such that hat the expression $\left(H_{t}^{h *}-H_{t}^{f}\right) \bar{D} d t+$ $\left(d H_{t}^{f}-d H_{t}^{h *}\right) \bar{P}$ in equation (7) is linear in $E_{t}-1, \Delta_{t}$ and $d w_{t}$. The first-order condition for the investor asset demands (for risk aversion $\rho$ ) is given by

$$
\begin{aligned}
\left(\begin{array}{cc}
H_{t}^{h} & H_{t}^{f} \\
H_{t}^{f *} & H_{t}^{h *}
\end{array}\right) & =\frac{1}{\rho d t} \mathcal{E}_{t}\left(\begin{array}{cc}
d R_{t}^{h} & d R_{t}^{f} \\
d R_{t}^{f *} & d R_{t}^{h *}
\end{array}\right) \Omega^{-1} \\
& =\frac{1}{\rho d t} \mathcal{E}_{t}\left(\begin{array}{cc}
d R_{t}^{h} \Omega_{11}^{-1}+d R_{t}^{f} \Omega_{21}^{-1} & d R_{t}^{h} \Omega_{12}^{-1}+d R_{t}^{f} \Omega_{22}^{-1} \\
d R_{t}^{f *} \Omega_{11}^{-1}+d R_{t}^{h *} \Omega_{21}^{-1} & d R_{t}^{f *} \Omega_{12}^{-1}+d R_{t}^{h *} \Omega_{22}^{-1}
\end{array}\right) .
\end{aligned}
$$

The excess returns are for the form

$$
\begin{aligned}
d R_{t}^{h}= & \alpha_{0}^{h} d t+\alpha_{D}^{h} D_{t}^{h} d t+\alpha_{\Delta}^{h} \Delta_{t} d t+\alpha_{\Lambda}^{h} \Lambda_{t} d t+p_{F} f_{D} \sigma_{D} d w_{t}^{h}+p_{\Delta} \sigma_{\Delta} d w_{t}+p_{\Lambda} \sigma_{\Lambda} d w_{t} \\
d R_{t}^{f}= & \alpha_{0}^{f} d t+\alpha_{D}^{f} D_{t}^{f} d t+\alpha_{\Delta}^{f} \Delta_{t} d t+\alpha_{\Lambda}^{f} \Lambda_{t} d t \\
& -\bar{P} e_{\Delta} \sigma_{D} d w_{t}-\bar{P} e_{\Lambda} \sigma_{\Lambda} d w_{t}+p_{F} f_{D} \sigma_{D} d w_{t}^{f}-p_{\Delta} \sigma_{\Delta} d w_{t}-p_{\Lambda} \sigma_{\Lambda} d w_{t} \\
d R_{t}^{f *}= & \alpha_{0}^{f *} d t+\alpha_{D}^{f *} D_{t}^{f} d t+\alpha_{\Delta}^{f *} \Delta_{t} d t+\alpha_{\Lambda}^{f *} \Lambda_{t} d t+p_{F} f_{D} \sigma_{D} d w_{t}^{f}-p_{\Delta} \sigma_{\Delta} d w_{t}-p_{\Lambda} \sigma_{\Lambda} d w_{t} \\
d R_{t}^{h *}= & \alpha_{0}^{h *} d t+\alpha_{D}^{h *} D_{t}^{h} d t+\alpha_{\Delta}^{h *} \Delta_{t} d t+\alpha_{\Lambda}^{h *} \Lambda_{t} d t \\
& +\bar{P} e_{\Delta} \sigma_{D} d w_{t}+\bar{P} e_{\Lambda} \sigma_{\Lambda} d w_{t}-p_{F} f_{D} \sigma_{D} d w_{t}^{h}+p_{\Delta} \sigma_{\Delta} d w_{t}+p_{\Lambda} \sigma_{\Lambda} d w_{t}
\end{aligned}
$$

\footnotetext{
${ }^{3}$ We note that the variance term $\sigma_{\Lambda}$ can be scaled to $\sigma_{\Lambda}=1$ without loss of generality as variation in $\sigma_{\Lambda}$ is observationally equivalent to a rescaling of the coefficients $p_{\Lambda}^{\prime}=p_{\Lambda} / \sigma_{\Lambda}$ and $e_{\Lambda}^{\prime}=e_{\Lambda} / \sigma_{\Lambda}$.
} 
where $\alpha_{0}^{i}, \alpha_{D}^{i}, \alpha_{\Delta}^{i}, \alpha_{\Lambda}^{i}$ are four sets of indices $i \in\{h, f, f *, h *\}$. Substitution then implies

$$
\begin{aligned}
H_{t}^{h *}-H_{t}^{f} & =\frac{1}{\rho d t} \mathcal{E}_{t}\left[d R_{t}^{f *} \Omega_{12}^{-1}+d R_{t}^{h *} \Omega_{22}^{-1}-d R_{t}^{h} \Omega_{12}^{-1}-d R_{t}^{f} \Omega_{22}^{-1}\right] \\
& =\frac{1}{\rho}\left[m_{\Delta} \Delta_{t}+m_{\Lambda} \Lambda_{t}\right]
\end{aligned}
$$

where we define coefficients

$$
\begin{aligned}
& m_{\Delta}=2 p_{\Delta}\left(\alpha_{D}+r\right)\left(\Omega_{12}^{-1}-\Omega_{22}^{-1}\right)-2\left[\left(\alpha_{D}+r\right) \bar{P}-\bar{D}\right] e_{\Delta} \Omega_{22}^{-1} \\
& m_{\Lambda}=2 p_{\Lambda}(-z+r)\left(\Omega_{12}^{-1}-\Omega_{22}^{-1}\right)-2[\bar{P}(-z+r) \bar{P}-\bar{D}] e_{\Lambda} \Omega_{22}^{-1} .
\end{aligned}
$$

Moreover

$$
d H_{t}^{h *}-d H_{t}^{f}=\frac{1}{\rho}\left[-\alpha_{D} m_{\Delta} \Delta_{t} d t+z m_{\Lambda} \Lambda_{t} d t\right]+\frac{1}{\rho}\left[m_{\Delta} \sigma_{\Delta}+m_{\Lambda} \sigma_{\Lambda}\right] d w_{t} .
$$

Finally, we substitute

$$
\Lambda_{t}=\frac{1}{e_{\Lambda}}\left(E_{t}-\bar{E}\right)-\frac{e_{\Delta}}{e_{\Lambda}} \Delta_{t}
$$

and find that the term $\left(H_{t}^{h *}-H_{t}^{f}\right) \bar{D} d t+\left(d H_{t}^{f}-d H_{t}^{h *}\right) \bar{P}$ is linear in $E_{t}-\bar{E}, \Delta_{t}$ and $d w_{t}$. Substitution into the forex order flow constraint (7) implies a representation

$$
d E_{t}=k_{1} \Delta_{t}+k_{2}\left(E_{t}-\bar{E}\right)+k_{3} d w_{t} .
$$

Under linearity of the price and exchange rate processes, the order flow constraint simplifies to a differential equation in only two state variables $\Delta_{t}$ and $E_{t}-1$. This allows us to characterize the exchange rate dynamics as a system of two first-order differential equations,

$$
\left(\begin{array}{c}
d \Delta_{t} \\
d E_{t}
\end{array}\right)=\left(\begin{array}{cc}
-\alpha_{D} & 0 \\
k_{1} & k_{2}
\end{array}\right)\left(\begin{array}{c}
\Delta_{t} \\
E_{t}-1
\end{array}\right) d t+\left(\begin{array}{c}
\sigma_{D} \\
k_{3}
\end{array}\right) d w_{t}
$$

The associated characteristic polynomial follows as

$$
\left|\begin{array}{cc}
-\alpha_{D}-\lambda & 0 \\
k_{1} & k_{2}-\lambda
\end{array}\right|=\left(-\alpha_{D}-\lambda\right)\left(k_{2}-\lambda\right)=0
$$

with characteristic roots $\lambda^{\prime}=k_{2}$ and $\lambda^{\prime \prime}=-\alpha_{D}$. A stable solution requires $k_{2}=z<0$. The exchange rate solution can then be written as a linear combination $e_{\Delta} \Delta_{t}+e_{\Lambda} \Lambda_{t}$ of the two stochastic integrals

$$
\Delta_{t}=\int_{-\infty}^{t} \exp \left[-\alpha_{D}(t-s)\right] \sigma_{D} d w_{s} \text { and } \Lambda_{t}=\int_{-\infty}^{t} \exp [z(t-s)] d w_{s}
$$

as conjectured in Proposition A1.

We can use the flow equation (7) and substitute the various terms

$$
\begin{aligned}
-\kappa d E_{t}= & \left(E_{t}-1\right) \overline{H D} d t+\left(H_{t}^{h *}-H_{t}^{f}\right) \bar{D} d t+\left(D_{t}^{h}-D_{t}^{f *}\right) \bar{H} d t+\left(d H_{t}^{f}-d H_{t}^{h *}\right) \bar{P}= \\
= & \left(E_{t}-1\right) \overline{H D} d t+\frac{1}{\rho}\left[m_{\Delta} \Delta_{t}+m_{\Lambda} \Lambda_{t}\right] \bar{D} d t+\Delta_{t} \bar{H} d t \\
& -\frac{1}{\rho}\left[-\alpha_{D} m_{\Delta} \Delta_{t} d t+z m_{\Lambda} \Lambda_{t} d t\right] \bar{P}-\frac{1}{\rho}\left[m_{\Delta} \sigma_{\Delta}+m_{\Lambda}\right] \bar{P} d w_{t} \\
= & \left(E_{t}-1\right) \overline{H D} d t+\left[\frac{1}{\rho} m_{\Delta} \bar{D}-\frac{1}{\rho}-\alpha_{D} m_{\Delta} \bar{P}+\bar{H}\right] \Delta_{t} d t \\
& +\left[\frac{1}{\rho} m_{\Lambda} \bar{D}-\frac{1}{\rho} z m_{\Lambda} \bar{P}\right] \Lambda_{t} d t-\frac{1}{\rho}\left[m_{\Delta} \sigma_{\Delta}+m_{\Lambda}\right] \bar{P} d w_{t} .
\end{aligned}
$$


Next we use $\Lambda_{t}=\frac{1}{e_{\Lambda}}\left(E_{t}-1\right)-\frac{e_{\Delta}}{e_{\Lambda}} \Delta_{t}$ to get

$$
\begin{aligned}
-\kappa d E_{t}= & \left(E_{t}-1\right) \overline{H D} d t+\left(H_{t}^{h *}-H_{t}^{f}\right) \bar{D} d t+\left(D_{t}^{h}-D_{t}^{f *}\right) \bar{H} d t+\left(d H_{t}^{f}-d H_{t}^{h *}\right) \bar{P}= \\
= & \left(E_{t}-1\right) \overline{H D} d t+\left[\frac{1}{\rho} m_{\Delta} \bar{D}-\frac{1}{\rho}-\alpha_{D} m_{\Delta} \bar{P}+\bar{H}\right] \Delta_{t} d t \\
& +\left[\frac{1}{\rho} m_{\Lambda} \bar{D}-\frac{1}{\rho} z m_{\Lambda} \bar{P}\right] \Lambda_{t} d t-\frac{1}{\rho}\left[m_{\Delta} \sigma_{\Delta}+m_{\Lambda}\right] \bar{P} d w_{t} \\
= & \left(E_{t}-1\right) \overline{H D} d t+\left[\frac{1}{\rho} m_{\Delta} \bar{D}-\frac{1}{\rho}-\alpha_{D} m_{\Delta} \bar{P}+\bar{H}\right] \Delta_{t} d t \\
& +\left[\frac{1}{\rho} m_{\Lambda} \bar{D}-\frac{1}{\rho} z m_{\Lambda} \bar{P}\right] \frac{1}{e_{\Lambda}}\left(E_{t}-1\right) d t-\left[\frac{1}{\rho} m_{\Lambda} \bar{D}-\frac{1}{\rho} z m_{\Lambda} \bar{P}\right] \frac{e_{\Delta}}{e_{\Lambda}} \Delta_{t} d t \\
& -\frac{1}{\rho}\left[m_{\Delta} \sigma_{\Delta}+m_{\Lambda}\right] \bar{P} d w_{t} \\
= & \left\{\left[\frac{1}{\rho} m_{\Lambda} \bar{D}-\frac{1}{\rho} z m_{\Lambda} \bar{P}\right] \frac{1}{e_{\Lambda}}+\overline{H D}\right\}\left(E_{t}-1\right) d t+ \\
& \left\{\frac{1}{\rho} m_{\Delta} \bar{D}-\frac{1}{\rho}-\alpha_{D} m_{\Delta} \bar{P}+\bar{H}-\left[\frac{1}{\rho} m_{\Lambda} \bar{D}-\frac{1}{\rho} z m_{\Lambda} \bar{P}\right] \frac{e_{\Delta}}{e_{\Lambda}}\right\} \Delta_{t} d t \\
& -\frac{1}{\rho}\left[m_{\Delta} \sigma_{\Delta}+m_{\Lambda}\right] \bar{P} d w_{t} .
\end{aligned}
$$

A comparison of coeffients with $d E_{t}=k_{1} \Delta_{t}+k_{2}\left(E_{t}-\bar{E}\right)+k_{3} d w_{t}$ implies that

$$
\begin{aligned}
& k_{1}=-\frac{1}{\kappa}\left\{\frac{1}{\rho} m_{\Delta} \bar{D}-\frac{1}{\rho}-\alpha_{D} m_{\Delta} \bar{P}+\bar{H}-\left[\frac{1}{\rho} m_{\Lambda} \bar{D}-\frac{1}{\rho} z m_{\Lambda} \bar{P}\right] \frac{e_{\Delta}}{e_{\Lambda}}\right\} \\
& k_{2}=z=-\alpha_{\Lambda}=-\frac{1}{\kappa}\left\{\left[\frac{1}{\rho} m_{\Lambda} \bar{D}-\frac{1}{\rho} z m_{\Lambda} \bar{P}\right] \frac{1}{e_{\Lambda}}+\overline{H D}\right\} \\
& k_{3}=\frac{1}{\kappa \rho}\left[m_{\Delta} \sigma_{\Delta}+m_{\Lambda}\right] \bar{P} .
\end{aligned}
$$

Using the equilibrium conjecture $E_{t}=1+e_{\Delta} \Delta_{t}+e_{\Lambda} \Lambda_{t}$, we can write

$$
\begin{aligned}
d E_{t} & =e_{\Delta} d \Delta_{t}+e_{\Lambda} d \Lambda_{t}= \\
& =e_{\Delta}\left(-\alpha_{D} \Delta_{t} d t+\sigma_{D} d w_{t}\right)+e_{\Lambda}\left(z \Lambda_{t} d t+d w_{t}\right) \\
& =-e_{\Delta} \alpha_{D} \Delta_{t} d t+e_{\Lambda} z \Lambda_{t} d t+\left(e_{\Delta} \sigma_{D}+e_{\Lambda}\right) d w_{t} .
\end{aligned}
$$

Using again $\Lambda_{t}=\frac{1}{e_{\Lambda}}\left(E_{t}-1\right)-\frac{e_{\Delta}}{e_{\Lambda}} \Delta_{t}$, we obtain

$$
\begin{aligned}
d E_{t} & =e_{\Delta} d \Delta_{t}+e_{\Lambda} d \Lambda_{t}= \\
& =-e_{\Delta} \alpha_{D} \Delta_{t} d t+e_{\Lambda} z\left[\frac{1}{e_{\Lambda}}\left(E_{t}-1\right)-\frac{e_{\Delta}}{e_{\Lambda}} \Delta_{t}\right] d t+\left(e_{\Delta} \sigma_{D}+e_{\Lambda}\right) d w_{t} \\
& =z\left(E_{t}-1\right) d t-e_{\Delta}\left[\alpha_{D}+z\right] \Delta_{t} d t+\left(e_{\Delta} \sigma_{D}+e_{\Lambda}\right) d w_{t},
\end{aligned}
$$

which implies $k_{1}=-e_{\Delta} \alpha_{D}, k_{2}=z$, and $k_{3}=e_{\Delta} \sigma_{D}+e_{\Lambda}$. Combining the latter three expressing with the previous equations gives

$$
\begin{aligned}
-e_{\Delta} \alpha_{D} & =-\frac{1}{\kappa}\left\{\frac{1}{\rho} m_{\Delta} \bar{D}-\frac{1}{\rho}-\alpha_{D} m_{\Delta} \bar{P}+\bar{H}-\left[\frac{1}{\rho} m_{\Lambda} \bar{D}-\frac{1}{\rho} z m_{\Lambda} \bar{P}\right] \frac{e_{\Delta}}{e_{\Lambda}}\right\} \\
z & =-\alpha_{\Lambda}=-\frac{1}{\kappa}\left\{\left[\frac{1}{\rho} m_{\Lambda} \bar{D}-\frac{1}{\rho} z m_{\Lambda} \bar{P}\right] \frac{1}{e_{\Lambda}}+\overline{H D}\right\} \\
k_{3} & =e_{\Delta} \sigma_{D}+e_{\Lambda}=\frac{1}{\kappa \rho}\left[m_{\Delta} \sigma_{\Delta}+m_{\Lambda}\right] \bar{P} .
\end{aligned}
$$




\section{A.3. Market Equilibrium}

In order to find the solution parameters $k_{1}, k_{2}=z$ and $k_{3}$, we have to impose the market clearing conditions (3) and determine the steady state levels for the exchange rate, $\bar{E}$, the equity price, $\bar{P}$, and the foreign equity holding, $\bar{H}$. In order to obtain non-negative (steady state) prices $(\bar{P}>0)$ and positive (steady state) home and foreign holdings $(0<\bar{H}<1)$, we have to restrict the parameter domain of your model. In particular we have to impose an upper bound $\bar{\rho}$ on the risk aversion and a lower bound $\underline{\kappa}$ on the elasticity of the forex liquidity supply. Proposition 5 characterizes the equilibrium properties:

\section{Proposition A2 (Market Equilibrium):}

Home and foreign investors make investment according to assumptions 1 to 4 . For a sufficiently low risk aversion of the investors with $\rho<\bar{\rho}$ and a sufficiently price inelastic forex supply $\kappa>\underline{\kappa}$, there exists a unique stable linear equilibrium

$$
\begin{aligned}
P_{t}^{h} & =p_{0}+p_{F} F_{t}^{h}+p_{\Delta} \Delta_{t}+p_{\Lambda} \Lambda_{t} \\
P_{t}^{f} & =p_{0}+p_{F} F_{t}^{f}-p_{\Delta} \Delta_{t}-p_{\Lambda} \Lambda_{t} \\
E_{t} & =1+e_{\Delta} \Delta_{t}+e_{\Lambda} \Lambda_{t}
\end{aligned}
$$

where we define as $F_{t}^{h}$ and $F_{t}^{f}$ the expected present value of the future home and foreign dividend flows, respectively. The variable $\Delta_{t}=D_{t}^{h}-D_{t}^{f *}$ represents the relative dividend flows for the two countries and $\Lambda_{t}$ a weighted average of past relative dividend innovations decaying at rate $z<0$. For the price parameters we find

$$
p_{0}<0, p_{F}=1, p_{\Delta}>0, e_{\Delta}<0 .
$$

Portfolio holdings are given by

$$
\left(\begin{array}{cc}
H_{t}^{h} & H_{t}^{f} \\
H_{t}^{f *} & H_{t}^{h *}
\end{array}\right)=\left(\begin{array}{cc}
1-\bar{H} & \bar{H} \\
1-\bar{H} & \bar{H}
\end{array}\right)+\left(\begin{array}{cc}
-1 & -1 \\
1 & 1
\end{array}\right) \frac{1}{2 \rho}\left(m_{\Delta} \Delta_{t}+m_{\Lambda} \Lambda_{t}\right)
$$

for the parameters $m_{\Delta}<0$, and $m_{\Lambda}>0$.

Proof of Proposition A2: The two market clearing conditions $H_{t}^{h}+H_{t}^{h *}=1$ and $H_{t}^{f *}+H_{t}^{f}=1$ imply each 4 symmetric parameter contraints (for $D_{t}^{h}, D_{t}^{f *}, \Lambda_{t}$, constant) given by

$$
\begin{aligned}
p_{0} & =\frac{-\rho \operatorname{det} \Omega-\mathcal{E}_{t}\left(d E_{t} d P_{t}^{f *}\right)\left(-\Omega_{12}+\Omega_{11}\right)}{r\left(\Omega_{11}-2 \Omega_{12}+\Omega_{22}\right)} \\
p_{F} & =1 \\
p_{\Delta} & =-e_{\Delta} \frac{\left[\left(\alpha_{D}+r\right) \bar{P}-\bar{D}\right]\left(\Omega_{21}+\Omega_{11}\right)}{\left(\alpha_{D}+r\right)\left(\Omega_{11}+2 \Omega_{21}+\Omega_{22}\right)} \\
p_{\Lambda} & =-e_{\Lambda} \frac{\left[\left(-z_{2}+r\right) \bar{P}-\bar{D}\right]\left(\Omega_{21}+\Omega_{11}\right)}{\left(-z_{2}+r\right)\left(\Omega_{11}+2 \Omega_{21}+\Omega_{22}\right)} .
\end{aligned}
$$


The forex order flow constraint (7) implies an additional 3 constraints (for $\Delta_{t}, \Lambda_{t}, d w_{t}$ ) given by

$$
\begin{aligned}
e_{\Delta}\left(\overline{H D}-\kappa \alpha_{D}\right)+m_{\Delta} \frac{1}{\rho}\left(\bar{D}+\alpha_{D} \bar{P}\right) & =-\bar{H} \\
e_{\Lambda}\left(\overline{H D}+\kappa z_{2}\right)+m_{\Lambda} \frac{1}{\rho}\left(\bar{D}-z_{2} \bar{P}\right) & =0 \\
e_{\Delta} \kappa \sigma_{D}+e_{\Lambda} \kappa-m_{\Delta} \frac{1}{\rho} \bar{P} \sigma_{\Delta}-m_{\Lambda} \frac{1}{\rho} \bar{P} & =0,
\end{aligned}
$$

with

$$
\begin{aligned}
& m_{\Delta}=2 p_{\Delta}\left(\alpha_{D}+r\right)\left(\Omega_{12}^{-1}-\Omega_{22}^{-1}\right)-2\left[\left(\alpha_{D}+r\right) \bar{P}-\bar{D}\right] e_{\Delta} \Omega_{22}^{-1} \\
& m_{\Lambda}=\left\{2 p_{\Lambda}\left(-z_{2}+r\right)\left(\Omega_{12}^{-1}-\Omega_{22}^{-1}\right)-2\left[\bar{P}\left(-z_{2}+r\right)-\bar{D}\right] e_{\Lambda} \Omega_{22}^{-1}\right\}
\end{aligned}
$$

These 7 equations determine the 7 price parameters $p_{0}, p_{F}, p_{\Delta}, p_{\Lambda}, e_{\Delta}, e_{\Lambda}, z$.

Moreover, for steady state levels $\bar{P}>0, \bar{D}>0, \bar{\Lambda}=0$ and $0<\bar{H}<1$ we require

$$
\begin{aligned}
\bar{P} & =p_{0}+\frac{\bar{D}}{r}+p_{\Lambda} \bar{\Lambda}=p_{0}+\frac{\bar{D}}{r} \\
\bar{H} & =\frac{\rho\left[\Omega_{11}-\Omega_{21}\right]-\mathcal{E}_{t}\left(d E_{t} d P_{t}^{f *}\right) / d t}{\rho\left(\Omega_{11}-2 \Omega_{21}+\Omega_{22}\right)} .
\end{aligned}
$$

The respective covariances are given by

$$
\begin{aligned}
& \Omega_{11}=\left(f_{D} \sigma_{D}\right)^{2}+2\left[p_{\Delta} \sigma_{\Delta}+p_{\Lambda}\right]^{2}+2 f_{D} \sigma_{D}\left[p_{\Delta} \sigma_{\Delta}+p_{\Lambda}\right] \\
& \Omega_{12}=-2\left(p_{\Delta} \sigma_{\Delta}+p_{\Lambda}\right)^{2}-\left[2\left(p_{\Delta} \sigma_{\Delta}+p_{\Lambda}\right)+f_{D} \sigma_{D}\right] \bar{P}\left(e_{\Delta} \sigma_{D}+e_{\Lambda}\right)-2\left(p_{\Delta} \sigma_{\Delta}+p_{\Lambda}\right) f_{D} \sigma_{D} \\
& \Omega_{22}=\left(f_{D} \sigma_{D}\right)^{2}+2\left[\bar{P}\left(e_{\Delta} \sigma_{D}+e_{\Lambda}\right)+p_{\Delta} \sigma_{\Delta}+p_{\Lambda}\right]^{2}+2 f_{D} \sigma_{D}\left[\bar{P}\left(e_{\Delta} \sigma_{D}+e_{\Lambda}\right)+p_{\Delta} \sigma_{\Delta}+p_{\Lambda}\right]
\end{aligned}
$$

and furthermore

$$
\bar{\Omega}=2\left(f_{D} \sigma_{D}\right)^{2}+2\left[\bar{P}\left(e_{\Delta} \sigma_{D}+e_{\Lambda}\right)\right]^{2} .
$$

where we defined $\bar{\Omega}=\Omega_{11}+2 \Omega_{21}+\Omega_{22}>0$ as the instantaneous varaince of the total market portfolio of all domestic and foreign equity.

Combining these equations (52) to (54) and (62) we obtain an expression which characterizes the root $z$ of the system as

$$
\frac{\rho}{2}(\overline{H D}+\kappa z) \bar{\Omega}=f(z),
$$

where we define $f(z)=[(-z+r) \bar{P}-\bar{D}](\bar{D}-z \bar{P})$. The function $f(z)$ represents a convex parabola and has two intersects with the x-axes at $z_{1}=-\bar{D} / \bar{P}+r \leq 0$ and $z_{2}=\bar{D} / \bar{P} \geq 0$. Since $\frac{\rho}{2}(\overline{H D}+\kappa z) \bar{\Omega}$ is upward sloping, and positive for $z=0$, it intersects the parabola twice. The first intersection $z$ is negative and the second one it is positive. We discard the positive root because it is unstable.

Assume the forex supply is sufficiently price inelastic with $\kappa>\bar{\kappa}=\overline{H D P} /(\bar{D}-r \bar{P})=\overline{H D P} /\left(-r p_{0}\right)$. Then $\frac{\rho}{2}(\overline{H D}+\kappa z) \bar{\Omega}(z)$ intersects the x-axis to the right of $z_{1}=-\bar{D} / \bar{P}+r$ and the root $z$ is confined to the interval $z \in[-\bar{D} / \bar{P}+r,-\overline{H D} / \kappa]$. This implies $(-z+r) \bar{P}-\bar{D}<0$. Moreover, we require that the mean reversion parameter $\alpha_{D}$ of the dividend process is sufficiently large so that $-\alpha_{D}<-\bar{D} / \bar{P}+r$ or $\left(\alpha_{D}+r\right) \bar{P}-\bar{D}>0$. The latter condition 
can be rewritten as $\alpha_{D} \bar{P}>-r p_{0}$, where $p_{0}>0$ represents the risk discount on the asset price. We can make $p_{0}$ sufficiently small by setting a low upper threshold value for the investor risk aversion, hence require $\bar{\rho}>\rho$.

With these two conditions on $\kappa$ and $\rho$ we can now sign the parameters. To simplify notation we define

$$
k_{1}=\frac{\left(\overline{H D}-\alpha_{D} \kappa\right) \bar{P}}{\left(\bar{D}+\alpha_{D} \bar{P}\right)}, \quad k_{2}=\frac{(\overline{H D}+z \kappa) \bar{P}}{(\bar{D}-z \bar{P})}=z .
$$

We can then rewrite the price coefficients as

$$
\begin{aligned}
& e_{\Delta}=\frac{\bar{H}}{\left(\overline{H D}-\kappa \alpha_{D}\right)\left(1-\frac{k_{2}\left[\left(\alpha_{D}+r\right) \bar{P}-\bar{D}\right]}{k_{1}\left[\left(-z_{2}+r\right) \bar{P}-\bar{D}\right]}\right)}<0 \\
& p_{\Delta}=-e_{\Delta} \frac{\left[\left(\alpha_{D}+r\right) \bar{P}-\bar{D}\right]\left(\Omega_{21}+\Omega_{11}\right)}{\left(\alpha_{D}+r\right) \bar{\Omega}}>0,
\end{aligned}
$$

because $\left(\alpha_{D}+r\right) \bar{P}-\bar{D}>0,(-z+r) \bar{P}-\bar{D}<0, \overline{H D}-\kappa \alpha_{D}<\overline{H D}+\kappa z<0, k_{1}<0$ and $k_{2}<0$. 


\section{A.4. Uniqueness of the Stable Equilibrium}

We first note that there is a unique stable negative root $z<0$. Moreover, equation (63) can be rewritten as

$$
2\left(f_{D} \sigma_{D}\right)^{2}+2\left[\bar{P}\left(e_{\Delta} \sigma_{D}+e_{\Lambda}\right)\right]^{2}=\frac{[(-z+r) \bar{P}-\bar{D}](\bar{D}-z \bar{P})}{\frac{\rho}{2}(\overline{H D}+\kappa z)}>0 .
$$

A necessary condition for the existance of a real solution for $\bar{e}=e_{\Delta} \sigma_{D}+e_{\Lambda}$ is

$$
V(\rho, \kappa)=\frac{[(-z+r) \bar{P}-\bar{D}](\bar{D}-z \bar{P})}{\rho(\overline{H D}+\kappa z)}-\left(f_{D} \sigma_{D}\right)^{2} \geq 0 .
$$

This condition is satisfied only if $\rho\left(f_{D} \sigma_{D}\right)^{2}$ is sufficiently small or risk aversion is below as certain threshold $\rho<\bar{\rho}$. Given $\bar{e} \equiv e_{\Delta} \sigma_{D}+e_{\Lambda}<0$ (shown in corollary 2), we can then rewrite equation (63) in linear form as

$$
e_{\Delta} \sigma_{D}+e_{\Lambda}=-\frac{1}{\bar{P}} \sqrt{V(\rho, \kappa)}
$$

We define a vector $\mathbf{e}=\left(e_{\Delta}, e_{\Lambda}, m_{\Delta}, m_{\Lambda}\right)$ and matrices

$$
\mathbf{A}=\left(\begin{array}{cccc}
\sigma_{D} & 1 & 0 & 0 \\
\left(\overline{H D}-\kappa \alpha_{D}\right) & 0 & \frac{1}{\rho}\left(\bar{D}+\alpha_{D} \bar{P}\right) & 0 \\
0 & (\overline{H D}+\kappa z) & 0 & \frac{1}{\rho}(\bar{D}-z \bar{P}) \\
\kappa \sigma_{\Delta} & \kappa & -\frac{1}{\rho} \bar{P} \sigma_{\Delta} & -\frac{1}{\rho} \bar{P}
\end{array}\right) \quad \mathbf{b}=\left(\begin{array}{c}
-\frac{1}{\bar{P}} \sqrt{V(\rho, \kappa)} \\
-V(\rho, \kappa) \\
0 \\
0
\end{array}\right)
$$

so that the linear system $\mathbf{A e}=\mathbf{b}$ summarizes the 4 equations (52), (53), (54) and (69). For $\operatorname{det}(\mathbf{A}) \neq 0$ there exists a unique solution for $\mathbf{e}$.

$$
\begin{aligned}
\operatorname{det}(\mathbf{A})= & \sigma_{D}\left|\begin{array}{ccc}
0 & \frac{1}{\rho}\left(\bar{D}+\alpha_{D} \bar{P}\right) & 0 \\
(\overline{K D}+\kappa z) & 0 & \frac{1}{\rho}(\bar{D}-z \bar{P}) \\
\kappa & -\frac{1}{\rho} \bar{P} \sigma_{\Delta} & -\frac{1}{\rho} \bar{P}
\end{array}\right|-\left|\begin{array}{ccc}
\left(\overline{K D}-\kappa \alpha_{D}\right) & \frac{1}{\rho}\left(\bar{D}+\alpha_{D} \bar{P}\right) & 0 \\
0 & 0 & \frac{1}{\rho}(\bar{D}-z \bar{P}) \\
\kappa \sigma_{\Delta} & -\frac{1}{\rho} \bar{P} \sigma_{\Delta} & -\frac{1}{\rho} \bar{P}
\end{array}\right| \\
= & \sigma_{D}\left[\frac{1}{\rho}\left(\bar{D}+\alpha_{D} \bar{P}\right) \frac{1}{\rho}(\bar{D}-z \bar{P}) \kappa+\frac{1}{\rho} \bar{P}(\overline{H D}+\kappa z) \frac{1}{\rho}\left(\bar{D}+\alpha_{D} \bar{P}\right)\right] \\
& -\sigma_{\Delta}\left[\frac{1}{\rho}\left(\bar{D}+\alpha_{D} \bar{P}\right) \frac{1}{\rho}(\bar{D}-z \bar{P}) \kappa+\frac{1}{\rho} \bar{P}\left(\overline{H D}-\kappa \alpha_{D}\right) \frac{1}{\rho}(\bar{D}-z \bar{P})\right] \\
= & \frac{\bar{P}}{\rho^{2}} \sigma_{D}\left[(\overline{H D}+\kappa z)\left(\bar{D}+\alpha_{D} \bar{P}\right)-\left(\overline{K D}-\kappa \alpha_{D}\right)(\bar{D}-z \bar{P})\right] \\
= & \frac{\bar{P}}{\rho^{2}} \sigma_{D}\left[\overline{H D D}+\overline{H D} \alpha_{D} \bar{P}+\kappa z \bar{D}+\kappa z \alpha_{D} \bar{P}-\overline{H D D}+\overline{H D} z \bar{P}+\kappa \alpha_{D} \bar{D}-\kappa \alpha_{D} z \bar{P}\right] \\
= & \frac{\overline{P D}}{\rho^{2}} \sigma_{D}\left(\alpha_{D}+z\right)(\overline{H P}+\kappa)>0 .
\end{aligned}
$$

Next we show that this implies also a unique solution for the price coefficients $\mathbf{p}=\left(p_{\Delta}, p_{\Lambda}\right)$. Note that

$$
\left(\Omega_{11}+\Omega_{12}\right) / d t=\left(f_{D} \sigma_{D}\right)^{2}-\left[2\left(p_{\Delta} \sigma_{\Delta}+p_{\Lambda} \sigma_{\Lambda}\right)+f_{D} \sigma_{D}\right] \bar{P}\left(e_{\Delta} \sigma_{D}+e_{\Lambda}\right)
$$

is linear in $\mathbf{p}$ for a fixed vector $\mathbf{e}$. The equations (50) and (50) are therefore of the form $\mathbf{C p}=\mathbf{d}$, where we define

$$
\mathbf{C}=\left(\begin{array}{cc}
2 c_{\Delta} \bar{P} \bar{e} \sigma_{\Delta}-1 & 2 c_{\Delta} \bar{P} \bar{e} \\
2 c_{\Lambda} \bar{P} \bar{e} \sigma_{\Delta} & 2 c_{\Lambda} \bar{P} \bar{e}-1
\end{array}\right), \quad \mathbf{d}=\left(\begin{array}{c}
c_{\Delta}\left[\left(f_{D} \sigma_{D}\right)^{2}-f_{D} \sigma_{D} \bar{P} \bar{e}\right] \\
c_{\Lambda}\left[\left(f_{D} \sigma_{D}\right)^{2}-f_{D} \sigma_{D} \bar{P} \bar{e}\right]
\end{array}\right)
$$


with $\bar{e} \equiv e_{\Delta} \sigma_{D}+e_{\Lambda}, \bar{\Omega}=\Omega_{11}+2 \Omega_{21}+\Omega_{22}$ and additional constants

$$
c_{\Delta}=\frac{e_{\Delta}\left[\left(\alpha_{D}+r\right) \bar{P}-\bar{D}\right]}{\left(\alpha_{D}+r\right) \bar{\Omega}}, \quad c_{\Lambda}=\frac{e_{\Lambda}[(-z+r) \bar{P}-\bar{D}]}{(-z+r) \bar{\Omega}} .
$$

For $\operatorname{det}(\mathbf{C}) \neq 0$ we can invert $\mathbf{C}$ and obtain a unique solution for $\mathbf{p}$. Finally, the coefficient $p_{0}$ is uniquely determined by equation (48).

\section{A.4. Additional Propositions}

\section{Corollary 1 (Rebalancing and Equity Return Differences):}

The domestic investor rebalances her foreign investment portfolio toward home country equity if the return on her foreign equity holdings exceeds the return on her home equity investments. Formally, the foreign equity holding change $d H_{t}^{f}$ and the excess return of the foreign equity over home equity $d r_{t}^{f}-d r_{t}^{h}=\left(d R_{t}^{f}-d R_{t}^{h}\right) / \bar{P}$ expressed in domestic currency feature a negative covariance given by

$$
\operatorname{Cov}\left(d H_{t}^{f}, d r_{t}^{f}-d r_{t}^{h}\right)=\kappa \frac{1}{\bar{P}}\left[\frac{1}{\bar{P}} f_{D} \sigma_{D}+2 p_{\Delta} \sigma_{D}+2 p_{\Lambda}+e_{\Delta} \sigma_{D}+e_{\Lambda}\right]\left(e_{\Delta} \sigma_{D}+e_{\Lambda}\right) d t<0,
$$

and for the home equity investment of the foreign investor we have $d H_{t}^{h *}=-d H_{t}^{f}$.

Proof of Corollary 1: Based on the price functions Eqs. (44)-(45) and the exchange rate return

$$
\begin{aligned}
d E_{t} & =e_{\Delta} d \Delta_{t}+e_{\Lambda} d \Lambda_{t}= \\
& =-e_{\Delta} \alpha_{D} \Delta_{t} d t+e_{\Lambda} z\left[\frac{1}{e_{\Lambda}}\left(E_{t}-1\right)-\frac{e_{\Delta}}{e_{\Lambda}} \Delta_{t}\right] d t+\left(e_{\Delta} \sigma_{D}+e_{\Lambda}\right) d w_{t} \\
& =z\left(E_{t}-1\right) d t-e_{\Delta}\left[\alpha_{D}+z\right] \Delta_{t} d t+\left(e_{\Delta} \sigma_{D}+e_{\Lambda}\right) d w_{t}
\end{aligned}
$$

we obtain for the excess returns

$$
\begin{aligned}
& d R_{t}^{h}=d P_{t}^{h}-r P_{t}^{h} d t+D_{t}^{h} d t \\
& =d P_{t}^{h}+\ldots \text { (ignoring } d t \text { terms) } \\
& =p_{F} d F_{t}^{h}+p_{\Delta} d \Delta_{t}+p_{\Lambda} d \Lambda_{t} \\
& d R_{t}^{f} \approx-d E_{t} \bar{P}+d P_{t}^{f *}-d E_{t} d P_{t}^{f *}-r\left[P_{t}^{f *}-\bar{P}\left(E_{t}-1\right)\right] d t+\left[D_{t}^{f *}-\bar{D}\left(E_{t}-1\right)\right] d t \\
& =-d E_{t} \bar{P}+d P_{t}^{f *}+\ldots . .(\text { ignoring } d t \text { terms }) \\
& =-\bar{P}\left(e_{\Delta} \sigma_{D}+e_{\Lambda}\right) d w_{t}+p_{F} d F_{t}^{f *}-p_{\Delta} d \Delta_{t}-p_{\Lambda} d \Lambda_{t}+\ldots . \text { (ignoring } d t \text { terms) } \\
& d R_{t}^{f}-d R_{t}^{h}=-\bar{P}\left(e_{\Delta} \sigma_{D}+e_{\Lambda}\right) d w_{t}+p_{F}\left[d F_{t}^{f *}-d F_{t}^{h}\right]-2 p_{\Delta} d \Delta_{t}-2 p_{\Lambda} d \Lambda_{t}+\ldots \\
& =-\bar{P}\left(e_{\Delta} \sigma_{D}+e_{\Lambda}\right) d w_{t}-f_{D} d \Delta_{t}-2 p_{\Delta} d \Delta_{t}-2 p_{\Lambda} d \Lambda_{t}+\ldots \\
& =-\bar{P}\left(e_{\Delta} \sigma_{D}+e_{\Lambda}\right) d w_{t}-\left[f_{D}+2 p_{\Delta}\right] \sigma_{D} d w_{t}-2 p_{\Lambda} d w_{t}+\ldots \\
& =-\left[\bar{P}\left(e_{\Delta} \sigma_{D}+e_{\Lambda}\right)+f_{D} \sigma_{D}+2 p_{\Delta} \sigma_{D}+2 p_{\Lambda}\right] d w_{t}+\ldots . \text { (ignoring } d t \text { terms) } \\
& d R_{t}^{f *}-d R_{t}^{h}=2 p_{\Delta}\left(\alpha_{D}+r\right) \Delta_{t} d t+2 p_{\Lambda}(-z+r) \Lambda_{t} d t-\left[f_{D} \sigma_{D}+2 p_{\Delta} \sigma_{D}+2 p_{\Lambda}\right] d w_{t} .
\end{aligned}
$$


The instantaneous volatility of the excess return follows as

$$
\begin{aligned}
\mathcal{E}_{t}\left(d r_{t}^{f}-d r_{t}^{h}\right)\left(d r_{t}^{f}-d r_{t}^{h}\right) & =\frac{1}{\bar{P}^{2}} \mathcal{E}_{t}\left(d R_{t}^{f}-d R_{t}^{h}\right)\left(d R_{t}^{f}-d R_{t}^{h}\right)= \\
& =\frac{1}{\bar{P}^{2}}\left[\bar{P}\left(e_{\Delta} \sigma_{D}+e_{\Lambda}\right)+f_{D} \sigma_{D}+2 p_{\Delta} \sigma_{D}+2 p_{\Lambda}\right]^{2} \mathcal{E}_{t}\left(d w_{t} d w_{t}\right) \\
& =\frac{2}{\bar{P}^{2}}\left[\bar{P}\left(e_{\Delta} \sigma_{D}+e_{\Lambda}\right)+f_{D} \sigma_{D}+2 p_{\Delta} \sigma_{D}+2 p_{\Lambda}\right]^{2} d t
\end{aligned}
$$

For holding changes we find

$$
d H_{t}^{f}=\frac{1}{2 \rho}\left(m_{\Delta} d \Delta_{t}+m_{\Lambda} d \Lambda_{t}\right)=\frac{1}{2 \rho}\left(m_{\Delta} \sigma_{D}+m_{\Lambda}\right) d w_{t}+\ldots
$$

which implies

$$
\begin{aligned}
\operatorname{Cov}\left(d H_{t}^{f}, d r_{t}^{f}-d r_{t}^{h}\right) & =\frac{1}{2 \rho}\left(m_{\Delta} \sigma_{D}+m_{\Lambda}\right) \frac{2}{\bar{P}}\left[\bar{P}\left(e_{\Delta} \sigma_{D}+e_{\Lambda}\right)+f_{D} \sigma_{D}+2 p_{\Delta} \sigma_{D}+2 p_{\Lambda}\right] d t \\
& =\left(e_{\Delta} \sigma_{D}+e_{\Lambda}\right) \frac{\kappa}{\bar{P}^{2}}\left[\bar{P}\left(e_{\Delta} \sigma_{D}+e_{\Lambda}\right)+f_{D} \sigma_{D}+2 p_{\Delta} \sigma_{D}+2 p_{\Lambda}\right] d t \\
& =\frac{\kappa}{\bar{P}^{2}}\left[\bar{P}\left(e_{\Delta} \sigma_{D}+e_{\Lambda}\right)^{2}+\left(e_{\Delta} \sigma_{D}+e_{\Lambda}\right)\left(f_{D} \sigma_{D}+2 p_{\Delta} \sigma_{D}+2 p_{\Lambda}\right)\right] d t
\end{aligned}
$$

and also

$$
\begin{aligned}
\beta & =\frac{\operatorname{Cov}\left(d H_{t}^{f}, d r_{t}^{f}-d r_{t}^{h}\right)}{\operatorname{Var}\left(d r_{t}^{f}-d r_{t}^{h}\right)}=\frac{\left(m_{\Delta} \sigma_{D}+m_{\Lambda}\right) \bar{P}}{2 \rho\left[\bar{P}\left(e_{\Delta} \sigma_{D}+e_{\Lambda}\right)+f_{D} \sigma_{D}+2 p_{\Delta} \sigma_{D}+2 p_{\Lambda}\right]} \\
& =\frac{\kappa\left(e_{\Delta} \sigma_{D}+e_{\Lambda}\right)}{2\left[\bar{P}\left(e_{\Delta} \sigma_{D}+e_{\Lambda}\right)+f_{D} \sigma_{D}+2 p_{\Delta} \sigma_{D}+2 p_{\Lambda}\right]}<0
\end{aligned}
$$

because $\left(e_{\Delta} \sigma_{D}+e_{\Lambda}\right) \frac{\kappa \rho}{\bar{P}}=m_{\Delta} \sigma_{\Delta}+m_{\Lambda}<0$. Symmetry of the model implies $\mathcal{E}_{t}\left(d E_{t} d R_{t}^{h}\right)=-\mathcal{E}_{t}\left(d E_{t} d R_{t}^{f *}\right)$. Furthermore,

$$
\mathcal{E}_{t}\left(d E_{t} d R_{t}^{h}\right) / d t=\left(e_{\Delta} \sigma_{D}+e_{\Lambda}\right)\left[f_{D} \sigma_{D}+2\left(p_{\Delta} \sigma_{D}+p_{\Lambda}\right)\right]<0
$$

amounts to showing that $\bar{e} \equiv e_{\Delta} \sigma_{D}+e_{\Lambda}<0$ as long as $f_{D} \sigma_{D}+2\left(p_{\Delta} \sigma_{D}+p_{\Lambda}\right)>0$. To simplify notation we define

$$
k_{1}=\frac{\left(\overline{H D}-\alpha_{D} \kappa\right) \bar{P}}{\left(\bar{D}+\alpha_{D} \bar{P}\right)}, \quad k_{2}=\frac{(\overline{H D}+z \kappa) \bar{P}}{(\bar{D}-z \bar{P})} .
$$

Clearly, $k_{1}<0$ and $k_{2}<0$ under the parameter constraints of proposition 5 . Moreover, $k_{1}-k_{2}<0$, because (for $\left.\alpha_{D}>-z\right)$ we find

$$
(\bar{D}-z \bar{P})\left(\overline{H D}-\alpha_{D} \kappa\right)-\left(\bar{D}+\alpha_{D} \bar{P}\right)(\overline{H D}+z \kappa)=-\left(\alpha_{D}+z\right)[\bar{D} \kappa+\overline{P H D}]<0
$$

Substituting equations (52) and (53) into (54) implies

$$
e_{\Delta} \sigma_{\Delta}\left[\kappa+k_{1}\right]+e_{\Lambda}\left[\kappa+k_{2}\right]=\frac{-\overline{H P} \sigma_{\Delta}}{\left(\bar{D}+\alpha_{D} \bar{P}\right)}<0 .
$$

Subtracting the term $e_{\Delta} \sigma_{\Delta}\left(k_{1}-k_{2}\right)>0$ (because $e_{\Delta}<0$ ) from the left hand side implies $e_{\Delta} \sigma_{\Delta}\left[\kappa+k_{2}\right]+$ $e_{\Lambda}\left[\kappa+k_{2}\right]<0$ and also $e_{\Delta} \sigma_{\Delta}+e_{\Lambda}<0$, since $\kappa+k_{2}>0$ is trivially fulfilled (for $\kappa>0, \bar{H}>0, \bar{D}>0, \bar{P}>0$ ). 


\section{Empirical Internet Appendix}

Global Portfolio Rebalancing and Exchange Rates

December 15, 2021 


\section{Table A1: Equity Fund Rebalancing for Non-Dividend Adjusted Returns}

Fund rebalancing of the foreign investment share $\Delta h_{j, t}^{f}$ of fund $j$ in quarter $t$ (measured in percentages) is regressed on non-dividend adjusted excess returns of the foreign over the domestic investment share, $r_{j, t}^{f}-r_{j, t}^{h}$, and its lagged values $r_{j, t-l}^{f}-r_{j, t-l}^{h}$ for lags $l=1,2$. In Column (1) we report OLS regression results without fixed effects, Columns (2)-(7) add interacted time and fund domicile fixed effects, and Columns (3)-(7) add additional fund fixed effects. Column (5) splits the excess return on the foreign portfolio share into positive and negative realizations to test for symmetry of the rebalancing behavior. In Columns (6)-(7) we report the baseline regression of Column (3) for the subsample until June 2008 (Period I) and thereafter (Period II). We report robust standard errors clustered at the fund level for specification (1) and use ***, **, and * to denote statistical significance at the $1 \%, 5 \%$, and $10 \%$ level respectively.

Dependent variable:

Fund Level Rebalancing $\Delta h_{j, t}^{f}$
(1)
(2)
(3)
(4)
(5)
(6)
(7)

\begin{tabular}{|c|c|c|c|c|}
\hline$r_{j, t}^{f}-r_{j, t}^{h}$ & $\begin{array}{c}-1.781^{* * *} \\
(0.240)\end{array}$ & $\begin{array}{c}-2.469^{* * *} \\
(0.249)\end{array}$ & $\begin{array}{c}-2.397^{* * *} \\
(0.263)\end{array}$ & $\begin{array}{c}-2.455^{\text {*** }} \\
(0.278)\end{array}$ \\
\hline$r_{j, t-1}^{f}-r_{j, t-1}^{h}$ & & $\begin{array}{c}-1.682^{* * *} \\
(0.249)\end{array}$ & $\begin{array}{c}-1.503^{* * *} \\
(0.262)\end{array}$ & $\begin{array}{c}-1.703^{\text {*** }} \\
(0.276)\end{array}$ \\
\hline$r_{j, t-2}^{f}-r_{j, t-2}^{h}$ & & & & $\begin{array}{c}-0.996^{\text {*** }} \\
(0.274)\end{array}$ \\
\hline $\begin{array}{l}\left(r_{j, t}^{f}-r_{j, t}^{h}\right) \times 1_{\geq 0} \\
\left(r_{j, t}^{f}-r_{j, t}^{h}\right) \times 1_{<0}\end{array}$ & & & & \\
\hline $\begin{array}{l}\left(r_{j, t-1}^{f}-r_{j, t-1}^{h}\right) \times 1_{\geq 0} \\
\left(r_{j, t-1}^{f}-r_{j, t-1}^{h}\right) \times 1_{<0}\end{array}$ & & & & \\
\hline
\end{tabular}

$-3.400^{* * *}$

(0.453)

$-1.359^{* * *}$

(0.466)

$-0.557$

(0.447)

$-2.543^{* * *}$

$(0.470)$

Time $\times$ Fund Domicile FEs

$\begin{array}{cccc}\text { No } & \text { Yes } & \text { Yes } & \text { Yes } \\ \text { No } & \text { No } & \text { Yes } & \text { Yes } \\ 55.045 & 10.690 & 10.115 & 10.157 \\ 101,234 & 89,170 & 89,170 & 79,426 \\ 0.001 & 0.065 & 0.133 & 0.142\end{array}$

$-1.952^{* * *}$

$-2.435^{* * *}$

$(0.555)$

$-1.717^{* * *}$

$-1.420^{* * *}$

(0.579)

Fund FEs

$F$-statistic

Full

Full

Full

Full

Yes

Yes
Yes
4.073
15,981
0.168

Yes

Yes

10.107

12.717

89,170

0.168

73,189

0.134

Full

Full Full


Table A2: Fund Rebalancing Trimming Robustness

Regressions results in Tables 4 and 5 are shown for different levels of trimming of data outliers for the fund rebalancing variables $\Delta h_{j, t}^{f}$ or $\Delta h_{j, t}^{h *}$. We use ${ }^{* * *}, * *$, and $*$ to denote statistical significance at the $1 \%, 5 \%$, and $10 \%$ level, respectively.

\begin{tabular}{|c|c|c|c|c|c|}
\hline \multirow{3}{*}{$\begin{array}{c}\text { Trimming } \\
\text { at }\end{array}$} & \multicolumn{2}{|c|}{ OLS Results (Table 4) } & \multicolumn{3}{|c|}{ 2SLS Results (Table 5) } \\
\hline & \multirow[t]{2}{*}{ Coefficient } & \multirow[t]{2}{*}{$R^{2}$} & \multicolumn{3}{|c|}{ GIV2 } \\
\hline & & & First-Stage & Second-Stage & Elasticity \\
\hline $0 \%$ & $0.739^{* *}$ & $4.1 \%$ & $1.222^{* * *}$ & 0.437 & 2.29 \\
\hline $1 \%$ & $0.896^{* *}$ & $4.5 \%$ & $1.298^{* * *}$ & 0.524 & 1.91 \\
\hline $2 \%$ & $1.003^{* * *}$ & $5.5 \%$ & $1.390^{* * *}$ & $0.800^{*}$ & 1.25 \\
\hline $2.5 \%$ & $1.046^{* * *}$ & $5.7 \%$ & $1.429^{* * *}$ & $0.926^{* *}$ & 1.08 \\
\hline $3 \%$ & $1.060^{* * *}$ & $5.7 \%$ & $1.439^{* * *}$ & $1.037^{* *}$ & 0.96 \\
\hline $4 \%$ & $1.144^{* * *}$ & $5.4 \%$ & $1.403^{* * *}$ & $1.156^{* *}$ & 0.87 \\
\hline $5 \%$ & $1.229^{* * *}$ & $5.9 \%$ & $1.421^{* * *}$ & $1.207^{* *}$ & 0.83 \\
\hline
\end{tabular}




\section{Table A3: Filtering Fund Rebalancing}

Fund rebalancing terms $\Delta h_{j, t}^{f}$ and $\Delta h_{j, t}^{h *}$ of fund $j$ in quarter $t$ (measured as percentage) are regressed on fund size [ln $\left.(A s s e t s)_{j, t-1}\right]$, the Herfindahl-Hirschman Index of fund concentration $\left(H H I_{j, t-1}\right)$, and their interaction with a fund's foreign excess return $r_{j, t}^{f}-r_{j, t}^{h}$ and $r_{j, t}^{h *}-r_{j, t}^{f *}$, respectively. In specification (1), we use as dependent variable $\Delta h_{j, t}^{f}$ the fund-level rebalancing of home funds (domiciled in currency area $c$ ) toward foreign equity (i.e., portfolio outflows from currency area $c$ ). In specification (2), we use as dependent variable $\Delta h_{j, t}^{h *}$, the rebalancing of foreign domiciled funds from foreign equity positions into equity in currency area $c$ (i.e., portfolio inflows into currency area $c$ ). Specifications (1) and (2) filter fund heterogeneity in rebalancing for GIV2. The respective regression residuals are then used for the construction of the granular instrumental variables. We report robust standard errors clustered at the fund level for all specifications and use ${ }^{* * *}, * *$, and $*$ to denote statistical significance at the $1 \%, 5 \%$, and $10 \%$ level, respectively.

\begin{tabular}{|c|c|c|}
\hline \multirow[t]{3}{*}{ Dependent variable: } & Fund Level Rebalancing $\Delta h_{j, t}^{f}$ & Fund Level Rebalancing $\Delta h_{j, t}^{h *}$ \\
\hline & GIV2 & GIV2 \\
\hline & $(1)$ & $(2)$ \\
\hline \multirow{2}{*}{$\ln (\text { Assets })_{j, t-1}$} & 0.006 & $0.029^{* * *}$ \\
\hline & $(0.017)$ & $(0.007)$ \\
\hline \multirow{2}{*}{$H H I_{j, t-1}$} & $4.627^{* * *}$ & $1.330^{*}$ \\
\hline & $(1.492)$ & $(0.740)$ \\
\hline \multirow[t]{2}{*}{$\left(r_{j, t}^{f}-r_{j, t}^{h}\right) \times \ln (\text { Assets })_{j, t-1}$} & $-0.061^{* * *}$ & \\
\hline & $(0.010)$ & \\
\hline \multirow{2}{*}{$\left(r_{j, t}^{h *}-r_{j, t}^{f *}\right) \times \ln (\text { Assets })_{j, t-1}$} & & $-0.026^{* * *}$ \\
\hline & & $(0.003)$ \\
\hline \multirow{2}{*}{$\left(r_{j, t}^{f}-r_{j, t}^{h}\right) \times H H I_{j, t-1}$} & $-19.805^{* * *}$ & \\
\hline & $(5.833)$ & \\
\hline \multirow[t]{2}{*}{$\left(r_{j, t}^{h *}-r_{j, t}^{f *}\right) \times H H I_{j, t-1}$} & & $-3.129^{*}$ \\
\hline & & $(1.711)$ \\
\hline Time FEs & No & No \\
\hline Fund FEs & Yes & Yes \\
\hline$F$-statistic & 43.800 & 83.653 \\
\hline Observations & 104,012 & 236,697 \\
\hline Adjusted $R^{2}$ & 0.088 & 0.042 \\
\hline
\end{tabular}


Table A4: Aggregate Equity Rebalancing and the Exchange Rate - Country Group Analysis

The effective (log) foreign currency appreciation $-\Delta E_{c, t}$ in quarter $t$ (scaled by a factor of 100) for the four currency areas $c$ (i.e., U.S., U.K., Eurozone, Canada) is regressed on the net equity rebalancing flows (expressed in percentages of the average foreign equity positions). We pool data for the U.S. and U.K. currency in odd columns characterized by higher reporting completeness and alternatively for the Eurozone (EZ) and Canada (CA) currency in even columns characterized by lower reporting quality. In Columns (1)-(2) we use the full period sample and in Columns (3)-(6) we present subsample results. In Column (1), we report OLS regression coefficients for the aggregate rebalancing $\Delta H_{c, t}^{f}$ of the foreign portfolio share of all funds domiciled in $c$ and the aggregate rebalancing $\Delta H_{c, t}^{h *}$ of the portfolio share invested in $c$ by equity funds domiciled outside $c$. Column (2) combines both terms to the net aggregate equity outflow $\Delta H_{c, t}^{N e t}=2 \mu_{c, t-1} \Delta H_{c, t}^{f}-2\left(1-\mu_{c, t-1}\right) \Delta H_{c, t}^{h *}$ from currency area $c$, where $\mu_{c, t-1}$ denotes the ratio of aggregate outbound to the sum of aggregate outbond and inbound equity investments. Columns (3)-(6) repeat the regressions in Columns (1)-(2) for a pre-crisis 1999-2007 subsample amd a crisis/post-crisis 2008-2015 subsample. We use ***, **, and * to denote statistical significance at the $1 \%, 5 \%$, and $10 \%$ level, respectively.

\begin{tabular}{|c|c|c|c|c|c|c|}
\hline \multirow[t]{5}{*}{ Dependent var.: } & \multicolumn{6}{|c|}{ Effective Quarterly Foreign Currency Appreciation, $-\Delta E_{c, t}$} \\
\hline & \multicolumn{2}{|c|}{ Full Sample } & \multicolumn{2}{|c|}{ Period 1999-2007 } & \multicolumn{2}{|c|}{ Period 2008-2015 } \\
\hline & U.S. and U.K. & EZ and CA & U.S. and U.K. & $\mathrm{EZ}$ and $\mathrm{CA}$ & U.S. and U.K. & $\mathrm{EZ}$ and $\mathrm{CA}$ \\
\hline & OLS & OLS & OLS & OLS & OLS & OLS \\
\hline & (1) & $(2)$ & $(3)$ & $(4)$ & (5) & (6) \\
\hline \multirow[t]{2}{*}{$\Delta H_{c, t}^{N e t}$} & $0.982^{* *}$ & $1.273^{*}$ & 0.350 & 0.202 & $1.899^{* * *}$ & 1.305 \\
\hline & $(0.397)$ & $(0.711)$ & $(0.511)$ & $(1.138)$ & $(0.664)$ & $(0.897)$ \\
\hline$F$-statistic & 6.111 & 3.209 & 0.468 & 0.032 & 8.180 & 2.119 \\
\hline Observations & 72 & 71 & 17 & 19 & 55 & 52 \\
\hline Adjusted $R^{2}$ & 0.080 & 0.044 & 0.030 & 0.002 & 0.134 & 0.041 \\
\hline
\end{tabular}


Table A5: Narrative Approach to Large Fund Shocks

We follow the narrative approach proposed by Gabaix and Koijen (July 2021, page 15) and look for the narratives behind the largest fund-level shocks to equity inflows and outflows for the U.S. and the Eurozone. More specifically, we regress the (percentage) fund rebalancing terms $\Delta h_{j, t}^{f}$ and $\Delta h_{j, t}^{h *}$ on a single constant (separately for each currency) and collect the residuals $\breve{u}_{j t}$ of the eight respective panels. The residuals are re-scaled by a factor corresponding to the relative fund size to obtain an absolute flow measure. For outflows, we re-scale the residuals by $S_{j t}^{f}=A_{j t}^{f} / \sum_{j}\left(A_{j t}^{f}\right)$, i.e. the dollar value invested in non-domestic assets by fund $j$ divided by the total dollar invested by all funds in the panel in non-domestic assets; for inflows, we re-scale the residual by $S_{j t}^{h *}=A_{j t}^{h *} / \sum_{j}\left(A_{j t}^{h *}\right)$, i.e. the dollar value invested in domestic assets by foreign fund $j$ divided by the total dollar value invested by all foreign funds in domestic assets. The ten largest fund shocks for each currency are then selected by ranking (absolute) fund outflows $S_{j t}^{f} \times\left|\breve{u}_{j t}\right|$ and (absolute) fund inflows $S_{j t}^{h *} \times\left|\breve{u}_{j t}\right|$. We search the Factiva data set for news events that can explain these large shocks and report the quarter in Column (1), the size of the corresponding GIV shock in Column (2), the fund name in Column (3), the fund residence in Column (4), the relevant article link in Column (5), the article date in Colmun (6), and article source in Column (7), the rebalancing reason and explanation in Columns (8) and (9), respectively. Panels A and B concern outflow and inflow shocks for the U.S., respectively; Panels C and D the outflow and inflow shocks for the Eurozone, respectively. Appendix Figures 1 and 2 link these largest idosyncratic fund shock to the Granular Instrumental Variable (GIV1) series for the U.S. and the Eurozone, respectively.

Panel A: Largest Fund Shocks and U.S. Outflows

\begin{tabular}{|c|c|c|c|c|c|c|c|c|}
\hline Quarter & $\begin{array}{l}\text { GIV } \\
\text { shock } \\
\text { size }\end{array}$ & $\begin{array}{l}\text { Fund } \\
\text { Name }\end{array}$ & $\begin{array}{l}\text { Fund } \\
\text { Country }\end{array}$ & $\begin{array}{l}\text { Article } \\
\text { Links }\end{array}$ & $\begin{array}{l}\text { Article } \\
\text { Dates }\end{array}$ & $\begin{array}{l}\text { Article } \\
\text { Source }\end{array}$ & Reason & Explanation \\
\hline $2003 q 4$ & 0.885 & $\begin{array}{l}\text { Janus Capital } \\
\text { Management } \\
\text { LLC }\end{array}$ & US & $\begin{array}{l}\text { https://global- } \\
\text { factiva- } \\
\text { com.ezproxy.libra } \\
\text { ry.qmul.ac.uk/redi } \\
\text { r/default.aspx?P= } \\
\text { sa\&an=FTCOM0 } \\
0020031230 \text { dzci0 } \\
00 \text { c2\&cat=a\&ep }= \\
\text { ASE } \\
\end{array}$ & $19-12-2003$ & $\begin{array}{l}\text { Financial } \\
\text { Times }\end{array}$ & $\begin{array}{l}\text { Mutual Fund } \\
\text { Scandal }\end{array}$ & $\begin{array}{l}\text { "Janus Capital, one of the first fund groups to } \\
\text { become embroiled in New York attorney-general } \\
\text { Eliot Spitzer's crackdown on mutual fund trading } \\
\text { scandals, has offered to return } \$ 31.5 \mathrm{~m} \text { to its } \\
\text { investors as compensation for the improper } \\
\text { trading that took place in its funds." }\end{array}$ \\
\hline $2004 q 1$ & -0.457 & $\begin{array}{l}\text { New Jersey } \\
\text { Division of } \\
\text { Investment }\end{array}$ & US & 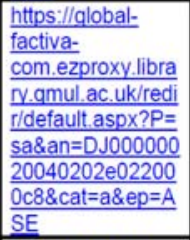 & $02-02-2004$ & $\begin{array}{l}\text { DowJones } \\
\text { Newswire }\end{array}$ & $\begin{array}{l}\text { For the first time, } \\
\text { an outside } \\
\text { consultant was } \\
\text { hired to manage } \\
\text { the pension fund }\end{array}$ & $\begin{array}{l}\text { "Opening a new era in New Jersey's investment } \\
\text { history, the state has hired an outside firm to } \\
\text { advise it on managing its } \$ 66.9 \text { billion pension } \\
\text { funds" }\end{array}$ \\
\hline $2008 q 1$ & -0.334 & $\begin{array}{l}\text { Capital } \\
\text { Research \& } \\
\text { Management } \\
\text { Co. (Global } \\
\text { Investors) }\end{array}$ & US & 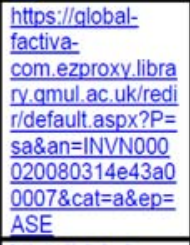 & $10-03-2008$ & $\begin{array}{l}\text { Invest-ment } \\
\text { News }\end{array}$ & Law suit dropped & $\begin{array}{l}\text { "California Attorney General Jerry Brown said } \\
\text { last month that the state has dropped a long- } \\
\text { running lawsuit against the nation's biggest } \\
\text { mutual fund group over an alleged failure to } \\
\text { adequately disclose revenue-sharing and } \\
\text { directed-brokerage agreements, also known as } \\
\text { "shelf space" payments." }\end{array}$ \\
\hline $2005 q 2$ & 0.333 & $\begin{array}{l}\text { Capital } \\
\text { Research \& } \\
\text { Management } \\
\text { Co. (Global } \\
\text { Investors) }\end{array}$ & US & 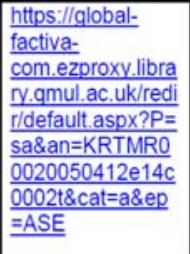 & $12-04-2005$ & $\begin{array}{l}\text { Morning- } \\
\text { star Column }\end{array}$ & $\begin{array}{l}\text { Charges made by } \\
\text { regulators }\end{array}$ & $\begin{array}{l}\text { "We're watching developments at American } \\
\text { Funds closely in light of recent charges made by } \\
\text { regulators. At this point, none of the parties } \\
\text { involved in the cases have offered up any } \\
\text { evidence, so we haven't drawn conclusions yet. } \\
\text { The charges don't reach the level of seriousness } \\
\text { of many of the market-timing cases, but they do } \\
\text { raise important issues that should be explored" }\end{array}$ \\
\hline $2004 q^{3}$ & 0.315 & $\begin{array}{l}\text { Capital } \\
\text { Research \& } \\
\text { Management } \\
\text { Co. (World } \\
\text { Investors) }\end{array}$ & US & 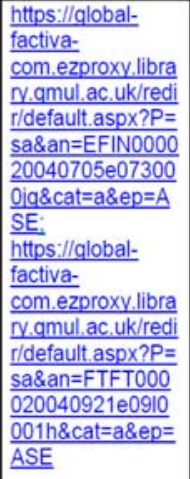 & $\begin{array}{l}03-07-2004 \\
21-09-2004\end{array}$ & $\begin{array}{l}\text { Financial } \\
\text { News: } \\
\text { Financial } \\
\text { Times }\end{array}$ & $\begin{array}{l}\text { 1) Restructuring } \\
\text { of the } \\
\text { management } \\
\text { teams; } \\
\text { 2) Departure of } \\
\text { Jon Lovelace, the } \\
\text { son of the } \\
\text { founder }\end{array}$ & $\begin{array}{l}\text { "Capital Research \& Management, part of the } \\
\text { US Capital Group, is dividing its team of } \\
\text { portfolio managers into two separate groups." : } \\
\text { "Jon Lovelace, the son of the founder whose } \\
\text { single-minded vision built the company, recently } \\
\text { retired after many years of holding various } \\
\text { senior roles in the company. He seemed almost } \\
\text { obsessive about sharing control with others, but } \\
\text { there is no doubt that with his departure the } \\
\text { group has lost a guiding presence, and also a } \\
\text { symbolic one, who maintained and shaped } \\
\text { Capital's corporate culture." }\end{array}$ \\
\hline
\end{tabular}


Panel B: Largest Fund Shocks and U.S. Inflows

\begin{tabular}{|c|c|c|c|c|c|c|c|c|}
\hline Quarter & \begin{tabular}{|l} 
GIV \\
shock \\
size
\end{tabular} & $\begin{array}{l}\text { Fund } \\
\text { Name }\end{array}$ & $\begin{array}{l}\text { Fund } \\
\text { Country }\end{array}$ & $\begin{array}{l}\text { Article } \\
\text { Links }\end{array}$ & $\begin{array}{l}\text { Article } \\
\text { Dates }\end{array}$ & $\begin{array}{l}\text { Article } \\
\text { Source }\end{array}$ & Reason & Explanation \\
\hline $2006 q^{3}$ & 0.760 & $\begin{array}{l}\text { Deutsche } \\
\text { Asset } \\
\text { Management } \\
\text { Investment } \\
\text { GmbH }\end{array}$ & $E Z$ & 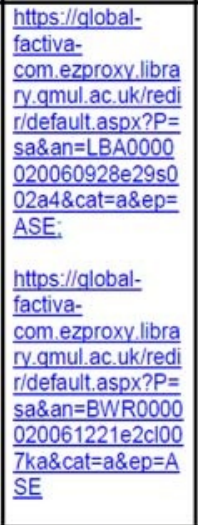 & $\begin{array}{l}28-09-2006 ; \\
21-12-2006\end{array}$ & $\begin{array}{l}\text { Reuters } \\
\text { News; } \\
\text { Business } \\
\text { Wire }\end{array}$ & $\begin{array}{l}\text { 1) Settlement } \\
\text { with SEC; } \\
\text { 2) Between } \\
\text { January and } \\
\text { December } 2006 \text {, } \\
\text { details of the } \\
\text { settlement } \\
\text { between DB and } \\
\text { the SEC for } \\
\text { market timing } \\
\text { wrongdoing were } \\
\text { made public }\end{array}$ & $\begin{array}{l}\text { "The U.S. asset management arm of Deutsche } \\
\text { Bank AG has agreed to pay \$19.3 million to } \\
\text { settle a case involving directed brokerage and } \\
\text { the Scudder Funds, U.S. regulators and the } \\
\text { company said on Thursday.": "Deutsche Asset } \\
\text { Management (DeAM), a unit of Deutsche Bank } \\
\text { (XETRA: DBKGn.DE / NYSE: DB), today } \\
\text { confirmed it has settled proceedings with the } \\
\text { Securities and Exchange Commission (SEC) } \\
\text { and the New York Attorney General (NYAG) on } \\
\text { behalf of Deutsche Asset Management Inc. } \\
\text { (DAMI) and Deutsche Investment Management } \\
\text { Americas Inc. (DIMA), the investment advisors } \\
\text { to many of the DWS Scudder Funds, regarding } \\
\text { allegedly improper market timing. The general } \\
\text { terms of these settlements were first disclosed } \\
\text { by Deutsche Bank in January } 2006 \text { and the full } \\
\text { settlement amounts have been included in prior } \\
\text { legal reserves. No further financial impact is } \\
\text { anticipated." }\end{array}$ \\
\hline $2006 q 2$ & 0.494 & $\begin{array}{l}\text { Deutsche } \\
\text { Asset Manage- } \\
\text { ment } \\
\text { Investment } \\
\text { GmbH }\end{array}$ & $E Z$ & 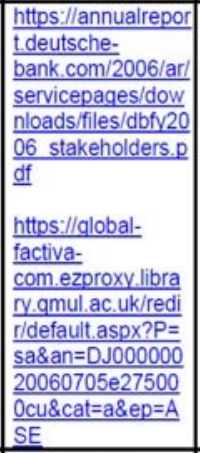 & $\begin{array}{l}03-2007 ; \\
05-07-2006\end{array}$ & $\begin{array}{l}2006 \\
\text { Annual } \\
\text { Report } \\
\text { Deutsche } \\
\text { Bank, } \\
\text { Chapter } \\
\text { "Share- } \\
\text { holders"; } \\
\\
\text { Dow Jones } \\
\text { Newswires }\end{array}$ & $\begin{array}{l}\text { 1) DWS launched } \\
\text { in the US in } \\
\text { February: } \\
\text { 2) hiring of many } \\
\text { new sales and } \\
\text { product } \\
\text { personnel }\end{array}$ & $\begin{array}{l}\text { "The DWS brand was also introduced in the } \\
\text { U.S. with the launch of DWS Scudder in } \\
\text { February."; "Deutsche Asset Management said } \\
\text { Wednesday it has added } 19 \text { people to the sales } \\
\text { and product development team at DWS } \\
\text { Scudder, the mutual-fund arm of Deutsche Bank } \\
\text { AG'S (DB) asset-management business in the } \\
\text { U.S. The move, which follows the hiring earlier } \\
\text { this year of } 16 \text { sales professionals, is part of the } \\
\text { asset manager's drive to focus on U.S. } \\
\text { distribution of products via the advisor channel" }\end{array}$ \\
\hline $2005 q 2$ & -0.487 & $\begin{array}{l}\text { State Street } \\
\text { Global } \\
\text { Advisors } \\
\text { France SA }\end{array}$ & $E Z$ & 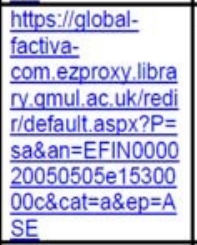 & $03-05-2005$ & $\begin{array}{l}\text { Financial } \\
\text { News }\end{array}$ & $\begin{array}{l}\text { Change of fund } \\
\text { managers }\end{array}$ & $\begin{array}{l}\text { "State Street Global Advisors promoted Paul } \\
\text { Duncombe to take over its UK business } \\
\text { following the departure of Nigel Wightman in } \\
\text { March. Duncombe has been global head of } \\
\text { currency management for the past nine years. } \\
\text { State Street also hired Valerie Nicholson from } \\
\text { F\&C Asset Management as director of } \\
\text { marketing and consultant liaison. Nicholson will } \\
\text { be based in the UK." }\end{array}$ \\
\hline $2007 q^{3}$ & 0.480 & $\begin{array}{l}\text { Natixis Asset } \\
\text { Management } \\
\text { SA }\end{array}$ & $E Z$ & 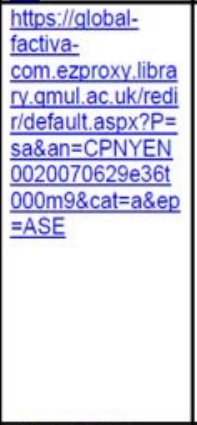 & $29-06-2007$ & $\begin{array}{l}\text { Company } \\
\text { News }\end{array}$ & $\begin{array}{l}\text { NATIXIS expands } \\
\text { its asset } \\
\text { management } \\
\text { business in the } \\
\text { United States }\end{array}$ & $\begin{array}{l}\text { "IXIS Asset Management US Group, a } \\
\text { subsidiary of Natixis, agrees to acquire Gateway } \\
\text { Investment Advisers, LP. } \\
\text { IXIS Asset Management US Group announced } \\
\text { today that it has entered into an agreement to } \\
\text { acquire Gateway Investment Advisers, a } \\
\text { Cincinnati-based investment manager with } \$ 7.5 \\
\text { billion in Assets under Management (as of } \\
\text { March } 31,2007 \text { ), including the Gateway Fund, } \\
\text { as well as a variety of sub-advised mandates } \\
\text { and private accounts. The terms of the } \\
\text { transaction were not disclosed. Completion of } \\
\text { the transaction is subject to customary closing } \\
\text { conditions, including obtaining any necessary } \\
\text { regulatory and other approvals." }\end{array}$ \\
\hline $2004 q 1$ & -0.466 & $\begin{array}{l}\text { BBVA Asset } \\
\text { Management } \\
\text { SA SGIIC }\end{array}$ & $E Z$ & $\begin{array}{l}\text { https://qlobal- } \\
\text { factiva- } \\
\text { com.ezproxy.libra } \\
\text { ry.qmul.ac.uk/redi } \\
\text { r/default.aspx?P= } \\
\frac{\text { sa\&an=FTFT000 }}{020040203 e 0230} \\
\frac{004 \times \& \text { cat }=a \& \text { ep }=}{\text { ASE }}\end{array}$ & $03-02-2004$ & \begin{tabular}{|l|} 
Financial \\
Times
\end{tabular} & $\begin{array}{l}\text { BBVA buys } \\
\text { Mexican Bank }\end{array}$ & $\begin{array}{l}\text { "Banco Bilbao Vizcaya Argentaria, Spain's } \\
\text { second-largest bank, yesterday unveiled a } \\
\text { Euros } 3.3 \mathrm{bn} \text { (Dollars } 4.1 \mathrm{bn} \text { ) deal to buy the } \\
\text { remaining } 40.6 \text { per cent of BBVA-Bancomer, the } \\
\text { Mexican bank in which it first took a stake } \\
\text { almost four years ago." }\end{array}$ \\
\hline
\end{tabular}


Panel C: Largest Fund Shocks and Eurozone Outflows

\begin{tabular}{|c|c|c|c|c|c|c|c|c|}
\hline Quarter & $\begin{array}{l}\text { GIV } \\
\text { shock } \\
\text { size }\end{array}$ & $\begin{array}{l}\text { Fund } \\
\text { Name }\end{array}$ & $\begin{array}{l}\text { Fund } \\
\text { Country }\end{array}$ & $\begin{array}{l}\text { Article } \\
\text { Links }\end{array}$ & $\begin{array}{l}\text { Article } \\
\text { Dates }\end{array}$ & $\begin{array}{l}\text { Article } \\
\text { Source }\end{array}$ & Reason & Explanation \\
\hline $2015 q 2$ & 0.530 & $\begin{array}{l}\text { APG Asset } \\
\text { Management } \\
\text { NV }\end{array}$ & $E Z$ & 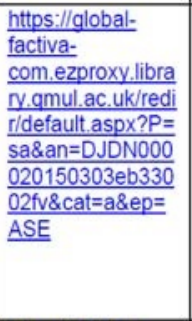 & 03-03-2015 & $\begin{array}{l}\text { Dow Jones } \\
\text { News-wires }\end{array}$ & $\begin{array}{l}\text { Accenture enters } \\
\text { into agreement with } \\
\text { APG to further } \\
\text { Optimize the } \\
\text { Pension Provider's } \\
\text { Operations }\end{array}$ & $\begin{array}{l}\text { "Accenture (NYSE: ACN) will support APG, } \\
\text { the largest Dutch pension provider, to further } \\
\text { optimize its current operations, under a multi- } \\
\text { year agreement, making Accenture one of } \\
\text { APG's first business partners of choice. The } \\
\text { agreement supports APG's existing strategy } \\
\text { to further improve operational and cost } \\
\text { efficiency, while maintaining high quality } \\
\text { products and services for its customers, in an } \\
\text { evolving pension market, driven by regulatory } \\
\text { changes and increasing digital consumer } \\
\text { needs." }\end{array}$ \\
\hline $2006 q 4$ & -0.507 & $\begin{array}{l}\text { Deutsche } \\
\text { Asset } \\
\text { Management } \\
\text { Investment } \\
\text { GmbH }\end{array}$ & $E Z$ & 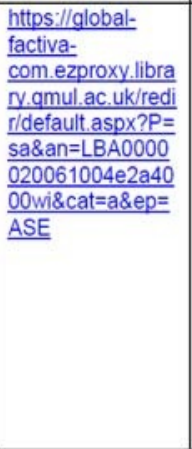 & 04-10-2006 & $\begin{array}{l}\text { Reuters } \\
\text { News }\end{array}$ & $\begin{array}{l}\text { Change of head of } \\
\text { DB fund DWS }\end{array}$ & $\begin{array}{l}\text { "The head of Germany's largest retail fund } \\
\text { business, Deutsche Bank's DWS, is to step } \\
\text { down, a source familiar with the situation told } \\
\text { Reuters on Wednesday. } \\
\text { Axel Benkner, global head of DWS, the retail } \\
\text { fund business of Deutsche Asset } \\
\text { Management, is expected to leave the post in } \\
\text { part due to a difference of opinion on how } \\
\text { closely the highly profitable DWS should be } \\
\text { integrated into Deutsche's asset } \\
\text { management operations, the source said. } \\
\text { A possible candidate to replace Benkner is } \\
\text { Klaus Kaldemorgen, currently global head of } \\
\text { equities at DWS, the source said, adding that } \\
\text { a decision had yet to be taken." }\end{array}$ \\
\hline $2003 q^{3}$ & -0.413 & $\begin{array}{l}\text { BBVA Asset } \\
\text { Management } \\
\text { SA SGIIC }\end{array}$ & EZ & 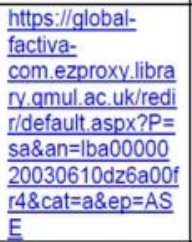 & \begin{tabular}{|c|}
$10-06-2003$ \\
\end{tabular} & $\begin{array}{l}\text { Reuters } \\
\text { News }\end{array}$ & $\begin{array}{l}\text { Divestiture from } \\
\text { Brazilian assets; it } \\
\text { could be rebalancing } \\
\text { out of Brazil due to } \\
\text { Brazilian currency } \\
\text { depreciation }\end{array}$ & $\begin{array}{l}\text { "Spain's second-biggest bank BBVA } \\
\text { (BBVA.MC) said on Tuesday it had } \\
\text { completed the sale of its Brazilian division to } \\
\text { Bradesco (BBDC4.SA), worth around } \$ 900 \\
\text { million ( } 2.63 \text { billion real)." }\end{array}$ \\
\hline $2014 q 2$ & 0.359 & $\begin{array}{l}\text { APG Asset } \\
\text { Management } \\
\text { NV }\end{array}$ & EZ & 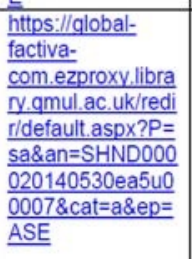 & $30-05-2014$ & $\begin{array}{l}\text { Shanghai } \\
\text { Daily }\end{array}$ & \begin{tabular}{|l|} 
Investment in a \\
Chinese warehouse \\
operator
\end{tabular} & $\begin{array}{l}\text { "DUTCH pension fund APG Asset } \\
\text { Management will pay up to US } 650 \text { million } \\
\text { for about a } 20 \text { percent stake in Chinese } \\
\text { warehouse operator e-Shang to ride the e- } \\
\text { commerce boom." }\end{array}$ \\
\hline $2006 q 3$ & 0.353 & $\begin{array}{l}\text { Deutsche } \\
\text { Asset } \\
\text { Management } \\
\text { Investment } \\
\text { GmbH }\end{array}$ & EZ & 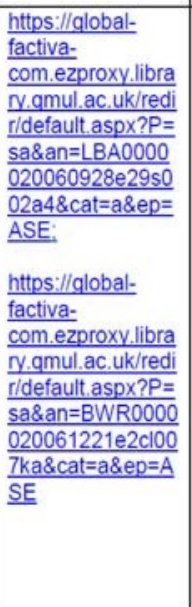 & $\begin{array}{l}\text { 28-09-2006; } \\
21-12-2006\end{array}$ & $\begin{array}{l}\text { Reuters } \\
\text { News; } \\
\text { Business } \\
\text { Wire }\end{array}$ & $\begin{array}{l}\text { 1) Settlement with } \\
\text { SEC; } \\
\text { 2)Between January } \\
\text { and December } \\
\text { 2006, details of the } \\
\text { settlement between } \\
\text { DB and the SEC for } \\
\text { market timing } \\
\text { wrongdoing were } \\
\text { made public }\end{array}$ & $\begin{array}{l}\text { Same as \#1 US inflows "The U.S. asset } \\
\text { management arm of Deutsche Bank AG has } \\
\text { agreed to pay \$19.3 million to settle a case } \\
\text { involving directed brokerage and the Scudder } \\
\text { Funds, U.S. regulators and the company said } \\
\text { on Thursday."; "Deutsche Asset } \\
\text { Management (DeAM), a unit of Deutsche } \\
\text { Bank (XETRA: DBKGn.DE / NYSE: DB), } \\
\text { today confirmed it has settled proceedings } \\
\text { with the Securities and Exchange } \\
\text { Commission (SEC) and the New York } \\
\text { Attorney General (NYAG) on behalf of } \\
\text { Deutsche Asset Management Inc. (DAMI) } \\
\text { and Deutsche Investment Management } \\
\text { Americas Inc. (DIMA), the investment } \\
\text { advisors to many of the DWS Scudder } \\
\text { Funds, regarding allegedly improper market } \\
\text { timing. The general terms of these } \\
\text { settlements were first disclosed by Deutsche } \\
\text { Bank in January } 2006 \text { and the full settlement } \\
\text { amounts have been included in prior legal } \\
\text { reserves. No further financial impact is } \\
\text { anticipated." }\end{array}$ \\
\hline
\end{tabular}


Panel D: Largest Fund Shocks and Eurozone Inflows

\begin{tabular}{|c|c|c|c|c|c|c|c|c|}
\hline Quarter & \begin{tabular}{|c} 
GIV \\
shock \\
size
\end{tabular} & $\begin{array}{l}\text { Fund } \\
\text { Name }\end{array}$ & $\begin{array}{l}\text { Fund } \\
\text { Country }\end{array}$ & $\begin{array}{l}\text { Article } \\
\text { Links }\end{array}$ & $\begin{array}{l}\text { Article } \\
\text { Dates }\end{array}$ & $\begin{array}{l}\text { Article } \\
\text { Source }\end{array}$ & Reason & Explanation \\
\hline $2004 q 1$ & -0.658 & $\begin{array}{l}\text { Janus Capital } \\
\text { Management } \\
\text { LLC }\end{array}$ & US & 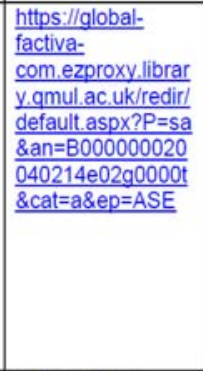 & \begin{tabular}{|c|}
$16-02-2004$ \\
\end{tabular} & Barron's & $\begin{array}{l}\text { Asset Restructuring } \\
\text { in the aftermath of } \\
\text { the Mutual Fund } \\
\text { Scandal (see shock } \\
\text { \#2 below) }\end{array}$ & $\begin{array}{l}\text { "In the aftermath of these embarrassments, } \\
\text { Denver-based Janus is striving to put its } \\
\text { other face forward. Late last year the } \\
\text { company said it will compensate its funds } \\
\text { and fund holders for } \$ 31.5 \text { million of lost } \\
\text { gains and other costs related to market } \\
\text { timing. As a result of trading shares in DST } \\
\text { Systems, a fund-industry servicer, for a DST } \\
\text { unit with } \$ 1 \text { billion of cash, Janus will be able } \\
\text { to cut its debt load to less than } 30 \% \text { of } \\
\text { capital. Management has been selling non- } \\
\text { strategic assets, broadening the company's } \\
\text { product lineup, and taking other steps to } \\
\text { restore investor confidence." }\end{array}$ \\
\hline $2003 q 4$ & 0.554 & $\begin{array}{l}\text { Janus Capital } \\
\text { Management } \\
\text { LLC }\end{array}$ & US & 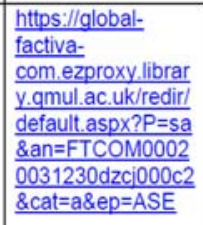 & \begin{tabular}{|l|}
$19-12-2003$ \\
\end{tabular} & \begin{tabular}{|l} 
Financial \\
Times
\end{tabular} & \begin{tabular}{|l|} 
Mutual Fund \\
Scandal (same \\
shock as shock \#1 \\
US outflows)
\end{tabular} & $\begin{array}{l}\text { "Janus Capital, one of the first fund groups to } \\
\text { become embroiled in New York attorney- } \\
\text { general Eliot Spitzer's crackdown on mutual } \\
\text { fund trading scandals, has offered to return } \\
\$ 31.5 \mathrm{~m} \text { to its investors as compensation for } \\
\text { the improper trading that took place in its } \\
\text { funds." }\end{array}$ \\
\hline $2009 q 1$ & 0.426 & $\begin{array}{l}\text { Capital } \\
\text { Research \& } \\
\text { Management } \\
\text { Co. (Global } \\
\text { Investors) }\end{array}$ & US & 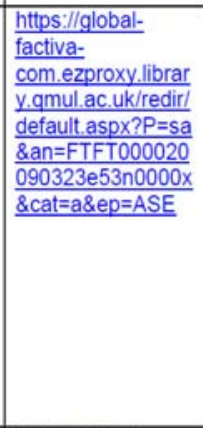 & $23-03-2009$ & \begin{tabular}{|l} 
Financial \\
Times
\end{tabular} & $\begin{array}{l}\text { More job losses at } \\
\text { money managers }\end{array}$ & $\begin{array}{l}\text { "Capital Group, the parent of one of the } \\
\text { largest managers, American Funds, has told } \\
\text { employees in an internal memo that it will } \\
\text { eliminate more jobs, its third round of cuts in } \\
\text { the past six months. The latest move is part } \\
\text { of a cost-cutting plan that includes a freeze } \\
\text { on pay rises, Capital said, It has already cut } \\
\text { close to } 600 \text { people, or } 6 \text { per cent of its staff. } \\
\text { Before the current crisis, the group had only } \\
\text { cut jobs once in its } 78 \text {-year history. } \\
\text { The memo said: "Given the continuing } \\
\text { business decline, deeper cost-cutting } \\
\text { measures will need to be pursued. } \\
\text { Unfortunately, these will include the } \\
\text { elimination of jobs across many groups." }\end{array}$ \\
\hline $2005 q 2$ & 0.409 & $\begin{array}{l}\text { Capital } \\
\text { Research \& } \\
\text { Management } \\
\text { Co. (World } \\
\text { Investors) }\end{array}$ & US & 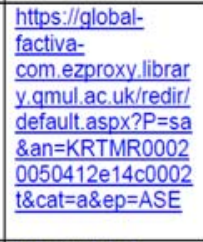 & $12-04-2005$ & $\begin{array}{l}\text { Morningstar } \\
\text { Column }\end{array}$ & $\begin{array}{l}\text { charges made by } \\
\text { regulators }\end{array}$ & $\begin{array}{l}\text { Same as \#4 US outflows "We're watching } \\
\text { developments at American Funds closely in } \\
\text { light of recent charges made by regulators. At } \\
\text { this point, none of the parties involved in the } \\
\text { cases have offered up any evidence, so we } \\
\text { haven't drawn conclusions yet. The charges } \\
\text { don't reach the level of seriousness of many } \\
\text { of the market-timing cases, but they do raise } \\
\text { important issues that should be explored" }\end{array}$ \\
\hline $2009 q 3$ & -0.325 & $\begin{array}{l}\text { Capital } \\
\text { Research \& } \\
\text { Management } \\
\text { Co. (Global } \\
\text { Investors) }\end{array}$ & US & 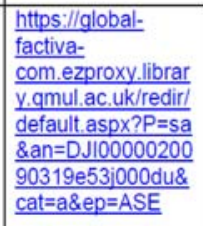 & \begin{tabular}{|l|}
$19-03-2009$ \\
\end{tabular} & \begin{tabular}{|l} 
DowJones \\
Newswires
\end{tabular} & $\begin{array}{l}\text { Capital Group Stake } \\
\text { In Vallourec Drops } \\
\text { Below 5\% Threshold }\end{array}$ & $\begin{array}{l}\text { "Acting as an investment adviser, Capital } \\
\text { Group held } 4.78 \% \text { of Vallourec's capital and } \\
4.77 \% \text { of its voting rights as of March } 13, \\
\text { according to the filing. That is down from the } \\
5.02 \% \text { of capital and } 5.01 \% \text { of voting rights } \\
\text { Capital Group said it owned in a previous } \\
\text { filing published Feb. } 13 . "\end{array}$ \\
\hline
\end{tabular}


Appendix Figure 1:

GIV Time Series for U.S. Net Outflows and Largest Fund Flow Events

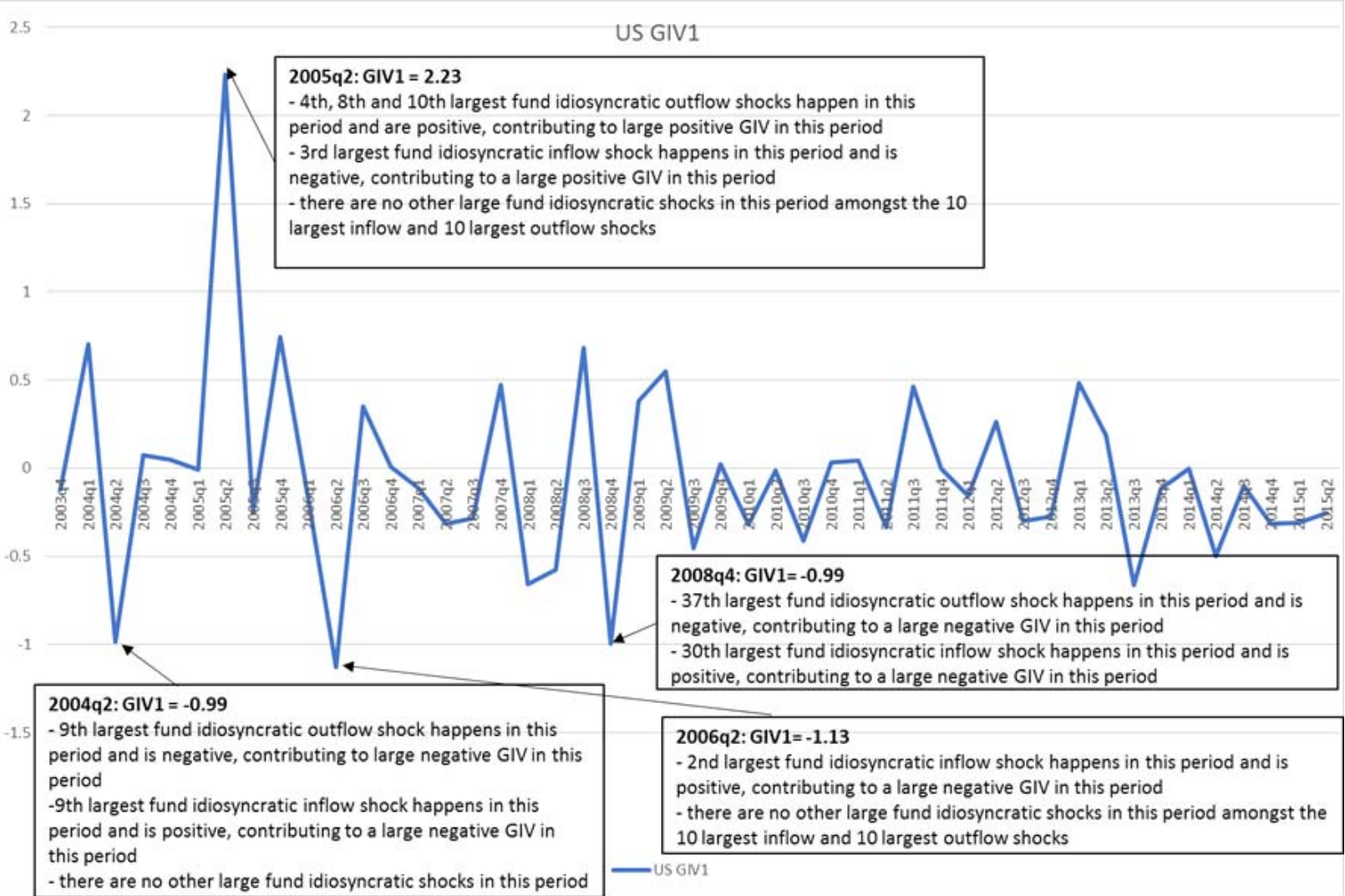


Appendix Figure 2

GIV Time Series for the Eurozone Net Outflows and Largest Fund Events

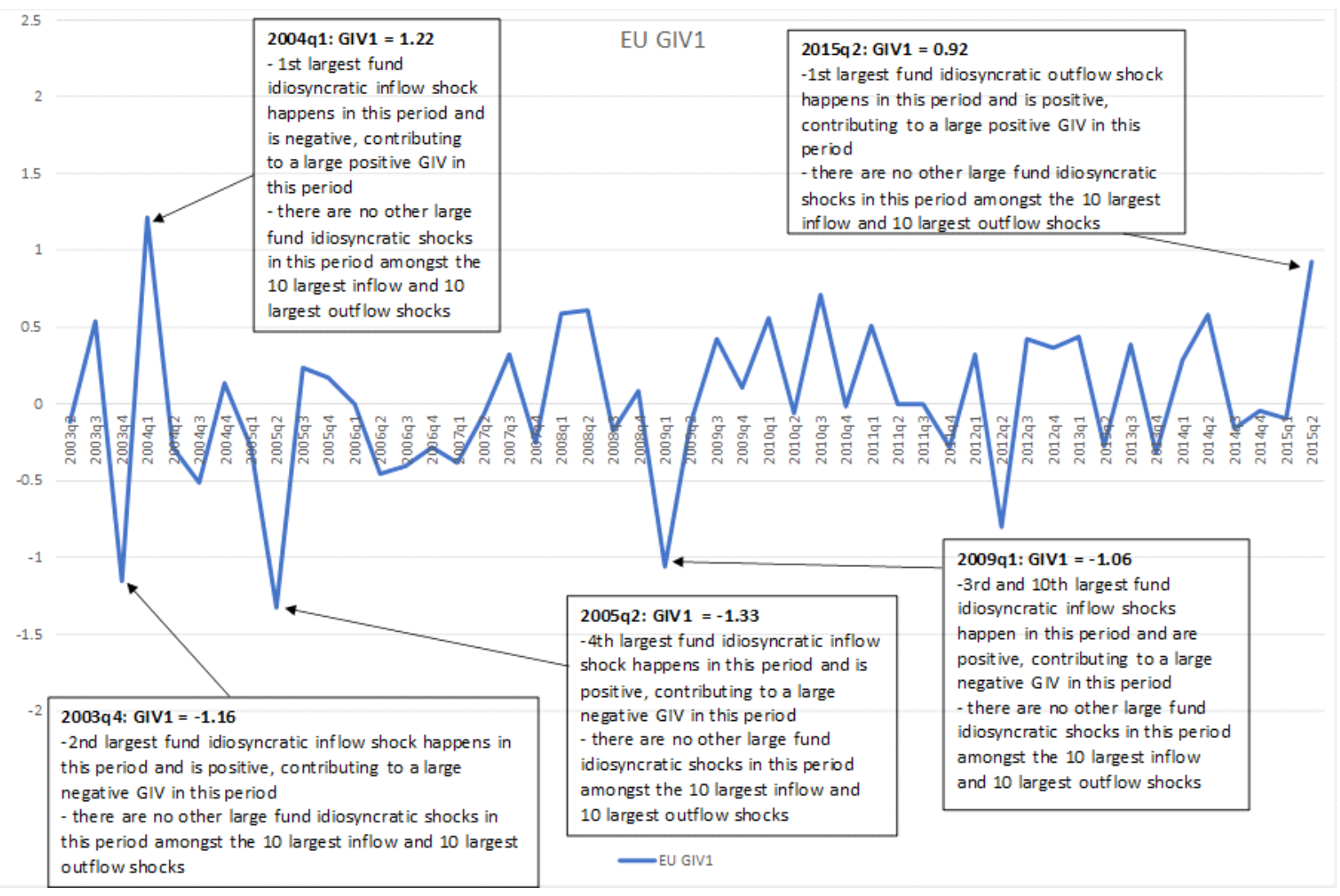

